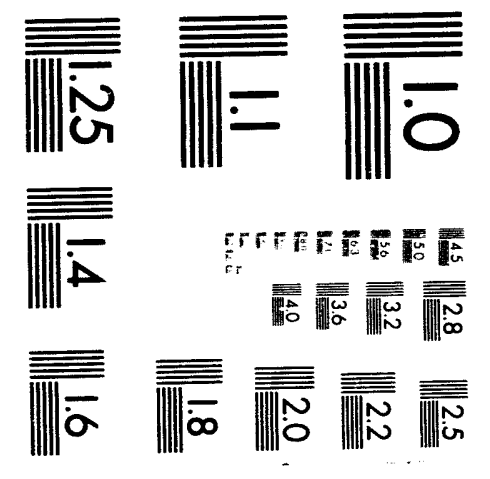



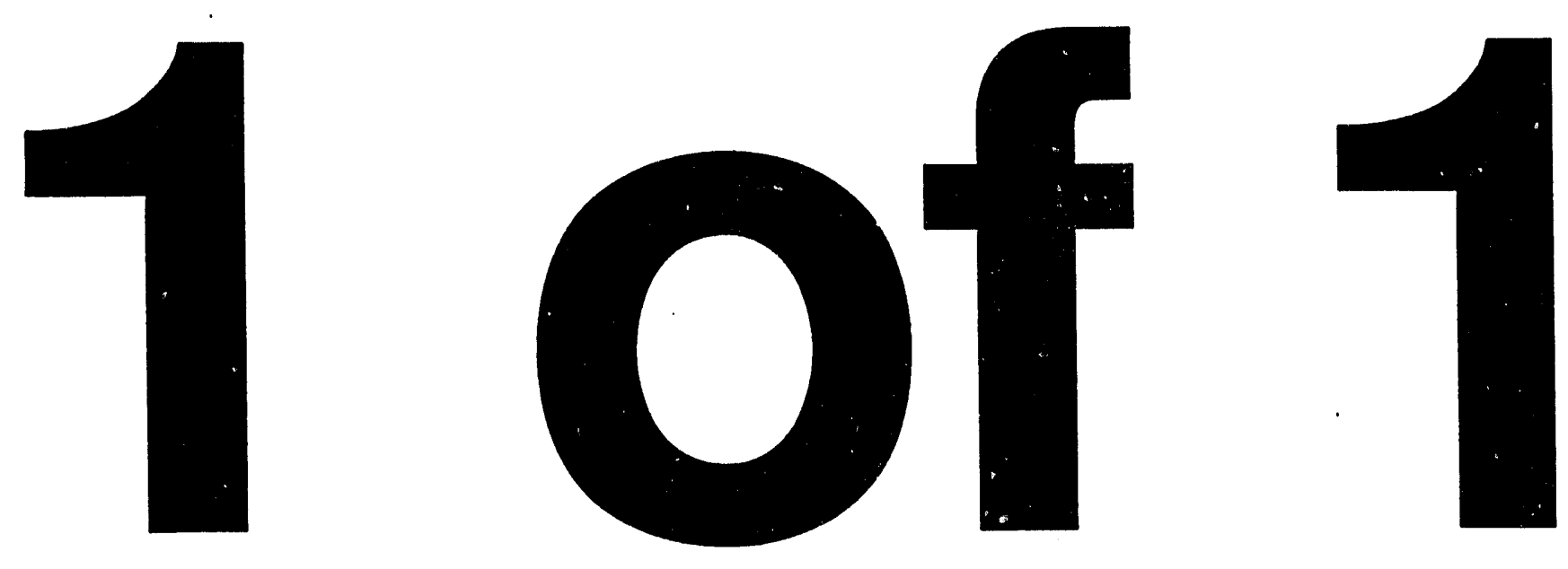
Orm

OAK RIDGE NATIONAL LABORATORY

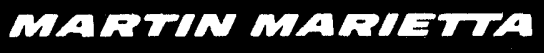

\section{Nuclear Decay Data Files of the Dosimetry Research Group}

K. F. Eckerman

R. J. Westfall

J. C. Ryman

M. Cristy 
This report has been reproduced directly from the best available copy.

Available to DOE and DOE contractors from the Office of Scientific and Technical Information, P.O. Box 62, Oak Ridge, TN 37831; prices available from (615) 576-8401, FTS 626-8401.

Available to the public from the National Technical Information Service, U.S. Department of Commerce, 5285 Port Royal Rd., Springfield, VA 22161.

This report was prepared as an account of work sponsored by an agency of the United States Government. Neither the United States Government nor any agency thereof, nor any of their employees, makes any warranty, express or implied, or assumes any legal liability or responsibility for the accuracy, completeness, or usefulness of any information, apparatus, product, or process disclosed, or represents that its use would not infringe privately owned rights. Reference herein to any specific commercial product, process, or service by trade name, trademark, manufacturer, or otherwise, does not necessarily constitute or imply its endorsement, recommendation, or favoring by the United States Government or any agency thereof. The views and opinions of authors expressed herein do not necessarily state or reflect those of the United States Government or any agency thereof. 
ORNL/TM-12350

Dist. Category UC-407

Health Sciences Research Division

\title{
NUCLEAR DECAY DATA FILES OF THE DOSIMETRY RESEARCH GROUP
}

\author{
K. F. Eckerman \\ R. J. Westfall \\ J. C. Ryman \\ M. Cristy
}

December 1993

Research sponsored by the Office of Health and Environmental Research, U. S. Department of Energy, Washington, DC 20545, and the Office of Radiation and Indoor Air, U. S. Environmental Protection Agency, Washington DC, 20460, under Interagency Agreement 1824-C148-A1, EPA NO. DW89934657-3.

\section{Prepared by}

OAK RIDGE NATIONAL LABORATORY

Oak Ridge, Tennessee 37831 managed by

Martin Marietta Energy Systems, Inc. for the

U. S. DEPARTMENT OF ENERGY

under Contract No. DE-AC05-84OR21400 


\section{TABLE OF CONTENTS}

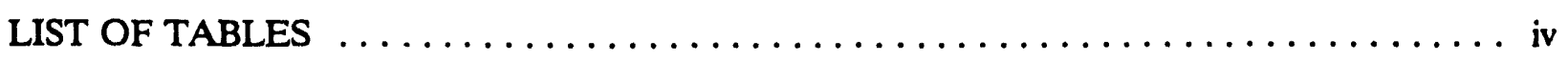

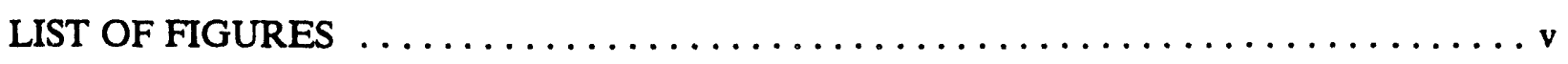

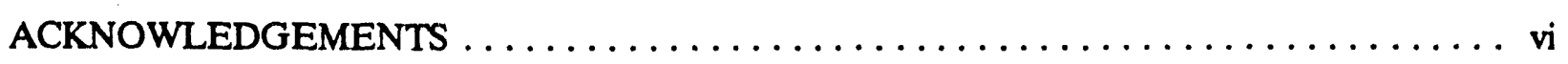

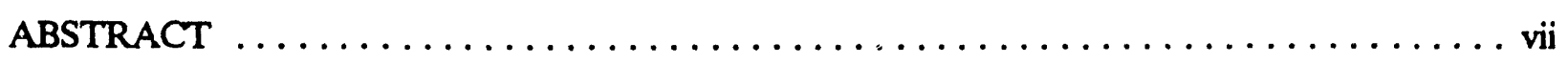

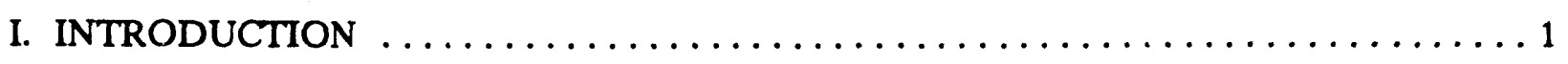

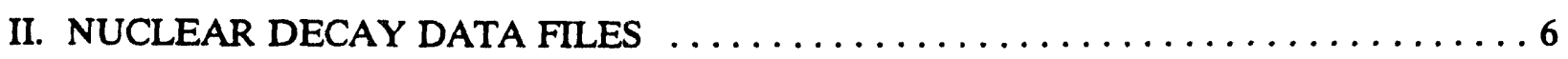

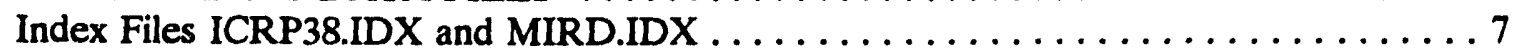

Radiation Files ICRP38.RAD and MIRD.RAD $\ldots \ldots \ldots \ldots \ldots \ldots \ldots \ldots \ldots \ldots$

Beta Spectra Files ICRP38.BET and MIRD.BET $\ldots \ldots \ldots \ldots \ldots \ldots \ldots \ldots \ldots$

III. OUTPUT FILES FROM UTILITY DEXRAX $\ldots \ldots \ldots \ldots \ldots \ldots \ldots \ldots \ldots \ldots \ldots$

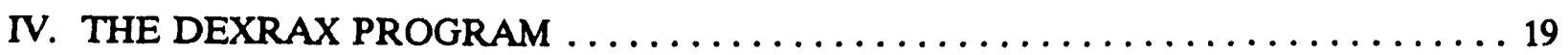

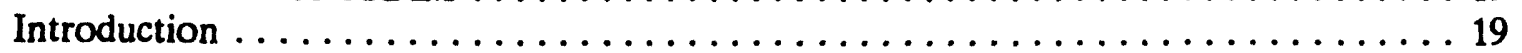

Directory Structure Required for DEXRAX $\ldots \ldots \ldots \ldots \ldots \ldots \ldots \ldots \ldots \ldots$

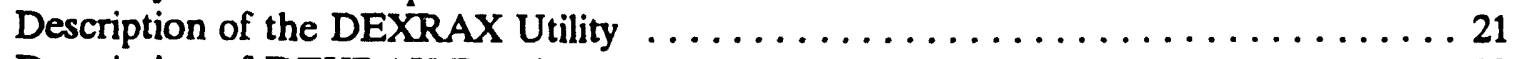

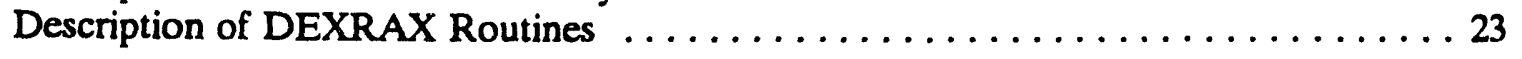

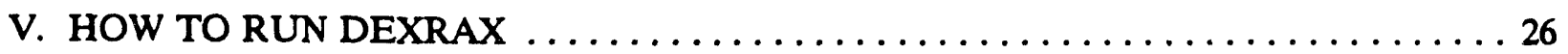

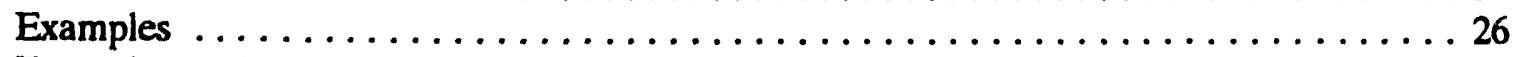

Example 1: Extracting Radiations Data for a Chain ................. 27

Example 2: Extracting Radiations Data and Beta Spectra for 2

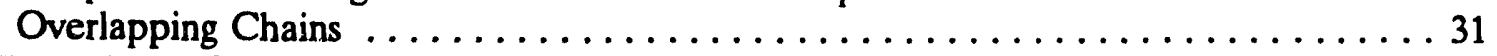

Example 3: Choosing a List of Nuclides, Without Daughters, and Writing

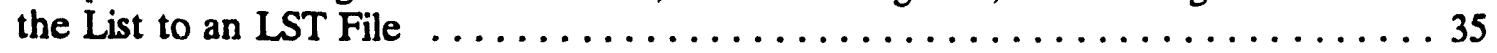

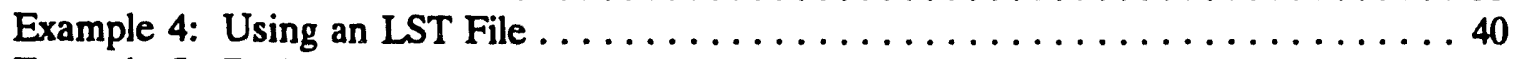

Example 5: Radiations Data from a Radionuclide with Spontaneous Fission . . . . . 40

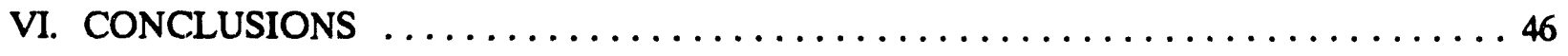

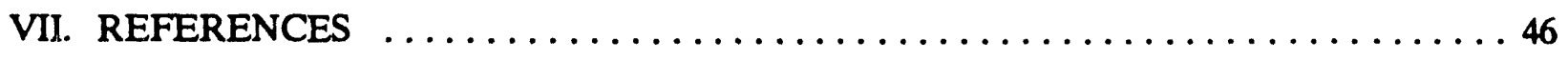

APPENDIX A SUMMARY OF NUCLEAR DECAY DATA $\ldots \ldots \ldots \ldots \ldots \ldots$ A-1 


\section{LIST OF TABLES}

Table 1. Nuclides in ICRP38 Collection from MIRD Monograph $\ldots \ldots \ldots \ldots 2$

Table 2. Nuclides for which MIRD Collection has Later ENSDF Date than ICRP38 Collection $\ldots \ldots \ldots \ldots \ldots \ldots \ldots \ldots \ldots$

Table 3. Structure of Records in ICRP38.IDX and MIRD.IDX Files $\ldots \ldots \ldots 8$

Table 4. First 36 and Last 13 Records of File ICRP38.IDX $\ldots \ldots \ldots \ldots$

Table 5. Records for First 8 Radionuclides in File ICRP38.RAD ........ 11

Table 6. Description of ICODE $\ldots \ldots \ldots \ldots \ldots \ldots \ldots \ldots \ldots \ldots \ldots \ldots \ldots \ldots \ldots \ldots \ldots$

Table 7. Excerpts from First 5 Records of File ICRP38.BET $\ldots \ldots \ldots \ldots \ldots 14$

Table 8. Structure of Records in DEXRAX Radiations Data Output File . . . . 15

Table 9. Example of a DEXRAX Radiations Data Output File $\ldots \ldots \ldots \ldots 16$

Table 10. Structure of Records in DEXRAX Beta Spectra Output File . . . . 17

Table 11. Example of a DEXRAX Beta Spectra Output File .......... 18

Table 12. Isomers with Nonstandard Naming Convention $\ldots \ldots \ldots \ldots . \ldots 39$

Table 13. Expressions for Computation of Intensities and Average

Energies of Radiations Accompanying Spontaneous Fission ..... 44

Table A-1. Summary Information on the Nuclear Transformation of the Radionuclides in ICRP38 Collection . . . . . . . . . . .

Table A-2. Summary Information on the Nuclear Transformation of the Radionuclides in MIRD Collection . . . . . . . . . . . . A-19 


\section{LIST OF FIGURES}

Figure 1. Composite Beta Spectrum for ${ }^{87} \mathrm{Kr} \ldots \ldots \ldots \ldots \ldots \ldots \ldots$

Figure 2. DCAL: Radiation Dose and Risk Calculational System $\ldots \ldots \ldots \ldots 20$

Figure $3 A . \quad$ DEXRAX Run, Example $1 \ldots \ldots \ldots \ldots \ldots \ldots \ldots \ldots \ldots \ldots \ldots$

Figure 3B. Log File from DEXRAX Run, Example $1 \ldots \ldots \ldots \ldots \ldots \ldots$

Figure 4A. DEXRAX Run, Example $2 \ldots \ldots \ldots \ldots \ldots \ldots \ldots \ldots \ldots \ldots \ldots \ldots \ldots$

Figure 4B. $\quad \log$ File from DEXRAX Run, Example $2 \ldots \ldots \ldots \ldots \ldots \ldots$

Figure 5A. DEXRAX Run, Example $3 \ldots \ldots \ldots \ldots \ldots \ldots \ldots \ldots \ldots \ldots \ldots \ldots$

Figure 5B. Contents of File MISC.LST Created in DEXRAX

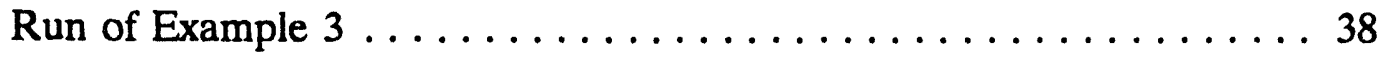

Figure 6A. DEXRAX Run, Example $4 \ldots \ldots \ldots \ldots \ldots \ldots \ldots \ldots \ldots \ldots$

Figure 6B. Log File DEXRAX.LOG from Examples 3 and $4 \ldots \ldots \ldots \ldots$

Figure 7. Example 5: Input and Output RAD Files for a

Nuclide with Spontaneous Fission 


\section{ACKNOWLEDGEMENTS}

This report represents a culmination of efforts by various members of the "Oak Ridge" dosimetry group undertaken during the preparation of Publication 30 of the International Commission on Radiological Protection. The authors wish to acknowledge the earlier efforts of M. R. Ford and S. B. Watson in assembling these data on the ORNL mainframe computers. Particular appreciation is extended to Prof. L. T. Dillman, Ohio Wesleyan University, whose technical expertise served the nuclear decay data needs of the "Oak Ridge" dosimetry group for many years.

Preparation of this report was funded by the Environmental Protection Agency. The development of the underlying methodologies were supported by the Office of Health and Environmental Research, U. S. Department of Energy. R. J. Westfall was supported by the Internship Program of the Oak Ridge Associated Universities. 


\begin{abstract}
This report documents the nuclear decay data files used by the Dosimetry Research Group at Oak Ridge National Laboratory and the utility DEXRAX which provides access to the files. The files are accessed, by nuclide, to extract information on the intensities and energies of the radiations associated with spontaneous nuclear transformation of the radionuclides. In addition, beta spectral data are available for all beta-emitting nuclides. Two collections of nuclear decay data are discussed. The larger collection contains data for 838 radionuclides, which includes the 825 radionuclides assembled during the preparation of Publications 30 and 38 of the International Commission on Radiological Protection (ICRP) and 13 additional nuclides evaluated in preparing a monograph for the Medical Internal Radiation Dose (MIRD) Committee of the Society of Nuclear Medicine. The second collection is composed of data from the MIRD monograph and contains information for 242 radionuclides. Abridged tabulations of these data have been published by the ICRP in Publication 38 and by the Society of Nuclear Medicine in a monograph entitled "MIRD: Radionuclide Data and Decay Schemes." The beta spectral data reported here have not been published by either organization. Electronic copies of the files and the utility, along with this report, are available from the Radiation Shielding Information Center at Oak Ridge National Laboratory.
\end{abstract}




\section{INTRODUCTION}

The Dosimetry Research Group (DRG) of the Health Sciences Research Division at Oak Ridge National Laboratory (ORNL) has for several years maintained data bases of nuclear decay data for use in dosimetric calculations ${ }^{1-4}$. Although other sources of radioactive decay information are available ${ }^{5,6}$, our data base, in machine-readable form, has been explicitly designed to address the needs in medical, environmental, and occupational radiation protection. These needs are generally served by information on the mean or unique energy of each radiation and its absolute intensity, including the subsequent atomic radiations. Calculations of the spatial distribution of absorbed dose (depthdose) requires information on the beta spectra, and these are compiled in a separate data file, also described herein.

The computer program EDISTR, developed by Dillman? ${ }^{7}$ is used to calculate the intensities and energies of the radiations of the radionuclides contained in the data files. Information on nuclear structure is taken from the Evaluated Nuclear Structure Data File (ENSDF) at the Brookhaven National Laboratory ${ }^{8}$. EDISTR, using information from ENSDF, computes and tabulates data for alpha, beta, gamma, internal conversion electron, $x$-ray, Auger-electron, and bremsstrahlung radiations emitted in spontaneous nuclear transformations of radionuclides. Beta spectral shapes are calculated to determine the mean energy of each beta transition. Data on radiations from spontaneously fissioning radionuclides (fission fragments, neutrons, prompt gammas, delayed gammas, and betas) are computed from the methods of Dillman and Jones ${ }^{14}$. The nuclear decay data used in the dosimetric calculations for Publication $30^{9}$ of the International Commission on Radiological Protection (ICRP) were derived from EDISTR and were subsequently published, in an abridged format, in ICRP Publication $38^{3}$. The unabridged data, including the beta spectral data, were maintained within the ICRP/ORNL dosimetric data files of the DRG. It is the unabridged data that is the subject of this report.

This report documents the decay data files currently used in dosimetric calculations at ORNL. The decay data files were constructed on the mainframe computers at ORNL, were subsequently moved to a microVAX computer, and now reside on various computing platforms, including personal computers and workstations. Access to the decay data records is provided by the FORTRAN utility code DEXRAX (DEcay eXtRActor[X]). The data are assembled in two collections. The collection referred to as "ICRP38" consists of data for 825 radionuclides that were within the ICRP/ORNL dosimetric files, plus an additional 13 radionuclides (see Table 1) evaluated during preparation of a 
Table 1. Nuclides in ICRP38 Collection from MIRD Monograph

\begin{tabular}{cccc}
\hline Nuclide & Half-life & Nuclide & Half-life \\
\hline O-14 & $70.599 \mathrm{~s}$ & Er-167m & $2.28 \mathrm{~s}$ \\
O-19 & $26.91 \mathrm{~s}$ & $\mathrm{Hg}-206$ & $8.15 \mathrm{~m}$ \\
$\mathrm{Cu}-57$ & $233 \mathrm{~ms}$ & $\mathrm{~Pb}-204 \mathrm{~m}$ & $67.2 \mathrm{~m}$ \\
$\mathrm{Se}-72$ & $8.40 \mathrm{~d}$ & $\mathrm{Bi}-204$ & $11.22 \mathrm{~h}$ \\
Rb-77 & $3.70 \mathrm{~m}$ & Po-209 & $102 \mathrm{y}$ \\
In-111m & $7.7 \mathrm{~m}$ & $\mathrm{Tl}-210$ & $1.30 \mathrm{~m}$ \\
Sb-118 & $3.6 \mathrm{~m}$ & & \\
\hline \hline
\end{tabular}

monograph $^{4}$ for the Medical Internal Radiation Dose (MIRD) Committee of the Society of Nuclear Medicine. The collection referred to as "MIRD" contains 242 radionuclides of interest to the medical community as published in the MIRD monograph4. The MIRD collection contains data for 161 radionuclides whose ENSDF dates are later than those in the ICRP38 collection (Table 2). In most instances the differences are of no dosimetric significance, but considerable differences may exist for some nuclides. For example, the total emitted energies for Te-123 in the two collections differ by more than a factor of two as a result of change in the estimated total energy (the $Q$ value) available for the beta transition.

Both data collections resulted from processing the ENSDF information through the EDISTR code plus adding information on spontaneously fissioning radionuclides from Dillman and Jones ${ }^{14}$. Our interest here is limited to the following data elements of the EDISTR output:

a. the complete listing of the emitted radiations, their types, energies, and absolute intensities for the radionuclide, and

b. the composite beta spectrum for a beta-emitting radionuclide ("composite" means that all the beta radiations are combined into one spectrum - see Fig. 1).

We shall refer to the former as "radiations" data and the latter as "beta spectra" data. Extraction of radiations data and/or beta spectra data for the radionuclide of interest via DEXRAX is the starting point of all dosimetric calculations performed for internal emitters by the DRG staff.

The ICRP38 and the MIRD collections and DEXRAX are available in electronic form, along with this report, from the Radiation Shielding Information Center (RSIC), Oak Ridge National Laboratory, P.O. Box 2008, Oak Ridge, TN 37831-6362, by requesting data library package DLC-172, entitled NUCDECAY, ICRP and MIRD Nuclear Decay Data. 
Table 2 Nuclic's for which MIRD collection has later ENSDF date than ICRP38 collection.

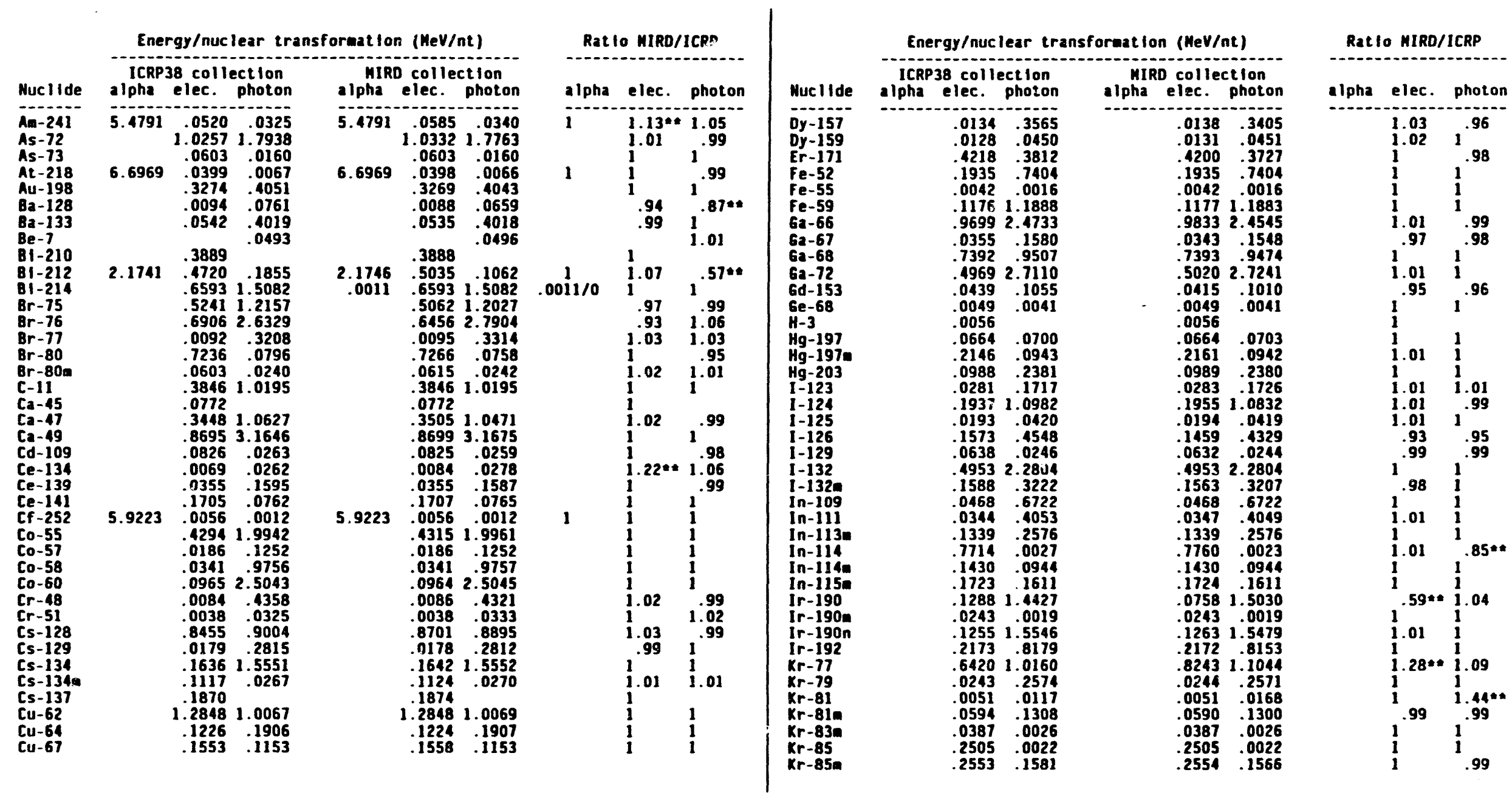

** Difference between MIRD and ICRP38 > 10\%.

Note: Ratios 1.00 shown as 1 . 
Table 2 (cont'd).

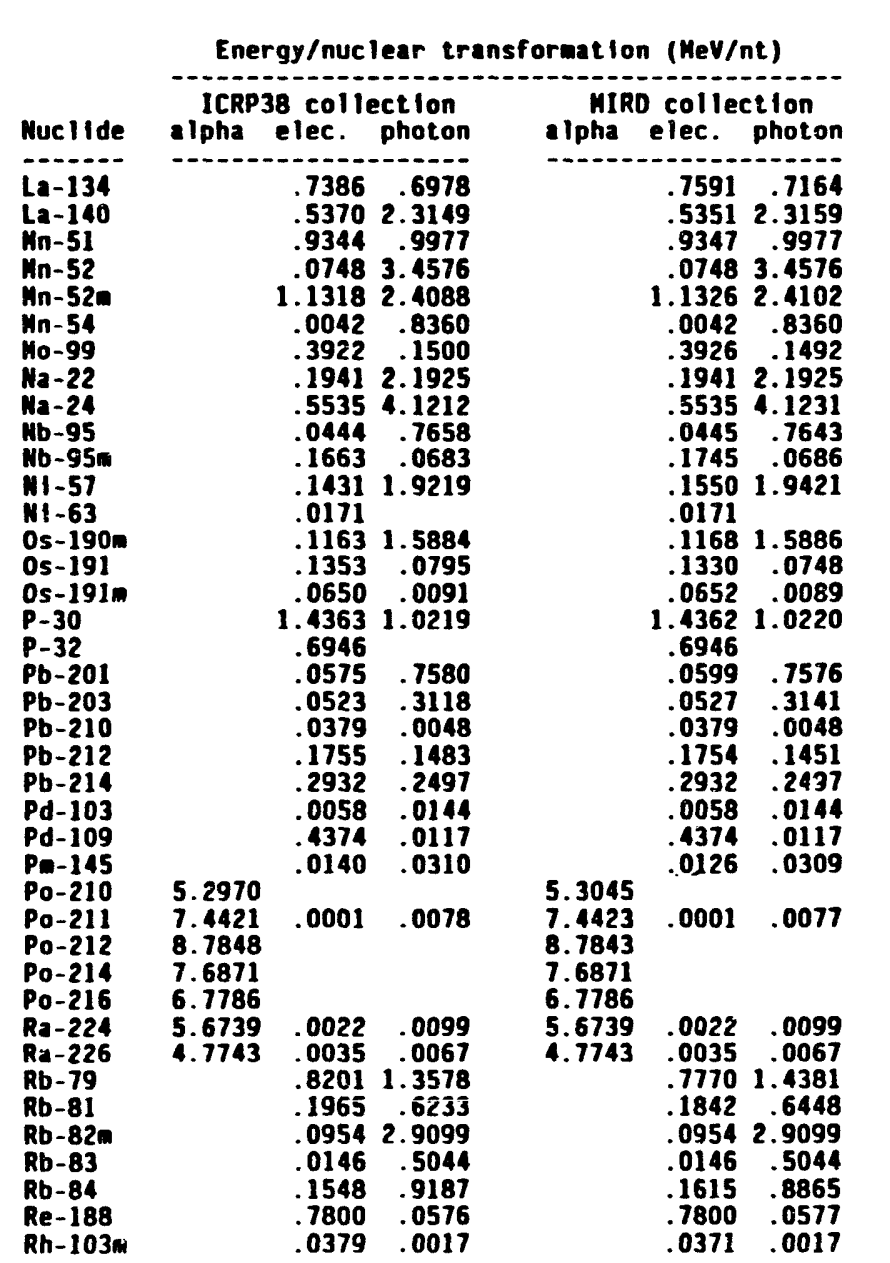

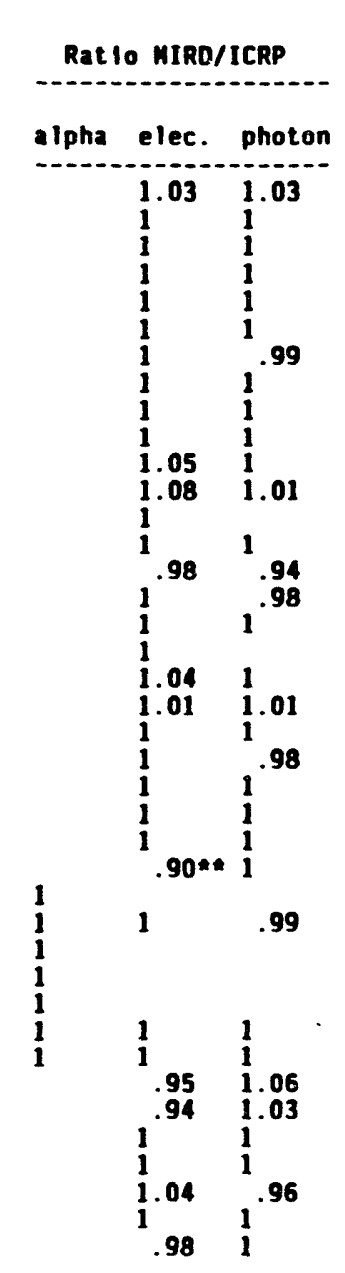

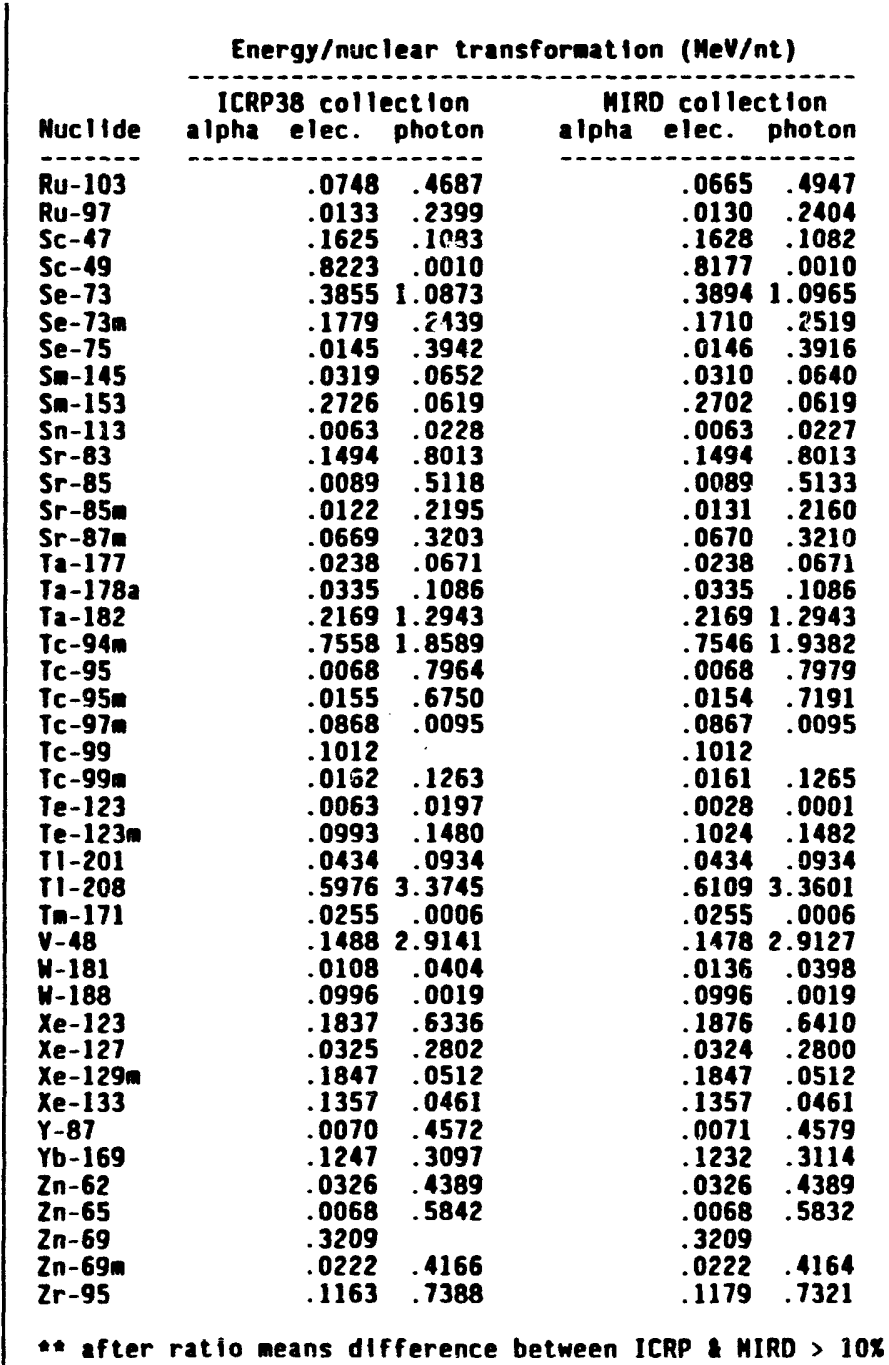

Rat Io MIRD/ICRP

Ipha elec photon $\begin{array}{ll}.89 * * 1.06 \\ .98 & 1 \\ 1.99 & 1 \\ 1.09 & 1.01 \\ .96 & 1.03 \\ 1.01 & .99 \\ .97 & .98\end{array}$ $.97 \quad .98$

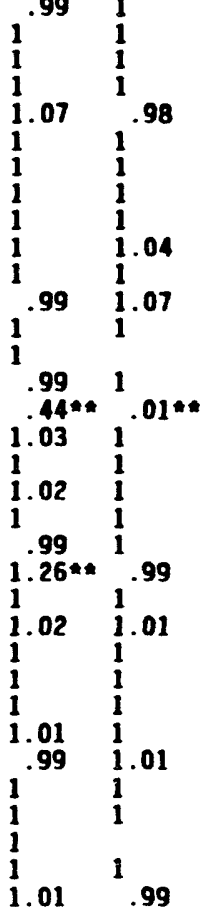

** Difference between MIRD and ICRP38 > 10\%.

Note: Ratios 1.00 shown as 1. 


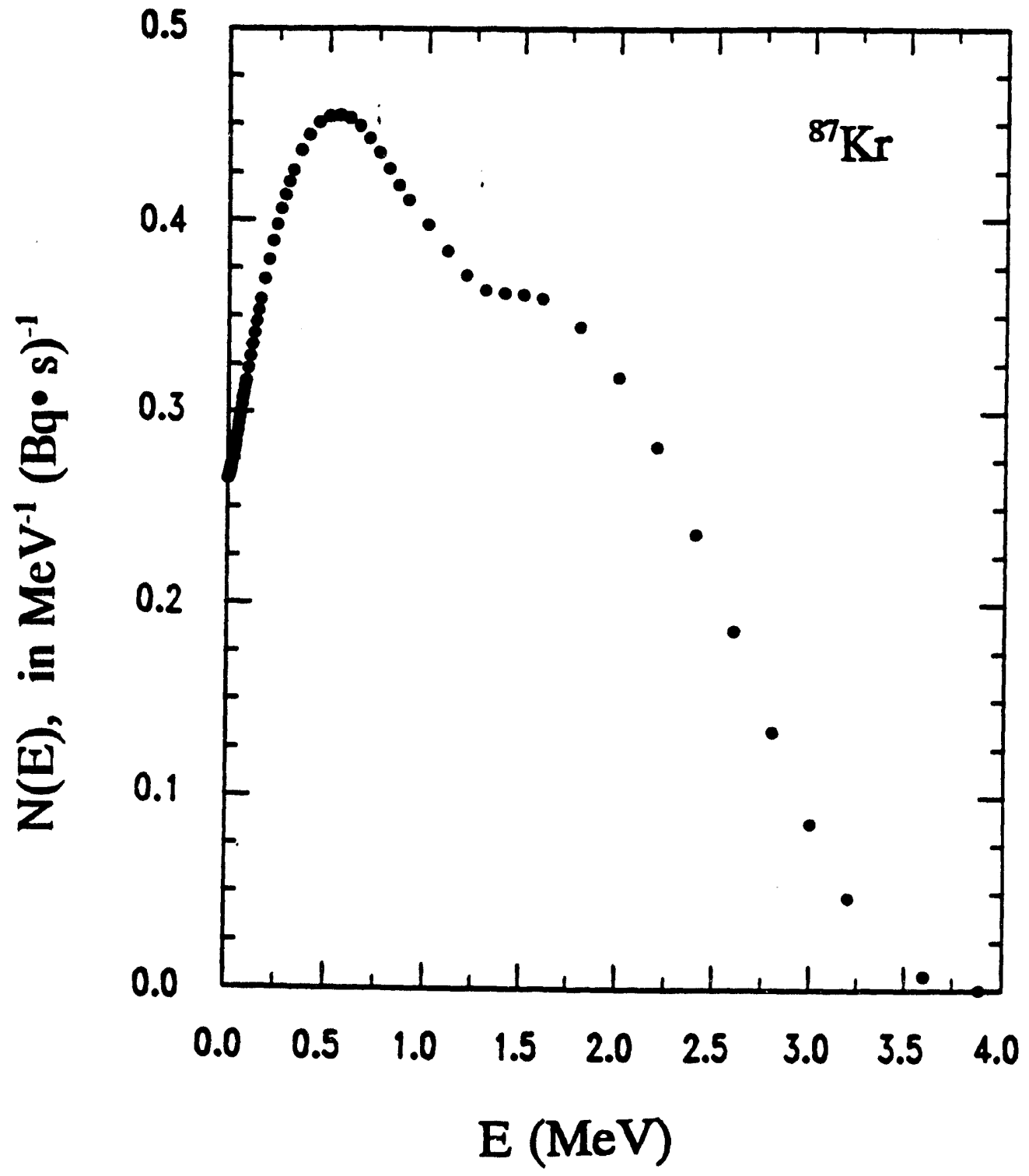

Figure 1. Composite Beta Spectrum for ${ }^{n} \mathrm{Kr}$. Each point represents a tabulated value. 


\section{NUCLEAR DECAY DATA FILES}

The radiations data files ICRP38.RAD and MIRD.RAD contain information on the absolute intensities and mean energies of all radiations emitted by the 838 and 242 radionuclides in the ICRP38 and MIRD collections, respectively. (For the fission component of spontaneously fissioning radionuclides, these files contain instead the number of spontaneous fissions per 100 decays and the number of neutrons per fission. When data on selected nuclides are extracted from the RAD files, as described later, the output files contain the information on the intensities and the mean energies of the various radiations associated with fission. See Fig. 7 and Table 13.) The radiations data extracted from these files are used in computing SEE values, the specific effective energy of Publication $30^{9}$. Our computer program for computing SEEs, SEECAL, is documented by Cristy and Eckerman $^{10}$, and is also available from RSIC.

Two other files, ICRP38.BET and MIRD.BET, contain the beta spectra data for all beta emitters in the two collections. EDISTR computed the spectra for each beta transition to determine the mean beta energy of the transition and tabulated the composite spectra for all beta transitions. The spectral data were not tabulated in ICRP Publication $38^{3}$ nor in the MIRD monograph ${ }^{4}$, but the former data were used in the calculations of the derived air concentration (DAC) for submersion exposure given in ICRP Publication $30^{\circ}$. Note: if your only interest in DEXRAX is extracting data to compute SEEs with SEECAL ${ }^{10}$, you will never need to extract data for beta spectra, because SEECAL uses the average energy of each beta transition contained in either ICRP38.RAD or MIRD.RAD. A future version of SEECAL will, however, use the spectral data.

To facilitate access to the information in the rather large data files, two additional files, the index files ICRP38.IDX and MIRD.IDX, have been constructed. The index files contain information needed to retrieve the records for the nuclide of interest from their corresponding RAD and BET files. Thus a triplet of files, with extensions IDX, RAD, and BET, define each collection. Our interest here is with the manner in which records are extracted from these files - the reader should consult the EDISTR manual ${ }^{2}$ for details regarding the generation of the information. Summary information on the nuclear transformations of the nuclides in the two collections is given in Appendix A. We proceed with a brief description of the three types of files, i.e., the index files ICRP38.IDX and MIRD.IDX, the radiation files ICRP38.RAD and MIRD.RAD, and the beta spectra files ICRP38.BET and MIRD.BET. When it is not necessary to differentiate between the collections we will refer to the files by their extensions, i.e., IDX, RAD, and BET. 


\section{Index Files ICRP38.IDX and MIRD.IDX}

The IDX files serve as the entrance into the larger radiations (RAD) and beta spectra (BET) data files. The IDX file contains one record for each nuclide in the collection. Each record has fields giving the location of and the number of records for the nuclide in the RAD and BET files. In addition to these pointers, other fields give the half-life, the modes of decay (e.g., alpha or beta), the identity of any radioactive decay products (daughters), the fraction of the nuclear transformations forming the daughters (the branching fractions), and the total energy emitted by alpha, electron, and photon radiations (excluding electrons and photons accompanying spontaneous fission). A description of the IDX records is given in Table 3, and excerpts from ICRP38.IDX are shown in Table 4.

The index files are direct-access files with the records sorted by the nuclide field so that a binary search can be performed to locate the record for a particular nuclide quickly. While the purpose of the IDX file was to provide the entrance into the larger RAD and BET files, they are of considerable utility in their own right. For example, it is possible to construct the entire decay chain for a radionuclide from the information in these files. 
Table 3. Structure of Records in ICRP38.IDX and MIRD.IDX Files.

\begin{tabular}{|c|c|c|}
\hline Variable & Format & Description \\
\hline \multicolumn{3}{|c|}{ Record \#1 FORMAT(2I4); length $=125$} \\
\hline First & 14 & Record number of first data record. \\
\hline Last & 14 & Record number of last data record. \\
\hline \multicolumn{3}{|c|}{$\begin{array}{l}\text { Data Records (First, ..., Last) } \\
\text { FORMAT(A7,A8,A2,A8,I7,I5,16,14,3(I4,E11.0),E7.0,2F8.0,A10); length = } 125\end{array}$} \\
\hline Nuclide & A7 & Name of nuclide; e.g., Am-241, Tc-99m. \\
\hline Half-life & A8 & Half-life of nuclide. \\
\hline Units & A2 & $\begin{array}{l}\text { Half-life units: us - microseconds, ms - milliseconds, } \\
\mathrm{s} \text { - seconds, } \mathrm{m} \text { - minutes, } \mathrm{d} \text { - day, and y - year. }\end{array}$ \\
\hline Decay Modes & A8 & $\begin{array}{l}\text { Decay modes; A denotes alpha, B- beta minus, } \\
\text { B+ beta plus, EC electron capture, IT internal transition, } \\
\text { and SF spontaneous fission. }\end{array}$ \\
\hline Index, Radiat. & I7 & Location of nuclide in ICRP38.RAD or MIRD.RAD file. \\
\hline Nrad & I5 & Number of radiation records for nuclide in *.RAD file. \\
\hline Index, Beta & I6 & Location of nuclide in ICRP33.BET or MIRD.BET file. \\
\hline Neng & 14 & For nuclide, number of spectral energies in ${ }^{*}$.BET. \\
\hline Index, D1 & 14 & Location of first daughter in IDX file (ICRP38 or MIRD). \\
\hline Frac1 & ¿11.0 & $\begin{array}{l}\text { Fraction of nuclear transformation forming first daughter } \\
\text { (branching fraction). }\end{array}$ \\
\hline Index, D2 & I4 & Location of second daughter in IDX file. \\
\hline Frac2 & E11.0 & Branching fraction for second daughter. \\
\hline Index, D3 & 14 & Location of third daughter in IDX file. \\
\hline Frac3 & E11.0 & Branching fraction for third daughter. \\
\hline $\mathrm{E}_{\mathrm{T}}$ : Alpha & F7.0 & Total energy of alpha emissions, $\mathrm{MeV} / \mathrm{nt}$. \\
\hline $\mathrm{E}_{\mathrm{T}}$ : Electron & F8.0 & Total energy of electron emissions, $\mathrm{MeV} / \mathrm{nt}$. \\
\hline $\mathrm{E}_{\mathrm{T}}$ : Photon & F8.0 & Total energy of photon emissions, $\mathrm{MeV} / \mathrm{nt}$. \\
\hline Date & A10 & Date of ENSDF evaluation for nuclide. \\
\hline
\end{tabular}


Table 4. First 36 and Last 13 Records of File ICRP38.IDX.

The $x$ 's within the dashed header lines mark the end of each field. See Table 3 for explanation of each field.

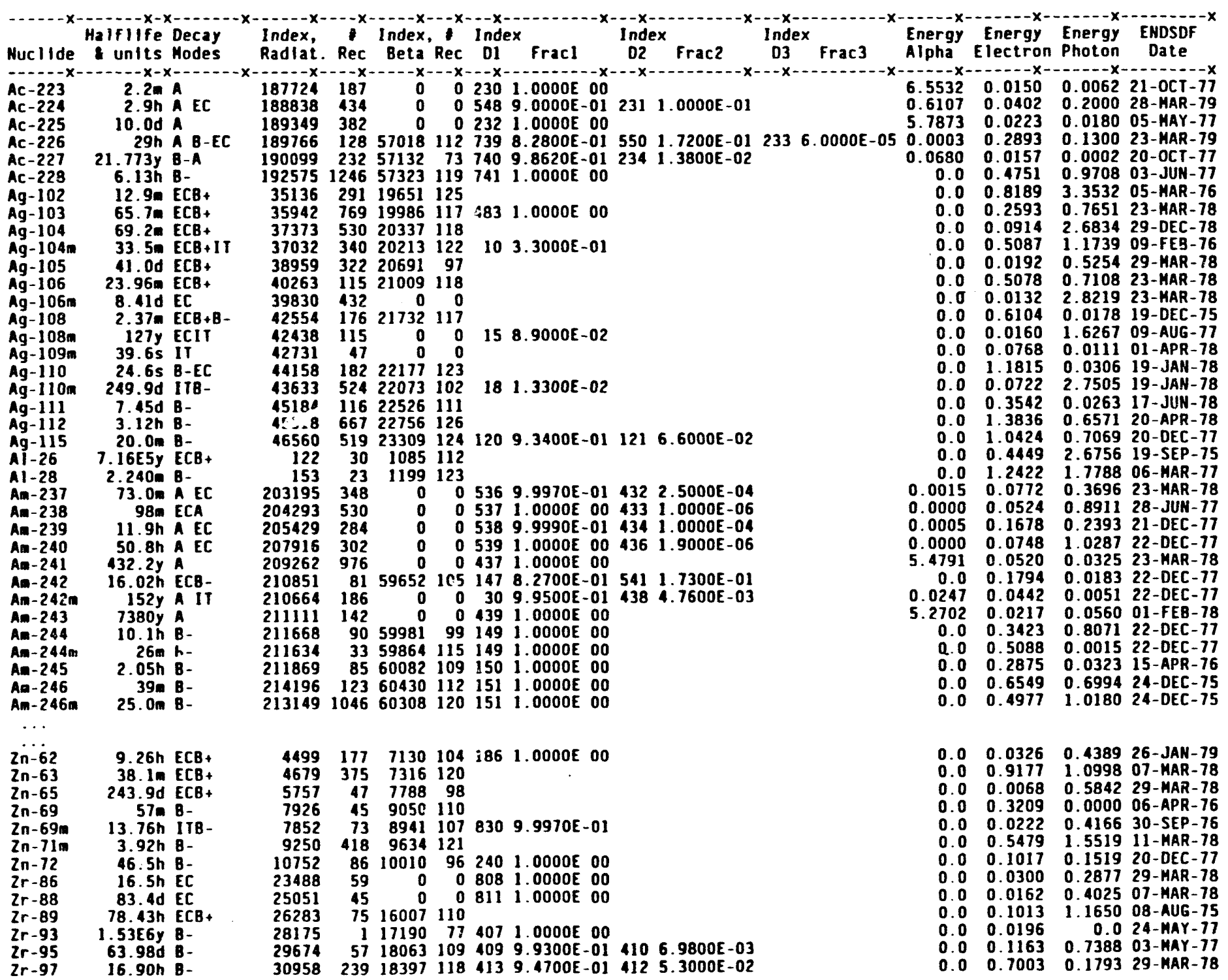




\section{Radiation Files ICRP38.RAD and MIRD.RAD}

The RAD files are direct-access files whose records contain data on the intensity and energy of each radiation emitied in nuclear transformations of the radionuclides. These are large files ICRP38.RAD contains 221,174 records for 838 radionuclides (6 Mbytes), and MIRD.RAD file has 43,851 records for 242 radionuclides (1.2 Mbytes).

For each nuclide, there is a header record containing the name of the nuclide, its half-life, and the number of radiation records for the nuclide. The radiation records follow the header - one record for each emitted radiation - and contain the following data: (1) an integer code (ICODE), which identifies the type of radiation; (2) the absolute intensity of the radiation, in percent (i.e., radiations per 100 decays); and (3) the unique or average energy of the radiation, in MeV. (For the fission component of spontaneously fissioning radionuclides (ICODE=9), these files contain instead the number of spontaneous fissions per 100 decays and the number of neutrons per fission. When data on selected nuclides are extracted from the RAD files, as described later, the output files contain the information on the intensities and the mean energies of the various radiations associated with fission.) An excerpt from ICRP38.RAD is given in Table 5, and the ICODE code is explained in Table 6. (In Table 6 note that, for spontaneous fission, ICODE is defined differently in ICRP38.RAD or MIRD.RAD from that in files of data extracted from these files.) The record number of the header and the number of radiation records for the nuclide of interest in the RAD files are contained in the corresponding index file (IDX). 
Table 5. Records for First 8 Radionuclides in File ICRP38.RAD.

\section{Contents of ICRP38.RAD}

H-3 $12.35 \mathrm{y}$

$51.00000 \mathrm{E}+02 \quad 5.68276 \mathrm{E}-03$

$\mathrm{Be}-7 \quad 53.3 \mathrm{~d}$

$11.03400 \mathrm{E}+01 \quad 4.77605 \mathrm{E}-01$

$68.04306 \mathrm{E}-06 \quad 4.77550 \mathrm{E}-01$

$61.18019 \mathrm{E}-07 \quad 4.77605 \mathrm{E}-01$

$21.63500 \mathrm{E}-02 \quad 5.47500 \mathrm{E}-05$

$\mathrm{Be}-10 \quad 1.600 \mathrm{E} 06$ y 1

$51.00000 \mathrm{E}+02 \quad 2.52256 \mathrm{E}-01$

C- $1120.38 \mathrm{~m}$

$49.97600 \mathrm{E}+01 \quad 3.85535 \mathrm{E}-01$

$31.99520 \mathrm{E}+02 \quad 5.11000 \mathrm{E}-01$

2 1.61920E-04 1.83300E-04

$28.09600 \mathrm{E}-05 \quad 1.83300 \mathrm{E}-04$

$\mathrm{N}-13 \quad 9.965 \mathrm{~m}$

$49.98200 \mathrm{E}+01 \quad 4.91829 \mathrm{E}-01$

3 1.99640E+02 5.11.000E-01

22.37600 E-04 2.77400E-04

21.18800 E- 04 2.77400E-04

$75.13373 \mathrm{E}-02 \quad 2.43000 \mathrm{E}-04$

$73.28914 \mathrm{E}-02 \quad 2.51999 \mathrm{E}-04$

7 1.02230E-02 2.58000E-04

7 5.18559E-03 2.65000E-04

7 8.00061E-02 2.66000E-04

C- $14 \quad 5730$ y

1

$51.00000 \mathrm{E}+02 \quad 4.94534 \mathrm{E}-02$

$0.15 \quad 122.2 \mathrm{~s}$

$49.98870 \mathrm{E}+01 \quad 7.35329 \mathrm{E}-01$

3 1.99774E+02 5.11000E-01

$22.64721 \mathrm{E}-04 \quad 3.92400 \mathrm{E}-04$

2 1.32360E-04 3.92400E-04

$72.11093 \mathrm{E}-02$ 3.56000E-04

$72.28289 \mathrm{E}-02 \quad 3.62000 \mathrm{E}-04$

$76.70043 E-03 \quad 3.68999 E-04$

$74.44718 \mathrm{E}-03 \quad 3.73000 \mathrm{E}-04$

$75.75170 \mathrm{E}-02 \quad 3.75000 \mathrm{E}-04$

F-18 $109.8 \mathrm{~m} \quad 2$

$41.00000 \mathrm{E}+02 \quad 2.49776 \mathrm{E}-01$

$32.00000 \mathrm{E}+02$ 5.11000E-01
Notes

Header record for $\mathrm{H}-3$.

First (and only) data record for $\mathrm{H}-3$.

Header record for $\mathrm{Be}-7$.

ICODE, intensity, and energy.

Intensity of radiation is in percent (i.e., radiations per 100 decays). Unique or average energy is in $\mathrm{MeV}$. 
Table 6. Description of ICODE

\begin{tabular}{ccll}
\hline ICODE & $\begin{array}{c}\text { Mnemonic } \\
\text { for ICODE }\end{array}$ & \multicolumn{1}{c}{ Description } & $\begin{array}{l}\text { ICODE pertains to } \\
\text { Input/Output File?a }\end{array}$ \\
\hline 1 & g & Gamma rays & Both \\
2 & $\mathrm{x}$ & X-rays & Both \\
3 & aq & Annihilation quanta & Both \\
4 & b+ & Beta + particles & Both \\
5 & b- & Beta - particles & Both \\
6 & ic & $\begin{array}{l}\text { Internal conversion } \\
\text { electrons }\end{array}$ & Both \\
7 & ae & Auger electrons & Both \\
8 & a & Alpha particles & Both \\
9 & & Spontaneous fission & Input file \\
9 & ff & Fission fragments & Output file \\
10 & n & Neutrons & Output file \\
11 & pg & Prompt gamma rays & Output file \\
12 & dg & Delayed gamma rays & Output file \\
13 & sb & Beta particles & Output file \\
& & associated with & \\
& & spontaneous fission & \\
\hline
\end{tabular}

anput file refers to standard file ICRP38. RAD or MIRD.RAD. Output file refers to DEXRAX radiations sutput file (see Tables 8-9).

bnemonic appears in output file only. 
Beta Spectra Files ICRP38.BET and MIRD.BET

The direct-access files ICRP38.BET and MIRD.BET contain the beta spectra data for the beta emitters in these collections. ICRP38.BET contains 61,249 records ( 0.7 Mbytes of data), while MIRD.BET has 3333 records ( 0.2 Mbytes). These spectral data were computed by EDISTR ${ }^{7}$ on a fixed energy grid, to facilitate tabulation of the composite spectra.

For each nuclide, the header record gives the name of the nuclide. The header is followed by a record containing the end-point energy of the spectrum, in $\mathrm{MeV}$. The subsequent data records contain the frequency $N(E)$ (number of betas per $\mathrm{MeV}$ per decay) at the standard energy grid points that are less than the end-point energy. The very last record is the frequency at the nuclide unique end-point energy. The number of beta particles per decay $Y$ is

$$
Y=\int_{0}^{\infty} N(E) d E
$$

and the average energy of the spectrum is

$$
\bar{E}=\frac{\int_{0}^{\infty} E N(E) d E}{Y} .
$$

The DEXRAX utility, discussed below, is used to extract the spectral data. It generates the appropriate energy grid and tabulates the spectrum as the number pairs $[E, N(E)]$.

For a beta emitter, the record number of the header and the number of points in the beta spectrum are given in the IDX record for the nuclide. If the beta spectrum is represented by $N$ number pairs, then BET contains $N+2$ records for the nuclide. Excerpts from ICRP38.BET are given in Table 7. 
Table 7. Excerpts from First 5 Records of File ICRP38.BET.

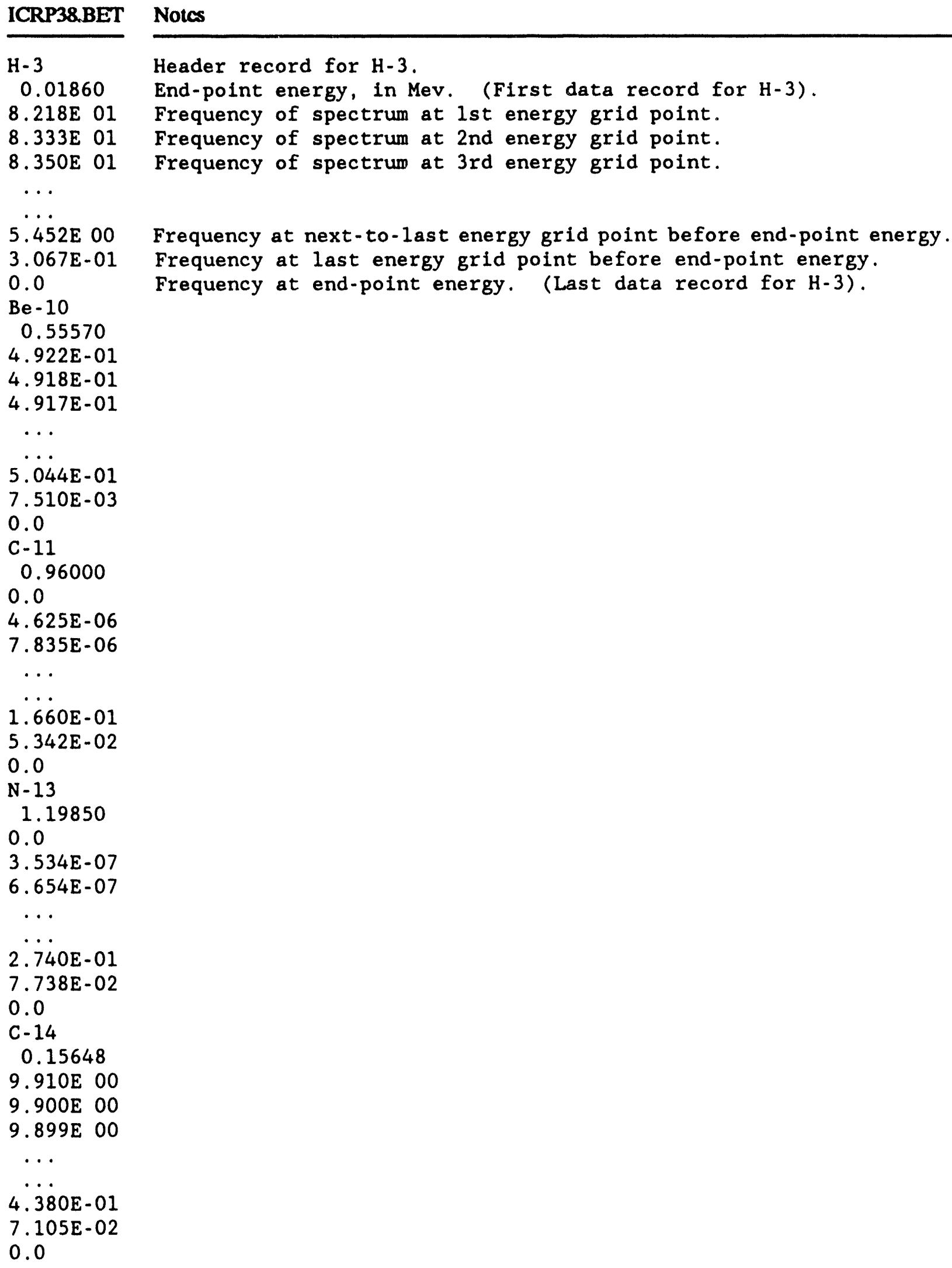


Table 8. Structure of Records in DEXRAX Radiations Data Output File.

(See text on p. 17 for Tables 8 and 9)

\begin{tabular}{|c|c|c|}
\hline \multicolumn{3}{|c|}{ Header Record for Each Nuclide } \\
\hline Variable & Format & Description \\
\hline Nuclide & A7 & Nuclide name; e.g., Am-241. \\
\hline Half-life & A8 & Half-life of nuclide. \\
\hline Units & A2 & Units of half-life; see Table 3. \\
\hline Decay Modes & A8 & Decay modes; see Table 3. \\
\hline No. Data Records & 14 & $\begin{array}{l}\text { Number of data records }=\text { number of } \\
\text { radiations. }\end{array}$ \\
\hline D1 & A7 & Name of daughter nuclide 1. \\
\hline Frac1 & A10 & Branching fraction for D1. \\
\hline D2 & A7 & Name of daughter nuclide 2. \\
\hline Frac2 & A10 & Branching fraction for $D 2$. \\
\hline D3 & A7 & Name of daughter nuclide 3 . \\
\hline Frac3 & A10 & Branching fraction for D3. \\
\hline \multicolumn{3}{|c|}{ FORMAT(A7, 1X, A8, A2, A8, I4, 3(1X,A7,1X,A10)). } \\
\hline \multicolumn{3}{|c|}{ Data (Radiations) Records, One for each Radiation. } \\
\hline Variable & Format & Description \\
\hline ICODE & I1 or 12 & Radiation type (see Table 6). \\
\hline Intensity & E11.5 & Number of radiations per decay. \\
\hline Energy & E11.5 & Unique or average energy, in $\mathrm{MeV}$. \\
\hline Mnemonic & A2 & Mnemonic for ICODE (see Table 6). \\
\hline
\end{tabular}

FORMAT(I1, 1X, E11.5, 1X, E11.5, 1X, A2) for ICODE $\leq 9$.

FORMAT(I2, OX, E11.5, 1X, E11.5, 1X, A2) for ICODE $\geq 10$. 
Table 9. Example of a DEXRAX Radiations Data Output File: Excerpts from File for U-236 and its Daughters.

The first 2 lines give the name of the output file, the version number and date of the DEXRAX code, and the date and time DEXRAX was run to produce this file. The next 3 lines give the pedigree of the DEXRAX executable file and the files ICRP38.IDX and ICRP38.RAD that were read during the run, i.e., directory information on size, date, and time of creation.

Then follow the data for each nuclide. See Table 8 for explanation of each field in the header and data records.

This is OEXRAX radiatlons data flle u236d. rad

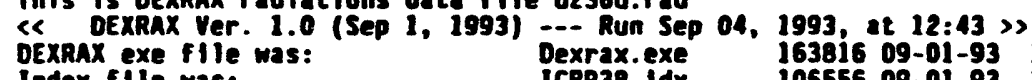

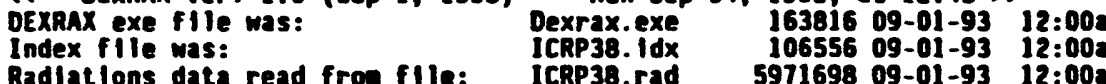

Index file was:
Radiatlons data read from flle: ICRP38. Idx 106556 09-01-93 12:00a
U-236 2.3415E7y 1 ICRP38.rad 5971698 09-01-93 12:00a

$2.59326 E-03 \quad 4.35888 E+00$

$8.38081 E-01$. $51825 E+00$ :

...

2.6438EE-01 3.66821E-03

8.13181E-02 B.11459E-04 ae

Th-232 1.405E10y A

$58 \mathrm{Ra}-228 \quad 1.0000 E$ DO

$1.99601 E-033.82780 E+00$ :

$2.29541 E-01$
$8.95163 E+00$

...

7̈̈.39637E-01 3.42636E-03 20

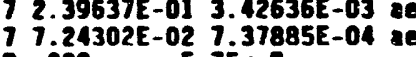

6 Ac-228 $1.0000 E$ OO

$1.000002+0079.26455-03$ b-

6.21118E-07 6.67000E-03 g

6 5.5568AE-01 2.76100E-03 ic

7 5.55684E-01 3.90899E-03

T.14315E-01 8.90000E-04

Ac-228 6.13h B- 1246 Th-228 1.0000 E 00

5 1.75748E-03 3.32876E-02 b-

5 2.63622E-04 $1.56668 E-02$ b-

7i.11652E+00 3.70476E-03 se

7.37875E-01 8.11352E-04

Th-228 1.9131 Y ${ }^{2}$.

$81 \mathrm{Ra}-224 \quad 1.0000 E$ DO

8. $5.00050 E-045.13839 E+00$ :

8 3.60036E-03 5.21114E+00 :

$7 \because 609060 \mathrm{E}-01$ 3. $42801 \mathrm{E}-03$ ae

Ra-224 3.66d A 75 Rn-220 1.0000E 00

3.09946E-05 5.03347E+00

$87.19874 E-05$ 5.04692E+00

...

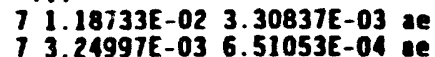

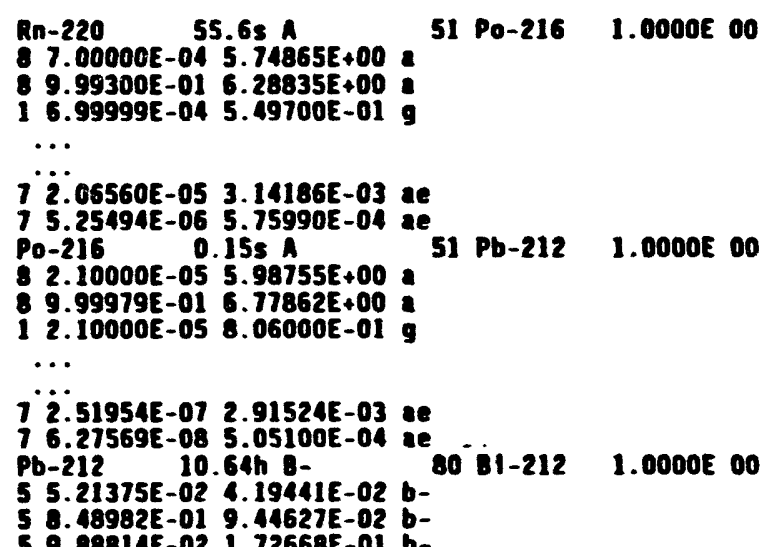

Rn-220 55.6s 51 Po-216 1.0000 OO

$7.00000 E-045.74865 E+00$

$9.99300 E-01$
$16.28835 E+00$

...

72.05560 E-05 3.14186E-03 ae

5.25494E-06 5.75990E-04

Po-216 $0.155 \AA \quad 51 \mathrm{~Pb}-212$ 1.0000E 00

2.10000E-05 5.98755E+00 a

$9.99979 E-01$
$12.77862 E+00$

7 2.51954E-07 $2.91524 E-03$ :

Pb-212 10.64 8- $8081-212 \quad 1.0000 E$ OO

$55.21375 E-02$ 4.19441E-02 b-

5 8.48982E-01 9.41627E-02

…

7 $5.37795 E-01 \quad 3.04071 E-03$ ae

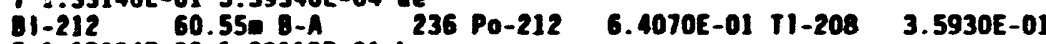

5 1.19004E-02 1.28119E-01 b-

5 T.80015E-04 $1.29618 E-01$ b-

$7 \ddot{2.99105 E-01 ~ 2.67166 E-03 ~}$

$78.71924 E-02$ 5.04845E-04 ae

Po-212 0.305usA

$8.99716 E-018.78453 E+00$.

3.69917E-05 $9.49700 E+00$ a

8 1.5964E-05 $1.04260 E+01$ a

II-208 3.075 - 230

5 5. $48395 E-041.52139 E-01$ b-

5 1.69504E-04 1.85507E-01 b

4.38716E-04 1.94015E-01 b-

$71.08696 E-012.92035 E-03$ at 


\section{OUTPUT FILES FROM UTILITY DEXRAX}

When DEXRAX is run, the principal output files are the radiations data file and/or the beta spectra file for the user-specified radionuclides. The output radiations data file, which always has the extension RAD, contains data for user-specified nuclides extracted from either the ICRP38.RAD or MIRD.RAD files, and some information from the associated index file is also included. As mentioned previously, the data for the fission component of spontaneously fissioning radionuclides is expanded in the output file (see Fig. 7 and Table 13). The beta spectra file, which always has the extension BET, includes data for user-specified nuclides extracted from either ICRP38.BET or MIRD.BET, along with the standard energy grid points and some information from the index file.

The structure of records in the radiations data file is given in Table 8, and excerpts from a file for U-236 and its daughters, as obtained from ICRP38.RAD, are given in Table 9. Note that each intensity in the radiation data output file is given as a fraction rather than a percent (i.e., radiations per decay rather than radiations per 100 decays). The structure of records in the beta spectra file is given in Table 10, and excerpts from a file for U-236 and its daughters are given in Table 11.

Two other types of output files, the LST file containing a list of nuclides for input to a later DEXRAX run and the LOG file, will be described later.

Table 10. Structure of Records in DEXRAX Beta Spectra Output Füle.

\section{Header Record for Each Nuclide}

Same as shown in Table 8 for radiations data output files, except that the number of data records $=$ number of energies at which the beta spectrum is tabulated.

\begin{tabular}{|c|c|c|}
\hline \multicolumn{3}{|c|}{ Data (Beta Spectra) Records, One for Each Energy } \\
\hline Variable & Format & Description \\
\hline Energy & F8.5 & $\begin{array}{l}\text { Standard energy of grid point, or end- } \\
\text { point energy for this nuclide. }\end{array}$ \\
\hline Frequency & E10.3 & $\begin{array}{l}\text { Number of beta particles per Mev } \\
\text { per nuclear transformation at this energy. }\end{array}$ \\
\hline
\end{tabular}


Table 11. Example of a DEXRAX Beta Spectra Output File: Excerpls from File for U-236 and its Daughters.

The first 2 lines give the name of the output file, the version number and date of the DEXRAX code, and the date and time DEXRAX was run to produce this file. The next 3 lines give the pedigree of the DEXRAX executable file and the files ICRP38.IDX and ICRP38.BET that were read during the run, i.e., directory information on size, date, and time of creation.

Then follows the data for each nuclite. See Table 10 for explanation of each field in the header and data records.

This is DEXRAX beta spectra file u236d bet

1993) -0. Run Sep 04, 1993 at 12.43 :22

DEXRAX exe flle was: (Sep 1, 19g3) Dexrax.exe

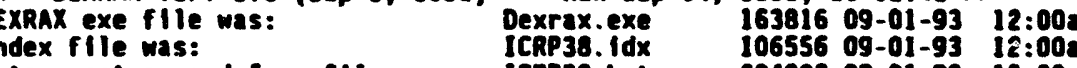

1CRP38 684882 09-01-93 12:002

Ra-228 $5.75 y$ :

72 Ac-228 1.6000 oO

$000107.515 E^{2}+01$

$000117.510 E+0$

$000127.506 E+01$

‥

$.032002 .579 E+00$

.03600 4.661E-01

$.038930 .000 E+00$

Ac-228 6.13h B-

$000001.915 E+00$
00010
$1.915 E+00$

119 Th-228 $1.0000 E 00$

.00011 1.915E+00

$.000161 .915 E+00$

$.000181 .915 E+00$

$000321.914 E+00$

$000361.914 E+00$

00060 i.

$000451.914 E+00$

00050 1.914E+00

$.001001 .913 E+00$

$.001101 .912 E+00$

$.001201 .912 E+00$

$.001601 .911 E+00$

$.001801 .911 E+00$

$003201.907 E+00$

$.003601 .906 E+00$

.

$004501.904 E+00$

$.005001 .902 E+00$

$.010001 .889 E+00$

$011001.887 \mathrm{E}+00$

$012001.884 E+00$

$.016001 .874 E+00$

$018001.868 E+00$

$020001.868 E+00$

$.032001 .853 E+00$

$036001.847 E+00$

04500 1.832

05000 i.

$.100001 .740 E+00$

$.110001 .721 E+00$

$120001.701 E+00$

$.160001 .619 E+00$

.18000 i.575E+00

20000 : $.530 E+00$

$.320001 .232 E+00$

$.360001 .133 E+00$

$400001.042 E+00$

.45000 9. $525 E-01$

1.00000 1.913E-01

$1.100001 .256 E-01$

i. $600002.328 E-02$

$800005.780 E-03$

$.000005 .771 E-04$

2.079240.000E+00

-212 10.64h 8

$000007.356 E+00$

opoic ?. 353

$550001.721 E-03$

$.572900 .000 E+00$

$-21200000.550$

$000105.2225-01$

$000115.2225-01$

2.20000 1.023E-03

$2.246000 .000 E+00$

-208 3.07: 8

$.000008 .041 E-0$

$.000108 .041 E-01$

i.60000 3.189E-02

$10381-212 \quad 1.0000 E 00$

120 Po-212 6.4070E-01 T1-208 3.5930E-01

117 


\section{THE DEXRAX PROGRAM}

\section{Introduction}

DEXRAX is distributed in one of three ways: (i) as a stand-alone package for those interested only in the nuclear decay data; (ii) with program SEECAL ${ }^{10}$; or (iii) as part of a larger dosimetric system, the DCAL system. The DCAL system (see Fig. 2) is a comprehensive radiation dose and risk calculational system being developed for the Environmental Protection Agency and will be documented elsewhere ${ }^{11}$.

Installation instructions are given with the appropriate distribution packet. In either case, the installation procedure sets up a standard directory structure on the hard disk of the user's PC and installs all necessary files into their appropriate directories. About 12 Mbytes of space on the disk is required during the installation, and about $3 \mathrm{Mbytes}$ will be released following the installation.

From here on, only the stand-alone system and running DEXRAX by itself are considered. The files given below are identical to the DEXRAX-related files supplied with the DCAL system, and the directories given below are a subset of the directories required for the DCAL system. Running DEXRAX in the DCAL system is trivial, because no user responses are required. Running DEXRAX and SEECAL as a unit is described in Cristy and Eckerman ${ }^{10}$.

\section{Directory Structure Required for DEXRAX}

You may choose a directory (or directory plus subdirectory) where the system is installed. The notation "\$DCAL", used below, stands for the name of the place where you install the system, e.g., "DCAL", "PHOENIX", "PHOENIXIDCAL", or "WANYTHNG1\ANYTHNG2". The default is "WCAL". Files supplied with DEXRAX and their directories are as follows:

File

\begin{tabular}{l}
\hline DEXRAX.BAT \\
DEXRAX.EXE \\
DEXRAX.INI \\
ICRP38.IDX \\
ICRP38.RAD \\
ICRP38.BET \\
MIRD.IDX \\
MIRD.RAD \\
MIRD.BET
\end{tabular}

\$DCAL
\$DCALIBIN
\$DCALIINI
\$DCALIDATNUC
\$DCALIDATNUC
\$DCALIDATNUC
\$DCALIDATNUC
\$DCALIDATINUC
\$DCALIDATINUC




\section{DCAL: RADIATION DOSE AND RISK CALCULATIONAL SYSTEM}

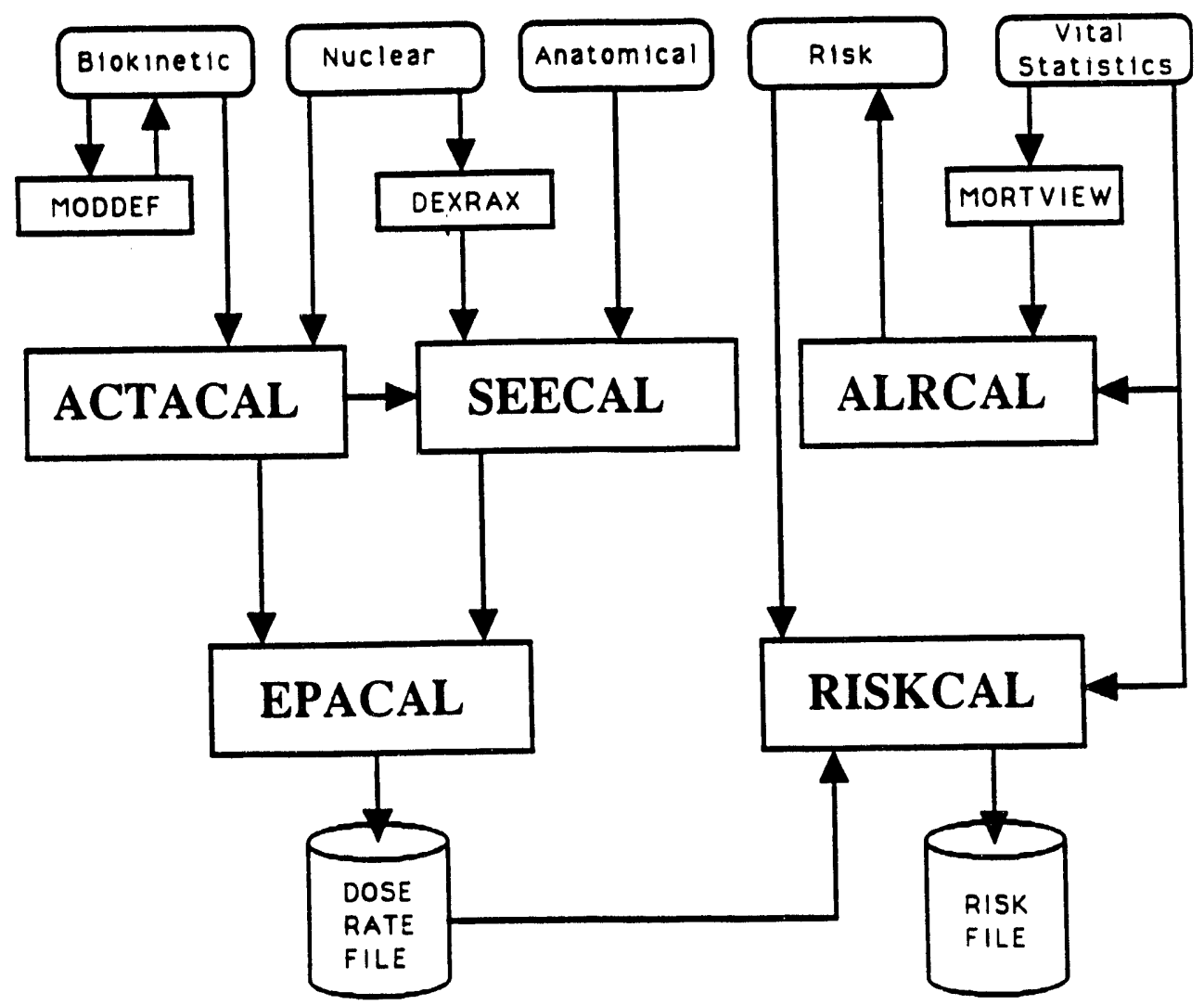

Figure 2. Schematic showing the programs, input data, and flow in the DCAL dosimetric system. The major data elements of the system are shown at the top of the figure (in the rectangles with rounded corners). The two cylinders at the bottom denote the repositories of dosimetric and risk data. Major computation modules in the system have names that end in "CAL" (large rectangles). No naming convention was applied to utilities modules (small rectangles). One might enter into the DCAL system using the utility MODDEF to define an age-specific biokinetic model, run ACTACAL to compute the activity of the radionuclide and any decay products in the body as a function of time following the intake either via ingestion, inhalation, or injection. The module SEECAL computes the dose rate in target tissues and organs per unit activity residing in source regions (as considered by ACTACAL). EPACAL operates on the activity-time information with the data from SEECAL to compute the dose rate as a function of time following the intake. These data can then be processed by RISKCAL with information on the age-specific risk per dose generated by ALRCAL to compute the lifetime risk and years of life lost per unit activity inhaled or ingested. U.S. vital statistical data, including the age and sex-specific cancer mortality data are accessed by MORTVIEW and ALRCAL to compute cancer risk information. 
When DEXRAX is installed, a directory \$DCALIWORK2 is created. All output files of DEXRAX are placed in the WORK2 directory. Note that DEXRAX is always run from the root directory \$DCAL, using the DEXRAX.BAT file.

The file DEXRAX.INI gives the name and location of the index file to be used by DEXRAX. Specifying the index file (IDX) uniquely determines which RAD and BET files are to be used. When DEXRAX is installed, these files are all placed in the directory \$DCALIDATNUC as shown above. If desired, you may elect to locate these files elsewhere by editing the DEXRAX.INI file and moving the files. Note that DEXRAX expects that the three files will be in the same directory. The file DEXI_AX.INI contains the following:

'INDEX.DAT'

'\$DCALIDATNUCICRP38.IDX'

The first field of the line gives the standard name of the index file as coded in DEXRAX, and the second field gives the path structure on your system to the ICRP38.IDX file. If you wish to use the MIRD collection, you should replace "ICRP38.IDX" with "MIRD.IDX." Note: you must not change the name in the first field.

\section{Description of the DEXRAX Utility}

The DEXRAX utility was written to extract the radiations data and beta spectra data for userspecified radionuclides from the RAD and BET files. This function is carried out as:

1. A list is created of the user-specified radionuclides. You have the option for automatic inclusion of any daughter nuclides to the list. Duplicate nuclides in the list are eliminated.

2. You have the option of extracting the radiations data and/or beta spectra for the nuclides in the above list or writing the list to a file for later processing.

As an example of the extraction of a complete decay chain by DEXRAX, consider uranium236. After starting DEXRAX, you would be prompted for the nuclide name and would enter " $U$ 236." You would be prompted whether to extract the data for daughter nuclides. If an affirmative response is given, DEXRAX assembles a list of all radioactive daughter nuclides associated with the decay of U-236 and subsequent radioactive daughter nuclides. For this example the resulting list would be:

$\begin{array}{llllll}\text { U-236 } & \text { Th-232 } & \text { Ra-228 } & \text { Ac-228 } & \text { Th-228 } & \text { Ra-224 } \\ \text { Rn-220 } & \text { Po-216 } & \text { Pb-212 } & \text { Bi-212 } & \text { Tl-208 } & \text { Po-212 }\end{array}$


Input

In addition to the information you specify, DEXRAX uses three data files, in read-only mode. These files were discussed in some detail above.

1. IDX File: The records of this file contain the pointers to the locations of the radiations data and beta spectra data in the corresponding RAD and BET files, respectively. In addition, it contains other data and information of interest.

2. RAD File: The records of this large direct-access file contain the information on the type of radiation, its absolute intensity, and its mean energy emitted in the nuclear transformation.

3. BET File: This direct-access file contains records of the absolute intensity of beta emission as a function of particle energy.

\section{Output}

DEXRAX creates several output files, the number depending on the nature of your requests. In all instances, the you are prompted for the stem of the file name, and DEXRAX adds a standard extension. The following files may be created:

1. Radiations Data File, extension RAD: At your option, the radiations data is extracted for the nuclides identified by you (and their daughter nuclides, if so elected). For each nuclide an appropriate header record is written, followed by the information on each emitted radiation.

2. Beta Spectra File, extension BET: At your option, beta spectra will be extracted for each beta emitter in the user-specified nuclide list (including any beta-emitting radioactive daughter nuclides if so elected.) The output file consists of a header record followed by records of the energy and differential yield of beta particles at the indicated energy.

3. Nuclide List File, extension LST: You may elect to create a file containing the names of nuclides of interest and extract the data, using the file, at a later time. The nuclide list file will include any radioactive daughter nuclides, if you so elect. Delaying the extraction may be useful if you want to examine the nuclide listing and eliminate from it any nuclides of limited dosimetric interest, e.g., very long-lived daughter nuclides. This file will not be created if you elect to extract the data during the interactive session. 
4. Log File, DEXRAX.LOG: Some of the information written to the screen during a DEXRAX session is written to the log file. The pedigree of the DEXRAX executable file and the standard input files read by DEXRAX during the session are also written here.

DEXRAX begins by asking you whether the names of the nuclides will be supplied during the session from the keyboard or from a file created during a previous DEXRAX run that contains the list of nuclides. You are asked what type of data should be extracted from the files, i.e., radiations data, beta spectra data, or both. You are further asked whether radioactive daughter nuclides should be included with each user-specified nuclide. An affirmative response will treat the user-specified radionuclide as the parent of a decay chain.

You are prompted to input the nuclide's name in the conventional notation; e.g., H-3, Al-26, Tc-99m, etc. The nuclide name is checked for appropriate format and it and any daughter products, if inclusion of daughter products was selected, are added to the nuclide list. If the requested nuclide is not contained in the files, you are so notified. You terminate the entry of nuclides by entering a blank line.

Once entry of nuclides has been terminated, the list is checked for any duplicate nuclides which might have occurred from consideration of decay chains headed by each of the user-specified nuclides. The final list of nuclides is shown and you are asked if you wish to extract the data for this list. If your response is affirmative, you will be prompted for names of the files that contain the extracted information. The session terminates after the extraction has been completed and the files written. A negative response results in an inquiry whether the list of nuclides should be written to a file for later use. An affirmative response is followed by a request for a name for the file, while a negative response results in termination of the program.

\section{Description of DEXRAX Routines}

DEXRAX is written in Microsoft FORTRAN and uses two special libraries. The two menus are based on the FORTRAN library FASTPLOT developed by R. C. Ward ${ }^{12}$, and DEXRAX uses a $C$ language routine ${ }^{13}$ to obtain the date and time stamp of the files accessed by DEXRAX. 


\section{MAIN Routine}

MAIN prompts you for input, calls routines to check the nuclide names (CHECK), assembles the decay chain (CHAIN), removes duplicate nuclides for the assembled list (WEED), and extracts the radiations data (EXTRAD) and/or the beta spectra (EXTBET). The list of nuclides, including daughter nuclides if requested, is contained in the array NAME, which is dimensioned to 400 at present. The record number of the nuclides in the index file (IDX) is contained in the array INDEX, also dimensioned to 400 .

\section{CHAIN Routines}

The routine CHAIN and its associated routines, FRWARD and RECVER, assemble the list of radioactive daughter nuclides headed by the specified parent nuclide. The COMMON block /CHAINS/ is used to communicate with CHAIN and its routines. The block is defined as:

COMMON /CHAINS/ NAMEN(30), IPOINTS(30), NDAU

where NAMEN is a CHARACTER*7 variable containing the names of the members of the decay chain (NAMEN(1) is the parent nuclide) of length NDAU (an integer). The integer variable IPOINTS contains the record number of the nuclides in the index file. CHAIN directs the assembly of the chain by calling the routine FRWARD to read a linear chain, noting the occurrence of any branches and their convergence, when processing previously detected branches. CHAIN calls RECVER to recover the location of any branches detected by FRWARD as it is processing a linear chain to termination. This collection of routines uses the index file to construct the decay chain.

\section{WEED Routine}

The routine WEED eliminates duplicate nuclides that entered into the assembled list either by overlapping decay chains or through user error. The former would occur, for example, if you requested the inclusion of daughters and then indicated $\mathrm{Pu}-236$ and Th-232 as two nuclides of interest.

\section{EXTRAD Routine}

This routine extracts the radiations data for the selected radionuclides from the direct-access file ICRP38.RAD or MIRD.RAD. Which RAD file is accessed depends on which index file (IDX) is being used. The input to the routine consists of the record number of the nuclides in the index file, contained in the INDEX array. For each nuclide a header record is included with the data records, as shown in Table 8. 


\section{EXTBET Routine}

The EXTBET routine extracts the number of beta partic'es emitted per unit energy per decay from the direct-access file ICRP38.BET or MIRD.BET. Which BET file is accessed depends on which index file (IDX) is being used. The standard energy grid is computed by EXTBET when it is first called. EXTBET writes the beta spectrum to the BET output file as pairs of energy and intensity of beta emission. The input to EXTBET is the list of record numbers of nuclides of interest in the IDX file, contained in the INDEX array. For each nuclide a header record is included in the same format as for the radiations data. The structure of the beta spectra file is given in Table 10 .

\section{IBINRY Function}

The IBINRY function preforms a binary search of the appropriate index file to determine the number of the record for the radionuclide of interest. If the requested nuclide is not contained in the file, the routine returns a value of zero.

\section{CHECK Function}

The CHECK function accepts the current nuclide name and returns the name in the format used in the index files. That is, the first character of the chemical symbol must be upper case, the second character, if present, lower case, and the final character - the metastable notation, if applicable - is in lower case. Thus, if CHECK is called with $\mathrm{cm}-244$, it returns Cm-244; if TC-99M, it returns Tc-99m. 


\section{HOW TO RUN DEXRAX}

Before running DEXRAX for the first time, install the program and related files, following instructions included with the installation diskettes.

To run DEXRAX, do the following:

1. Check file SDCALIINIDEXRAX.INI. If desired, edit this file to change from ICRP38 standard input files to MIRD standard input files, or vice-versa, as described above in the section "Directory Structure Required for DEXRAX" under "IV. THE DEXRAX PROGRAM." (Recall that SDCAI is our notation for whatever you chose as the DCAL root directory during installation; e.g., "WDCAL", "PHOENIXIDCAL", or "WANYTHNGIVANYTHNG2".

2. Change directory to SDCAL.

3. Type "dexrax" to run the program.

4. Select menu items and answer queries as they appear on the screen. This is explained by example below.

5. When finished, the output files will be in the directory SDCALIWORK2.

\section{Examples}

In Figs. 3-6 are shown four examples of DEXRAX ruris using the ICRP38.IDX index file. In the "a" part of each figure is shown what appears on the scri:en during the run - menus, queries, and output. In these examples the user has installed the system on drive $C$ : and the root directory \$DCAL for the system is WCAL. Screen clearing is indicated in the figures by the solid horizontal lines, and the user's input is underlined. In the "b" part is shown the LOG file for Figs. 3, 4, and 6 or the LST file for Fig. 5.

Each run begins with the user typing "dexrax" from the DOS prompt in directory IDCAL. The first screen produced by DEXRAX (see Fig. 3a) gives a header with the name, version number and date, and authors of DEXRAX, followed by information regarding the LOG file. If no file named DEXRAX.LOG exists in directory IDCALIWORK2, then the simple message "Log file will be: Dexrax.log" is printed, as in Example 1 (Fig. 3a). Otherwise, the user is given the choice whether to overwrite the existing file, append the new log file to the existing file, or rename the new log file, as in Examples 2-4. 
The second screen (see Fig. 3a) is a menu regarding mode of input for the nuclides: "Enter nuclides via the keyboard" or "Use existing LST file of nuclides". The former is the most common mode of input and is used in Examples 1, 2, and 3. The latter is used in Example 4.

The third screen is another menu, with choices on what type(s) of data to extract: radiations data only, beta spectra data only, or both types. If you are preparing data for input to SEECAL, select "radiations data only."

On the fourth (and final) screen you are queried about various things, e.g., whether to add radioactive daughters to the list of nuclides, the nuclide names or the name of the LST file containing the nuclides, the file name you want for the output files, etc. Various information on the nuclides is also written to the screen. See the various examples and figures for details.

\section{Example 1: Extracting Radiations Data for a Chain}

In the first example (Figs. 3a and $3 b$ ), the user extracted radiations data only (i.e., no beta spectra) for U-236 and its daughters. In the first menu he chose "Enter nuclides via the keyboard" and in the second menu he chose "Radiations data only." On the following screen he responded "y" to the question, "Add radioactive daughters to nucl. list?", which is the default, and entered "U-236" when prompted for nuclide name \# 1. When prompted for nuclide name \# 2, he hit <Enter> to indicate there were no further nuclides desired.

Then the program wrote a list of the 12 nuclides requested, i.e., U-236 and its daughters, wrote a message that data would be extracted from the ICRP38 collection (determined by file DEXRAX.INI), and then asked, "Do you want to extract the data now?" The user chose "y", the default, and the program then prompted for the stem name of the radiations data output file. The user responded with " $\mathrm{u} 236 \mathrm{~d}$ ", which was his personal mnemonic to indicate U-236 plus daughters (the stem can be anything from 1-8 characters). DEXRAX automatically adds the extension RAD to radiations data output files, so the output file is U236D.RAD.

DEXRAX then wrote to the screen summary information on each nuclide in the list: name, half-life, decay modes, number of radiations in file ICRP38.RAD for the nuclide, and the total energy of all emitted alpha particles, all electrons, and all photon radiations.

The message "Program DEXRAX ended normally" appeared and then the prompt for directory IDCAL.

The output files created during this run were DEXRAX.LOF and U236D.RAD, which appear in the directory IDCALIWORK2. The contents of DEXRAX.LOG are shown in Fig. 3b, and excerpts from U236D.RAD were given previously in Table 9. 
Figure 3a. DEXRAX Run, Example 1.

User elected to enter nuclides via the keyboard, chose radiations data only (i.e., no beta spectra), chose to include radioactive daughters, chose U-236, elected to extract the data during the run, and named the Jiations data output file U236D.RAD. User's responses are underlined, including menu selections. A long, solid horizontal line indicates that the screen was cleared by DEXRAX.

Session began when user typed "dexrax" in directory IDCAL.

\title{
$C: \backslash D C A L>$ dexrax
}

DEXRAX: Decay Data Extractor

Ver. 1.0 (Sep 1, 1993)

Oak Ridge National Laboratory Report ORNL/TM-12350

Authors: R.J. Westfa11, J.C. Ryman, M. Cristy, K.F. Eckerman

Oak Ridge National Laboratory

Oak Ridge, TN 37831-6383

Log file will be: Dexrax.log

Press <Enter> to clear screen \& continue DEXRAX

SEnter

\section{DEXRAX - Decay Data Extractor}

Ver. 1.0 (Sep 1, 1993)

Enter nuclides vis the keybonrd

Use existing LST file of nuclides

\author{
Use Arrow Keys To Make Selection \\ Press <Enter> To Execute, <Esc> To Exit
}

DEXRAX - Decay Data Extractor

Select Type of Data to be Extracted

Radiations data only

Beta spectra only

Radiations and beta spectra

Use Arrow Keys To Make Selection

Press <Enter> To Execute, <Esc> To Exit 
(Figure 3a, cont'd)

Add radioactive daughters to nucl. list $([y] / n)$ ? y

Enter nuclides (7 characters maximum !), e.t., Md-258, H-3, Pm-148m Blank entry terminates the read.

Nuclide \# 1: U-236

Nuclide \# 2: SEnter

No duplicates existed in list of length 12 . List includes:

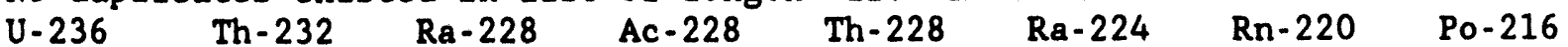

$\mathrm{Pb}-212 \quad \mathrm{Bi}-212 \quad \mathrm{Po}-212 \quad \mathrm{~T} 1-208$

Data will be extracted from the ICRP38 nuclear decay data files.

Do you want to extract the data now $([y] / n) ?$ y

Name of radiations file, .rad added $\rightarrow \underline{u 236 d}$

\begin{tabular}{|c|c|c|c|c|c|c|}
\hline Nuclide & $T-1 / 2$ & DecMode & \# rad. & $\begin{array}{c}\text { Emitted } \\
\text { Alpha }\end{array}$ & $\begin{array}{c}\text { Energy } \\
\text { Elec. }\end{array}$ & $\begin{array}{r}(\mathrm{MeV} / \mathrm{nt} \\
\text { Photon }\end{array}$ \\
\hline & - & - & & $\ldots$ & $\cdots$ & $\ldots$ \\
\hline 2 & $2.3415 \mathrm{E} 7$ & $\mathrm{~A}$ & 58 & 4.5052 & .0113 & .00 \\
\hline 32 & $1.405 \mathrm{E} 10$ & $\mathrm{~A}$ & 58 & 3.9959 & & \\
\hline$a-228$ & 5.75 & B- & 6 & .0000 & .0169 & .0000 \\
\hline$c-228$ & 6.13 & A - & 1246 & .0000 & .4751 & .9 \\
\hline$h-228$ & 1.9131 & $\mathrm{~A}$ & 81 & 5.3998 & .0205 & \\
\hline$a-224$ & 3.66 & $A$ & 75 & 5.67 & & \\
\hline$n-220$ & 55.6 & $5 \mathrm{~A}$ & 5 & 6.28 & & \\
\hline $0-216$ & 0.15 & $S \mathrm{~A}$ & 5]. & 6.77 & & \\
\hline$b-212$ & 10.64 & A $B$. & 80 & .0 & & \\
\hline & 60.55 & D B-A & 236 & 2.1 & & \\
\hline-212 & 0.305 & usA & 4 & 8.78 & & \\
\hline & & I B - & & 0 & & \\
\hline
\end{tabular}

Program DEXRAX ended normally.

Stop - Program terminated.

$C: \backslash D C A L \backslash$ 
Figure 3b. Log File from DEXRAX Run, Example 1.

Note that some of the information written to the screen during the run is repeated here. Fatal error messages written to the screen would also be repeated here. In addition is information on the pedigree of some of the DEXRAX standard files, which is also written to the radiations data output file. This file, like all DEXRAX output files, is written in directory ISDCALIWORK2.

This is DEXRAX log file Dexrax.log

《 DEXRAX Ver. 1.0 (Sep 1, 1993) -.. Run Sep 04, 1993, at 14:35 》

No duplicates existed in list of length 12 . List includes:

$\begin{array}{llllllll}\mathrm{U}-236 & \mathrm{Th}-232 & \mathrm{Ra}-228 & \mathrm{Ac}-228 & \text { Th-228 } & \mathrm{Ra}-224 & \mathrm{Rn}-220 & \text { Po-216 } \\ \mathrm{Pb}-212 & \mathrm{Bi}-212 & \mathrm{Po}-212 & \mathrm{Tl}-208 & & & & \end{array}$

Data will be extracted from the ICRP38 nuclear decay data files.

Radiations data written to file u236d.rad

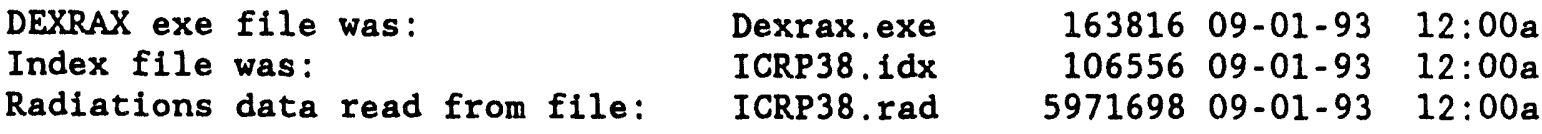

\begin{tabular}{|c|c|c|c|c|c|c|}
\hline Nuclide & $\mathrm{T}-1 / 2$ & DecMode & \# rad. & $\begin{array}{c}\text { Emitted } \\
\text { Alpha }\end{array}$ & $\begin{array}{c}\text { Energy } \\
\text { Elec. }\end{array}$ & $\begin{array}{c}(\mathrm{MeV} / \mathrm{nt}) \\
\text { Photon } \\
\ldots .\end{array}$ \\
\hline & יבחי & - & $\cdots$ & $-\cdots$ & - & $\ldots$ \\
\hline $\begin{array}{l}\text { U-236 } \\
\text { Th-232 }\end{array}$ & $2.3415 \mathrm{E} 7$ & y $A$ & 58 & & & $\begin{array}{l}.0015 \\
.0013\end{array}$ \\
\hline Ra-228 & $\begin{array}{r}.40510 \\
5.75\end{array}$ & $\begin{array}{ll}\begin{array}{l}y \\
\text { y }\end{array} & \text { B } \\
\text { y } & \text {. }\end{array}$ & $\begin{array}{r}58 \\
6\end{array}$ & $\begin{array}{l}.9959 \\
.0000\end{array}$ & $\begin{array}{l}.0124 \\
.0169\end{array}$ & $\begin{array}{l}.0013 \\
.0000\end{array}$ \\
\hline Ac -228 & 6.13 & h B - & 1246 & .0000 & .4751 & .9708 \\
\hline Th -228 & 1.9131 & y A & 81 & 5.3998 & .0205 & .0032 \\
\hline $\operatorname{Ra}-224$ & 3.66 & d A & 75 & 5.6739 & .0022 & .0099 \\
\hline$R n-220$ & 55.6 & s A & 51 & 6.2879 & .0050 & .0003 \\
\hline Po-216 & 0.15 & $s \mathrm{~A}$ & 51 & 6.7786 & .0000 & .0000 \\
\hline $\mathrm{Pb}-212$ & 10.64 & h B - & 80 & .0000 & .1755 & .1483 \\
\hline Bi-212 & 60.55 & m $B-A$ & 236 & 2.1 & & .1855 \\
\hline Po- 212 & 0.305 & usA & 4 & 8.7848 & .0 & .0000 \\
\hline T1-2 & 3.07 & m B - & 230 & .0000 & .5976 & 3.3745 \\
\hline
\end{tabular}




\section{Example 2: Extracting Radiations Data and Beta Spectra for 2 Overlapping Chains}

In the second example (Figs. $4 \mathrm{a}$ and $4 \mathrm{~b}$ ), the user extracted both radiations data and beta spectra for Pu-236 and Th-232 and their radioactive daughters. These two chains overlap, i.e., they have a common daughter, Th-228.

On the first screen the program noted that a log file named DEXRAX.LOG already existed, and the user chose to overwrite the file. On the next 2 screens with menus, the user chose "Enter nuclides via the keyboard" and "Radiations and beta spectra". On the following screen he responded " $y$ " to adding daughters and input the names of the 2 parent nuclides. The program then responded that it had weeded out 8 duplicates, i.e., that the 8 nuclides common to both chains would not be duplicated in the output files, and then wrote the names of the nuclides.

The user then again chose to extract the data during the run, and named the radiations data output file EXAMPLE2.RAD. The program then wrote summary information on the nuclides.

Next the program asked for a name for the beta spectra data output file, and the user named it EXAMPLE2.BET. Note that it did not have to have the same stem name as the RAD file. The program then wrote summary information on the beta-emitting nuclides from the list, including the number of records in file ICRP38.BET for each nuclide. Then the program terminated, as in the previous example.

Output files appearing in IDCALIWORK2 for this example were DEXRAX.LOG, EXAMPLE2.RAD, and EXAMPLE2.BET. The log file is shown in Fig. 4b. The RAD and BET files are not shown, but look similar to those shown previously in Tables 9 and 11. 
Figure 4a. DEXRAX Run, Example 2.

In this example, the user requested nuclides Pu-236 and Th-232 and their daughters. These two chains converge (at Th-228), and duplicate chain members were weeded out. Both radiations data and beta spectra were selected, and user named these files Example2.RAD and Example2.BET. Note that on the first screen DEXRAX wrote a message that a log file DEXRAX.LOG already existed, and the user was given choices whether to overwrite the old file, append new log information to the old file, or give the new log file a new name by changing the extension.

\section{$C: \backslash D C A L>\underline{\text { dexrax }}$}

DEXRAX: Decay Data Extractor

Ver. 1.0 (Sep 1, 1993)

Oak Ridge National Laboratory Report ORNL/TM-12350

Authors: R.J. Westfall, J.C. Ryman, M. Cristy, K.F. Eckerman Oak Ridge National Laboratory

Oak Ridge, TN 37831-6383

Log file Dexrax.log already exists - -

[0]verwrite, (a)ppend, or ( $r$ ) ename by changing extension $([0] / a / r)$ ?

Log file Dexrax.log will be overwritten

Press <Enter> to clear screen \& continue DEXRAX

sEnter>

DEXRAX - Decay Data Extractor

Ver. 1.0 (Sep 1, 1993)

Enter nuclides via the keyboard

Use existing LST file of nuclides

Use Arrow Keys To Make Selection

Press <Enter> To Execute, <Esc> To Exit

DEXRAX - Decay Data Extractor

Select Type of Data to be Extracted

Radiations data only

Beta spectra only

Radiations and beta spectra

Use Arrow Keys To Make Selection

Press <Enter> To Execute, <Esc> To Exit 
(Figure 4a, cont'd)

Add radioactive daughters to nucl. list $([y] / n) ?$ y

Enter nuclides (7 characters maximum!), e.g., Md-258, H-3, Pm-148m

Blank entry terminates the read.

Nuclide \# 1: $\mathrm{Pu}-236$

Nuclide \# 2: Th-232

Nuclide $\# 3:$ SEnter

Weeded out 8 duplicates in list of length 21. New 1ist, length 13, includes:

$\begin{array}{llllllll}\mathrm{Pu}-236 & \mathrm{U}-232 & \mathrm{Th}-228 & \mathrm{Ra}-224 & \mathrm{Rn}-220 & \mathrm{Po}-216 & \mathrm{~Pb}-212 & \mathrm{Bi}-212\end{array}$

Po-212 T1-208 Th-232 Ra-228 AC-228

Data will be extracted from the ICRP38 nuclear decay data files.

Do you want to extract the data now $([y] / n)$ ? y

Name of radiations file, .rad added $\rightarrow$ Example2

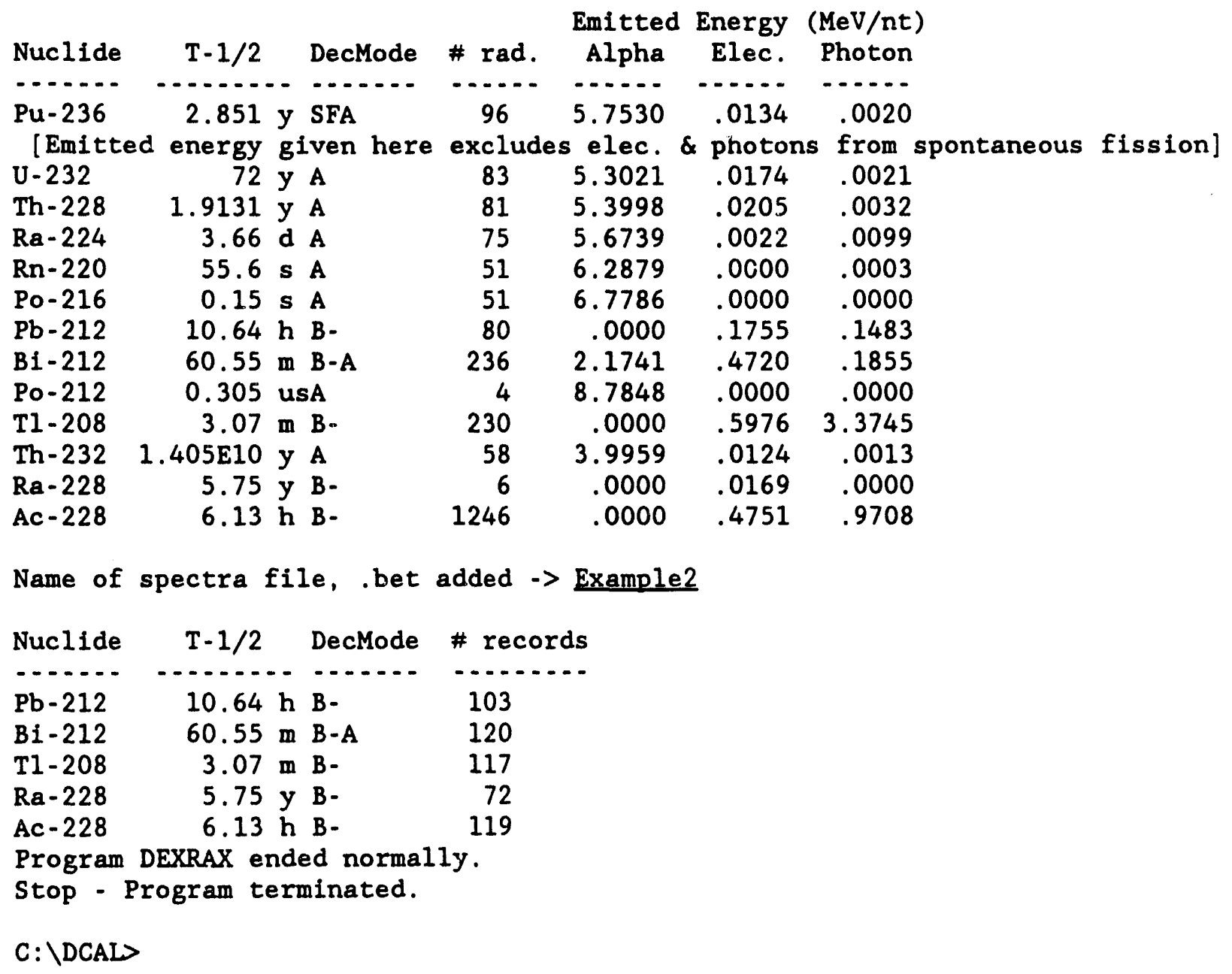


Figure 4b. Log File from DEXRAX Run, Example 2.

This is DEXRAX log file Dexrax.log

《 DEXRAX Ver. 1.0 (Sep 1, 1993) -.. Run Sep 04, 1993, at 14:59 》

Weeded out 8 duplicates in list of length 21. New list, length 13, includes: $\begin{array}{lllllll}\text { Pu-236 U-232 } & \text { Th-228 } & \text { Ra-224 } & \text { Rn-220 } & \text { Po-216 } & \text { Pb-212 } & \text { Bi-212 }\end{array}$ Po-212 T1-208 Th-232 Ra-228 Ac-228

Data will be extracted from the ICRP38 nuclear decay data files.

Radiations data written to file Example2.rad DEXRAX exe file was: Dexrax.exe Index file was:

Radiations data read from file: ICRP38.rad

$\begin{array}{rrr}163816 & 09-01-93 & 12: 00 a \\ 106556 & 09-01-93 & 12: 00 a \\ 5971698 & 09-01-93 & 12: 00 a\end{array}$

Emitted Energy (MeV/nt)

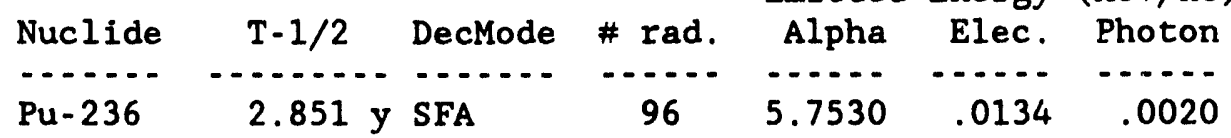

[Emitted energy given here excludes elec. \& photons from spontaneous fission]
U-232

Th- 228

$\mathrm{Ra}-224$

$\mathrm{Rn}-220$

Po- 216

$\mathrm{Pb}-212$

Bi-212

Po -212

Tl-208

Th -232

$\mathrm{Ra}-228$

Ac -228
72 y A

1.9131 y A

$3.66 \mathrm{~d} \mathrm{~A}$

$55.6 \mathrm{~s} \mathrm{~A}$

$0.15 \mathrm{~s} \mathrm{~A}$

$10.64 \mathrm{~h} \mathrm{~B}-$

$60.55 \mathrm{~m} \mathrm{~B}-\mathrm{A}$

0.305 us $A$

$3.07 \mathrm{~m} \mathrm{~B}$ -

$1.405 \mathrm{E} 10 \mathrm{y} \mathrm{A}$

5.75 y B-

$6.13 \mathrm{~h} \mathrm{~B}$ -

\section{3}

81

75

51

51

80

236

4
230

230

58

6
1246 $\begin{array}{lll}5.3021 & .0174 \quad .0021\end{array}$

$\begin{array}{lll}5.3998 & .0205 & .0032\end{array}$

$\begin{array}{lll}5.6739 & .0022 \quad .0099\end{array}$

$\begin{array}{lll}6.2879 & .0000 \quad .0003\end{array}$

$6.7786 \quad .0000 \quad .0000$

$\begin{array}{lll}.0000 & .1755 \quad .1483\end{array}$

$2.1741 \quad .4 / 20 \quad .1855$

$\begin{array}{lll}8.7848 & .0000 \quad .0000\end{array}$

$.0000 \quad .5976 \quad 3.3745$

$3.9959 \quad .0124 \quad .0013$

$.0000 \quad .0169 \quad .0000$

$\begin{array}{lll}.0000 & .4751 \quad .9708\end{array}$
Beta spectra written to file Example2.bet

DEXRAX exe file was: Dexrax.exe ICRP38, idx

Index file was:

ICRP38. bet

$\begin{array}{lll}163816 & 09-01-93 & 12: 00 a \\ 106556 & 09-01-93 & 12: 00 a \\ 684882 & 09-01-93 & 12: 00 a\end{array}$

Beta spectra read from file:

\begin{tabular}{|c|c|c|c|}
\hline Nuclide & $\mathrm{T}-1 / 2$ & DecMode & \# records \\
\hline - - - - - & $\ldots$ & $\ldots \ldots$ & - \\
\hline $\mathrm{Pb}-212$ & 10.64 & $B-$ & 103 \\
\hline Bi- 212 & 60.55 & $B-A$ & 120 \\
\hline T1-208 & 3.07 & B- & 117 \\
\hline $\mathrm{Ra}-228$ & 5.75 & B- & 72 \\
\hline$A C-228$ & $6.13 i$ & B- & 119 \\
\hline
\end{tabular}


Example 3: Choosing a List of Nuclides, Without Daughters, and Writing the List to an LST File

In the third example (Figs. 5a and 5b), the user requested 14 different nuclides, but without daughters this time. And instead of extracting the data during the run, he chose to write the nuclides to an LST file for later processing.

Note, on the screen after the menus, what happened when the user requested a non-existent nuclide (Nuclide \# 6, first attempt: Cs-237) or used improper format (Nuclide \# 12, first attempt: Cf252, without the required hyphen). The program responded with "Entry error or unlisted nuclide Cs-237", for example, and prompted the user for another nuclide name. Note, from other nuclides input, that the input is case-insensitive. Within DEXRAX, case is important, but nuclide names entered via the keyboard are converted by the program to the standard format. After nuclide input is finished, DEXRAX writes the names of the nuclides in standard format (see Fig. 5a).

Note also that DEXRAX could not find Np-236 in ICRP38.IDX (Nuclide \# 8, first attempt). There are two isomers of Np-236, which are designated as Np-236a and Np-236b in ICRP38.IDX, which must be requested by these names. Similarly, there are in the index files some metastable isomers, which are designated with " $\mathrm{m}^{n}$ and " $\mathrm{n}$ ", e.g., Ir-190m and Ir-190n. A list of the nuclides with our nonstaridard naming convention ( $a, b$, and $n$ nuclides) is given in Table 12 and is discussed in Appendix A.

When the user requested Np-236, the program wrote a message with the half-lives of Np-236a and $\mathrm{Np}-236 \mathrm{~b}$ and asked the user to re-input the desired isomer. Note that the user later requested Eu-150a and Eu-150b (\# 11 and \# 12). Here DEXRAX assumed that he knew what he wanted; ergo, if you are not sure, omit the "a" or " $b$ " and let DEXRAX help you.

When the user requested Sb-124m, DEXRAX wrote that there are two metastable isomers, Sb-124m and Sb-124n, gave their half-lives, and gave the user an opportunity to select either one. However, note later (\# 14) that when the user asked specifically for the " $n$ " isomer, Ir-190n, that DEXRAX assumed that he knew that he wanted the " $n$ " isotope and wrote no message. Ergo, if you are not sure which metastable isomer you want, request the " $\mathrm{m}$ " isomer and let DEXRAX help you.

After nuclide entry was finished, DEXRAX responded that it had weeded out one nuclide. The user asked for Cf-252 twice (\#12 and \# 15), and DEXRAX catches errors of this kind.

Note that when the user answered " $n$ " to the extracting the data now, the program then asked whether to write the nuclide list to a file. The user responded " $y$ " and then named the file MISC.LST in answer to a prompt. (If the user had responded " $n$ ", the program would have terminated immediately.) 
The program terminated, as in the previous examples. The two output files, DEXRAX.LOG and MISC.LST, were created in IDCALIWORK2. The contents of MISC.LST are given in Fig. 5b. Note that it is simply a list of nuclides in the standard format, one per line, ending with the key words "END LIST". The log file is given in Fig. 6b, combined with the log file for Example 4.

Figure 5a. DEXRAX Run, Example 3.

In this example, the user requested 14 different nuclides, without daughters, and chose to write the nuclide list to a file instead of extracting the data during the run. The user named this file MISC.LST. The next example, shown in Figure 6, will use the list file. Note also what happened when the user requested a nuclide that was not in the correct format, was not in the data base, or was one of the nuclides with "a,b" or " $m, n^{n}$ isomers.

\section{$C: \backslash D C A L>\underline{\text { dexrax }}$}

DEXRAX: Decay Data Extractor

Ver. 1.0 (Sep 1, 1993)

Oak Ridge National Laboratory Report ORNL/TM-12350

Authors: R.J. Westfall, J.C. Ryman, M. Cristy, K.F. Eckerman

Oak Ridge National Laboratory

Oak Ridge, TN 37831-6383

Log file Dexrax.log already exists -.

[0]verwrite, (a)ppend, or $(r)$ ename by changing extension $([0] / a / r)$ ? 0

Log file Dexrax.log will be overwritten

Press <Enter> to clear screen \& continue DEXRAX

$\leq$ Enter $>$

DEXRAX - Decay Data Extractor

Ver. 1.0 (Sep 1, 1993)

Enter nuclides via the keyboard

Use existing LST file of nuclides

Use Arrow Keys To Make Selection

Press <Enter> To Execute, <Esc> To Exit 
(Figure 5a, cont'd)

\author{
DEXRAX - Decay Data Extractor \\ Select Type of Data to be Extracted
}

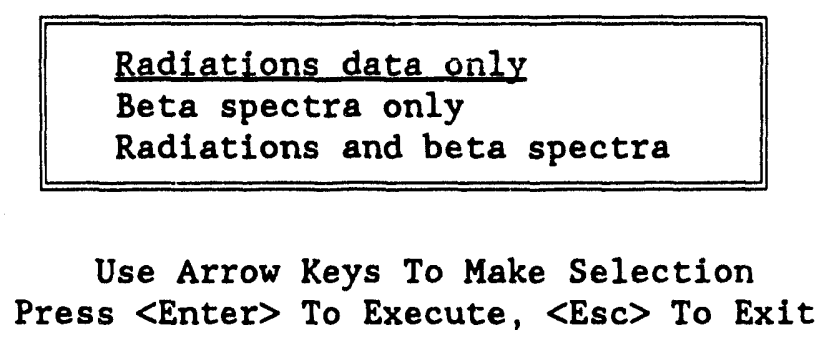

Add radioactive daughters to nucl. list $([y] / n) ? \underline{n}$

Enter nuclides ( 7 characters maximum!), e.g., Md-258, H-3, Pm-148m Blank entry terminates the read.

Nuclide \# 1: $\underline{\mathrm{Na}-24}$

Nuclide \# 2: $\mathbf{k}-40$

Nuclide \# 3: $\underline{\mathrm{Sr}-90}$

Nuclide \# 4: TC-99M

Nuclide \#5: I-131

Nuclide \# 6: $\underline{\text { Cs-237 }}$

Entry error or unlisted nuclide Cs -237

Nuclide \# 6: $\underline{\text { Cs-137 }}$

Nuclide \# 7: $\underline{\mathrm{Np}-237}$

Nuclide \# 8: $\mathrm{Np}-236$

Entry error or unlisted nuclide Np-236

Nuclide Np-236 has 2 isomers:

Np-236a with halflife 115E3y

and Np-236b with halflife $22.5 \mathrm{~h}$

Re-input entire name with appropriate " $a$ " or "b" designation

Nuclide \# 8: $\underline{\mathrm{Np}-236 \mathrm{a}}$

Nuclide \# 9: Am-241

Nuclide \#10: Eu-150a

Nuclide \#11: Eu-150b

Nuclide \#12: $\underline{\text { Cf252 }}$

Entry error or unlisted nuclide Cf252

Nuclide \#12: Cf-252

Nuclide \#13: $\underline{\mathrm{Sb}-124 \mathrm{~m}}$

Nuclide $\mathrm{Sb}-124 \mathrm{~m}$ has 2 metastable isomers:

Sb-124m with halflife $93 \mathrm{~s}$

and $\mathrm{Sb}-124 \mathrm{n}$ with halflife $20.2 \mathrm{~m}$

Input <Enter> to accept Sb-124m, or input " $n$ " for $S b-124 n: n$

Nuclide \#14: Ir-190n

Nuclide \#15: Cf-252

Nuclide \#16: SEnter> 
(Figure 5a, cont'd)

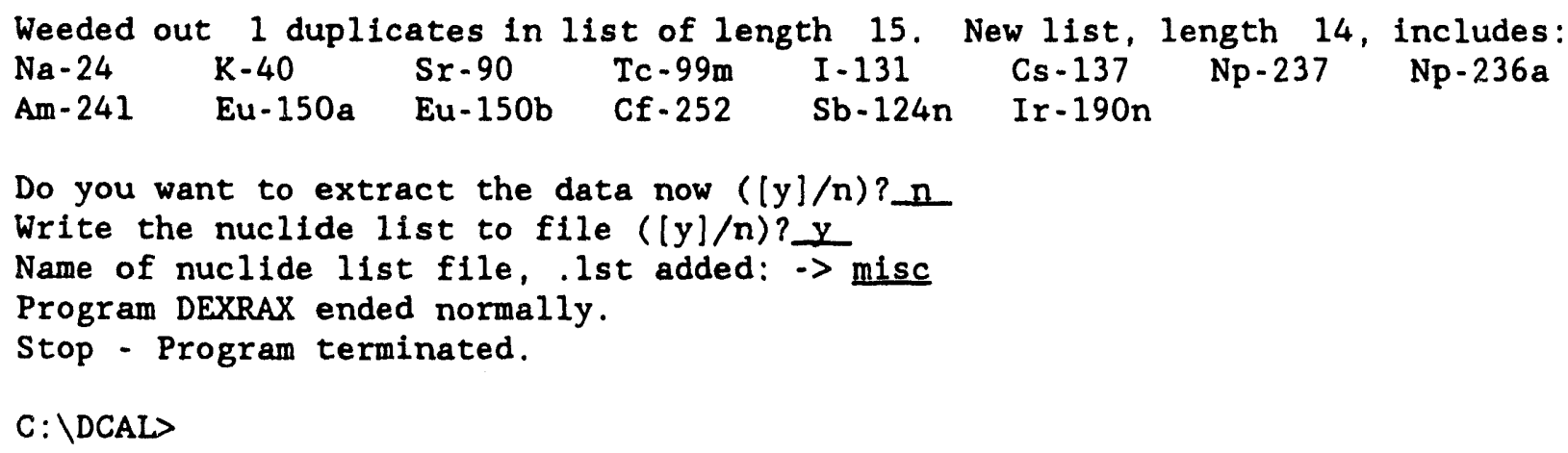

Figure 5b. Contents of File MISC.LST Created in DEXRAX Run of Example 3.
$\mathrm{Na}-24$
$\mathrm{K}-40$
$\mathrm{Sr}-90$
Tc $-99 m$
I -131
Cs -137
Np -237
$\mathrm{Np}-236 \mathrm{a}$
Am- 241
Eu-150a
Eu-150b
Cf -252
$\mathrm{Sb}-124 \mathrm{n}$
Ir-190n
END LIST 
Table 12. Isomers with Nonstandard Naming Convention ${ }^{1}$

\begin{tabular}{|c|c|c|c|c|c|c|}
\hline$\frac{\text { Nucl1de }}{E u-150 a}$ & $\begin{array}{l}\begin{array}{l}\text { Half- } \\
\text { l1fe }\end{array} \\
12.62 \mathrm{~h}\end{array}$ & $\begin{array}{l}\begin{array}{l}\text { Decay } \\
\text { Modes }\end{array} \\
\text { B-ECBt }\end{array}$ & \multicolumn{4}{|c|}{$\begin{array}{c}\text { Radioactive Daughters and } \\
\text { Branching Fractions }\end{array}$} \\
\hline $\begin{array}{l}\text { Eu-150a } \\
\text { Eu-150b } \\
\text { In-110a } \\
\text { In-110b } \\
\text { Ir-186a } \\
\text { Ir }-186 b \\
\text { Ir-190m } \\
\text { Ir-190n } \\
\text { Nb-89a } \\
\text { Nb-89b } \\
\text { Np-236a } \\
\text { Np-236b } \\
\operatorname{Re}-182 a \\
\operatorname{Re}-182 b \\
\text { Sb-120a } \\
\text { Sb-120b } \\
\text { Sb-124m } \\
\text { Sb-124n } \\
\text { Sb-128a } \\
\text { Sb-128b } \\
\text { Ta-178a } \\
\text { Ta-178b } \\
\text { Tb-156m } \\
\text { Tb-156n }\end{array}$ & $\begin{array}{r}12.62 \mathrm{~h} \\
34.2 \mathrm{y} \\
69.1 \mathrm{~m} \\
4.9 \mathrm{~h} \\
15.8 \mathrm{~h} \\
1.75 \mathrm{~h} \\
1.2 \mathrm{~h} \\
3.1 \mathrm{~h} \\
66 \mathrm{~m} \\
122 \mathrm{~m} \\
115 \mathrm{E} 3 \mathrm{y} \\
22.5 \mathrm{~h} \\
12.7 \mathrm{~h} \\
64.0 \mathrm{~h} \\
15.89 \mathrm{~m} \\
5.76 \mathrm{~d} \\
93 \mathrm{~s} \\
20.2 \mathrm{~m} \\
10.4 \mathrm{~m} \\
9.01 \mathrm{~h} \\
9.31 \mathrm{~m} \\
2.2 \mathrm{~h} \\
24.4 \mathrm{~h} \\
5.0 \mathrm{~h}\end{array}$ & $\begin{array}{l}\text { B-ECB+ } \\
\text { EC } \\
\text { ECB+ } \\
\text { ECB+ } \\
\text { ECB+ } \\
\text { ECB+ } \\
\text { IT } \\
\text { ITEC } \\
\text { ECB+ } \\
\text { ECB+ } \\
\text { ECB- } \\
\text { B-EC } \\
\text { ECB+ } \\
\text { EC } \\
\text { ECB+ } \\
\text { EC } \\
\text { ITB- } \\
\text { IT } \\
\text { B- } \\
\text { B- } \\
\text { EC } \\
\text { EC } \\
\text { IT } \\
\text { IT }\end{array}$ & $\begin{array}{l}\mathrm{Zr}-89 \\
\mathrm{Zr}-89 \\
\mathrm{Pu}-236 \\
\mathrm{Pu}-236\end{array}$ & $\begin{array}{l}1.000 E+00 \\
1.000 E+00 \\
8.900 E-02 \\
4.800 E-01\end{array}$ & $\begin{array}{l}U-236 \\
U-236\end{array}$ & $\begin{array}{l}9.110 \mathrm{E}-01 \\
5.200 \mathrm{E}-01\end{array}$ \\
\hline
\end{tabular}

${ }^{1}$ The MIRD collection conts ins only the Ir-190 isomers. The MIRD collection contains the $9.31 \mathrm{~m} \mathrm{Ta}-178 \mathrm{nt}$ :lide, which is listed as Ta-178 rather than Ta-178a because the Ta-178b isomer s not included. 


\section{Example 4: Using an LST File}

In the fourth example (Figs. 6a and 6b), the LST file created in Example 3 is used. Note, in the first screen, that the user chose to append the log file to the existing log file, which is the one just created in Example 3. The combined log file is given in Fig. $6 \mathrm{~b}$.

In the first menu the user selected "Use existing LST file of nuclides." In the second menu he chose "Radiations and beta spectra", which is different from what he chose in Example 3. He may do this, because the LST file contains no information on type of data to be extracted.

On the screen after the menus, he is prompted for the name of the LST file. After he inputs "misc", the program gives the names of the nuclides in the LST file and follows with the standard prompts and information as in previous examples. Output files are written in the standard work area, as before.

\section{Example 5: Radiations Data from a Radionuclide with Spontaneous Fission}

As mentioned previously, for spontaneous fission there is a difference between the standard files ICRP38.RAD or MIRD.RAD and the radiations data output file written by DEXRAX. Fig. 7 shows the radiations data for Cf-252: as given in ICRP38.RAD on the left and as given in an output file on the right.

On the left, note that the first radiation listed is spontaneous fission, ICODE $=9$. The numbers following ICODE indicate that $3.092 \%$ of the transformations of $\mathrm{Cf}-252$ are spontaneous fission and that there are 3.73 neutrons per fission. The rest of the radiations in the file are from alpha decay and show the radiation type (ICODE), intensity (percent), and average energy (MeV), as usual.

On the right, note that the first 5 radiations are from spontaneous fission, with ICODE values of 9 to 13 for fission fragments, neutrons, prompt gammas, delayed gammas, and beta particles, respectively. The numbers following ICODE give the intensity (fraction rather than percent, i.e., radiations per decay) and mean energy, and there is a mnemonic for ICODE at the end of the line. DEXRAX uses the methods of Dillman and Jones ${ }^{14}$, as given in Table 13, to calculate these numbers. 
(Figure 6a, cont'd)

Name of nuclide 11st flle for Input, lst added $\rightarrow$ mise

No duplicates existed in 11st of length 14. List includes:

$\begin{array}{llllllll}\mathrm{Na}-24 & \mathrm{~K}-40 & \mathrm{Sr}-90 & \mathrm{Tc}-99 m & \mathrm{I}-131 & \mathrm{Cs}-137 & \text { Np.237 } & \text { Np-236a }\end{array}$

Am-241 Eu-150a Eu-150b Cf-252 Sb-124n Ir-190n

Data will be extracted from the ICRP38 nuclear decay data files.

Do you want to extract the data now $([y] / n) ?$ y

Name of radiations data file, rad added $\rightarrow$ mise

\begin{tabular}{|c|c|c|c|c|c|c|c|}
\hline Nuclide & $T-1 / 2$ & DecMode & \# rad. & $\begin{array}{l}\text { Emltted } \\
\text { Alpha }\end{array}$ & $\begin{array}{c}\text { Energy } \\
\text { Elec }\end{array}$ & $\begin{array}{l}(\mathrm{MeV} / \mathrm{nt}) \\
\text { Photon }\end{array}$ & \\
\hline - & $\ldots$ & . . & . . . & $\ldots \ldots$ & . . . . & $\ldots \ldots$ & \\
\hline $\mathrm{Na}-24$ & 15.00 & A B- & 47 & .0000 & .5535 & 4.1212 & \\
\hline$k-40$ & $1.28 \mathrm{Eg}$ & $y$ B-EC & 25 & .0000 & .5226 & .1563 & \\
\hline Sr-90 & 29.12 & y B. & 1 & .0000 & .1957 & .0000 & \\
\hline Tc-99m & 6.02 & h IT & 57 & .0000 & .0162 & .1263 & \\
\hline$I-131$ & 8.04 & d B. & 172 & .0000 & .1917 & .3815 & \\
\hline Cs-137 & 30.0 & y $B$ - & 2 & .0000 & .1870 & .0000 & \\
\hline$N p-237$ & $2.14 \mathrm{E} 6$ & y A & 367 & 4.7687 & .0701 & .0346 & \\
\hline$N p-236 a$ & $115 \mathrm{E} 3$ & y ECB - & 99 & .0000 & .2083 & .1363 & \\
\hline Am-241 & 432.2 & y A & 976 & 5.4791 & .0520 & .0325 & \\
\hline $\mathrm{Eu}-150 \mathrm{a}$ & 12.62 & h B-ECB+ & 168 & .0000 & .3124 & .0468 & \\
\hline Eu-150b & 34.2 & y EC & 927 & .0000 & .0435 & 1.4964 & \\
\hline Cf -252 & 2.638 & y SFA & 67 & 5.9223 & .0056 & .0012 & \\
\hline $\begin{array}{l}\text { [Emitted } \\
\text { sb-124n }\end{array}$ & $\begin{array}{r}\text { energy } \\
20.2\end{array}$ & given here & $\begin{array}{l}\text { excludes } \\
29\end{array}$ & elec. & $\begin{array}{c}\text { \& photons } \\
.0247\end{array}$ & $\begin{array}{l}\text { s from spontaneous } \\
.0002\end{array}$ & \\
\hline Ir $-190 n$ & 3.1 & $h$ ITEC & 125 & .0000 & .1255 & 1.5546 & \\
\hline
\end{tabular}

Name of spectra file, .bet added $\rightarrow$ misc

\begin{tabular}{|c|c|c|c|}
\hline Nuclide & $T-1 / 2$ & DecMode & \# records \\
\hline 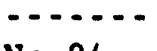 & 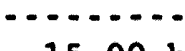 & $\cdots \cdots$ & -.... \\
\hline $\mathrm{Na}-24$ & $15.00 \mathrm{~h}$ & B- & 127 \\
\hline$K-40$ & $1.28 E 9 \mathrm{y}$ & $B-E C$ & 114 \\
\hline Sr -90 & $29.12 y$ & B- & 102 \\
\hline I-131 & 8.04 & B- & 108 \\
\hline Cs -137 & $30.0 \mathrm{y}$ & B - & 112 \\
\hline$N p-236 a$ & $115 \mathrm{E} 3 \mathrm{y}$ & ECB - & 98 \\
\hline Eu-150a & $12.62 \mathrm{~h}$ & B-ECB+ & 113 \\
\hline
\end{tabular}

Program DEXRAX ended normally.

Stop - Program terminated.

$C: \backslash D C A L>$ 
Figure 6b. Log File DEXRAX.LOG from Examples 3 and 4.

Note that the log file for Example 4 was appended to that for Example 3, because user requested it to be (see Figure 6a, first screen).

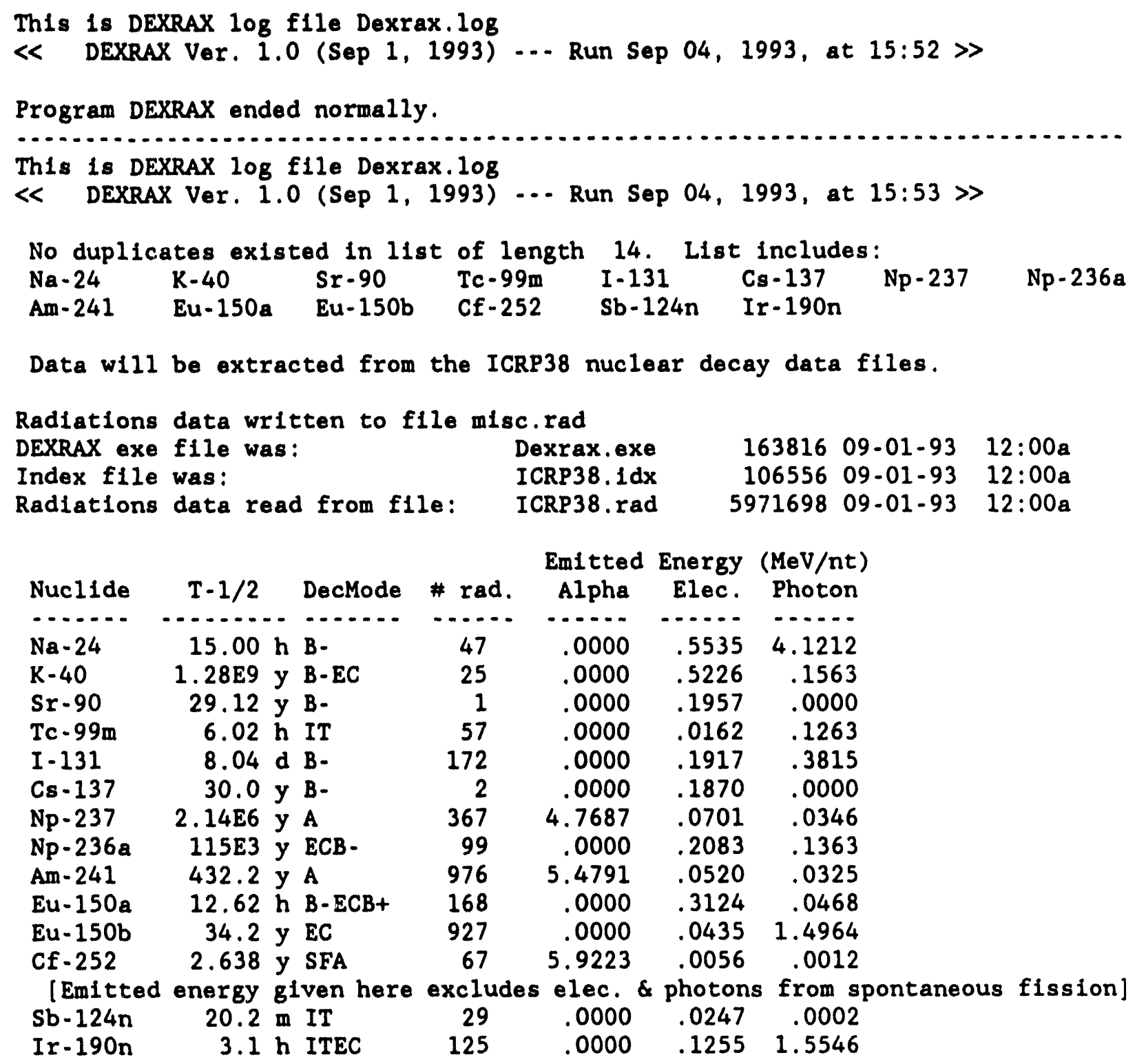


(Figure 6b, cont'd)

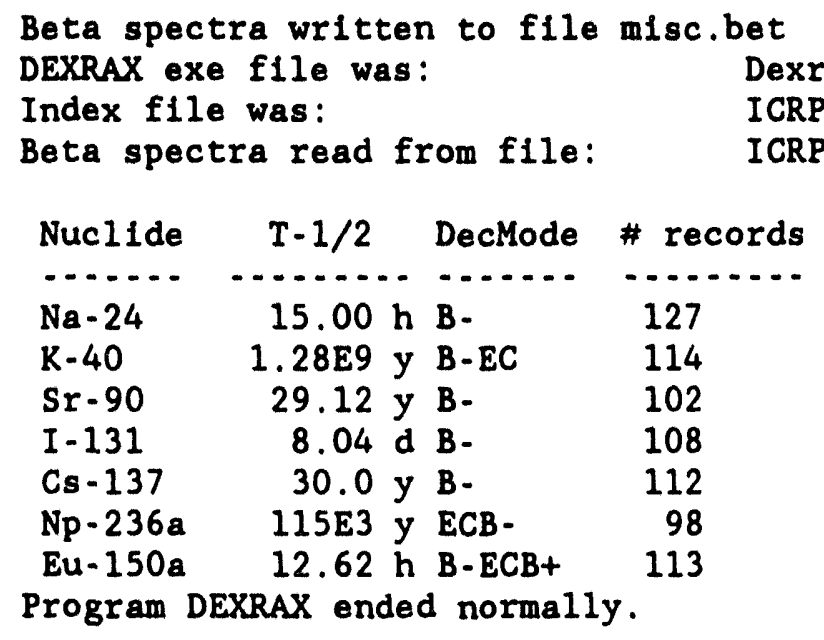

$16381609-01-93 \quad 12: 00 a$

$10655609-01-93 \quad 12: 00 a$

$684882 \quad 09-01-93 \quad 12: 00 a$

Dexrax.exe

Table 13. Expressions for Computation of Intensities and Average Energies of Radiations Accompanying Spontaneous Fission ${ }^{26}$

\begin{tabular}{lll}
\hline Radiation type & Average energy (MeV) & $\begin{array}{l}\text { Intensity in fraction } \\
\text { per decay }\end{array}$ \\
\hline Neutrons & $0.75+0.65(\bar{v}+1)^{1 / 2}$ & $\bar{v} f_{\mathrm{SF}}$ \\
Fission fragments & $0.0698{Z^{2}}^{2} \mathrm{~A}^{1 / 3}-10.988$ & $2 f_{\mathrm{SF}}$ \\
Prompt gamma rays & 0.8847 & $\mathbf{8 . 6 3 6 f _ { \mathrm { SF } }}$ \\
Delayed gamma rays & 0.9578 & $0.2102 \mathrm{~m}^{2} f_{\mathrm{SF}}$ \\
Beta particles & $0.2058 \mathrm{~m}$ & $\mathrm{mf}$ \\
\hline
\end{tabular}

Methods of Dillman and Jones ${ }^{14}$, as given by Dillman

${ }^{b}$ In this table, $\bar{v}$ - neutrons per fission, $f_{S F}$ - spontaneous fissions per decay, $Z$ - atomic number of parent, $A$ - mass number of parent, and $m-5.98$ $+92 A / 236-Z$. 
Figure 7. Example 5: Input and Output RAD Files for a Nuclide with Spontaneous Fission.

\section{Radiations Data for Cf-252, as Given in ICRP38.RAD}

Cf -252 2.638y 207 $5.80624 E-055.61645 E$ DO 1.93541E-03 5.82607E 00 $2.32250 E-015.97664 E$ OD $81.51930 E$ OI $6.07564 E 00$ $8.14810 E$ O1 $6.11835 E 00$ 1 1. $48269 \mathrm{E}-02$ Q.33990E-02 $62.19204 E-01$ 1.89390E-02 6 5.87066E $001.96200 E-02$ 6 4.86026E OO 2.44690E-02 6 3.07137E 00 3.86020E-02 $61.21195 \mathrm{E}$ OO $4.33990 \mathrm{E}-02$ 1 1.25980E-02 1.00200E-01 6 5.67693E-03 7.57399E-02 6 1.01993E-01 7.64208E-02 6 6.41127E-02 8.12699E-02 6 1.85042E-02 $9.54028 E-02$ $1.90970 \mathrm{E}-021.00200 \mathrm{E}-02$ 1.93816E-O3 $1.60000 \mathrm{E}-01$ 6 3. $13580 E-043.17800 E-02$ $61.921706031 .3550 E-01$ 6 1.97074E-03 1.36221E-01 . 6 3. $1181 \mathrm{E}-041.50000 \mathrm{E}-01$

2 2. $14785 E 001.49590 E-02$ 2 2.40130E-01 1.47030E-02 2 2.44729E $001.95520 E-02$ $25.78417 E-01$ 1.80601E-02 2 1.50561E-02 1.96630E-02

7 1.19882E-02 1.55252E-02 $79.11604 E-03 \quad 1.95302 E-02$ 7 $1.62866 \mathrm{E}-03 \quad 2.26386 \mathrm{E}-02$ $78.79871 E-01$ 1.48442E-02 7 6.20168E-01 1.88492E-02 7 1.03720E-01 $2.19576 \mathrm{E}-02$ 1.5331E OO 7. $14014 \mathrm{E}$ - $1.40002 \mathrm{C}-02$ 7 1. $49235 \mathrm{E}$ 01 $1.38850 \mathrm{E}-03$ 7 4.80867E OO $1.00747 \mathrm{E}-03$
Notes:

refers to spontaneous fission in this ile. Frequency of fissioning is $3.092 x$ and there are 3.73 neutrons per fission.

Intensities are in percent in this file, but are in absolute fractions in output file.

\section{Radiations Data for Cf-252, as Given in RAD Output File}

This is DEXRMX radiations data file Cf252.rad

《< DEXRAX Ver. 1.0 (Sep 1, 1993) -.- Run Sep 04, 1993, at 16:30 》 DEXRAX exe flle mas: Dexrax.exe 163816 09-01-93 12:00a Index flle was: $\quad$ ICRP38.1dx 106556 09-01-93 12:00a Radiations data read from file: 1 ICRP38. rad 5971698 09-01-93 12:00a
Cf-252 Cf -252 $2.638 y$ SFA 0 ff

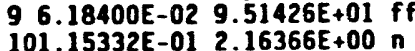

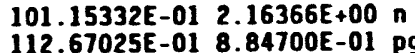

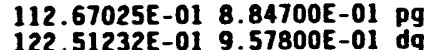
$\begin{array}{ll}122.51232 E-01 & 9.57800 E-01 ~ d g \\ 131.92239 E-01 & 1.27952 E+00 ~ s b\end{array}$

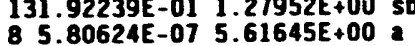
$8.80624 E-07$
$8.61645 E+00$
$81.93541 E-05$
$5.82607 E+00$ $1.93541 E-055.82607 E+00$ 1.325300 $8.14810 E-016.11835 E+00$ 1. $1.48260 \mathrm{E}-03$ 1.33990E-02 9 $5.87066 \mathrm{E}-021.96200 \mathrm{E}-02$ IC $4.86026 E-02$ 2.44690E-02 ic 3.07137E-02 3.86020E-02 ic $1.21195 \mathrm{E}-02$ 4.33990E-02 ic $1.25980 E-041.00200 E-019$ 6 5.67693E-05 7.57399E-02 ic Notes:

In output file, spontaneous fission is expanded into icODE = 9 to 13 (fission fragments, neutrons, prompt gamas, folloulng ICODE on and energies.

Hnemonics for each radiation type are given in output flle.

\section{$61.01993 E-03$ 7.64208E-02 ic}

6 6.41127E-04 8.12699E-02 IC

6 1.90970E-04 $1.00200 E-01$ ic

$11.93816 \mathrm{E}-051.60000 \mathrm{E}-01 \mathrm{~g}$

$63.43580 \mathrm{E}-06$ 3.17800E-02 IC

$61.92170 \mathrm{E}-06 \mathrm{C} 1.35540 \mathrm{E}-01$ ic

6 1.97074-05 1.36221E-01

6 .

6 3.47181E-06 $1.60000 \mathrm{E}^{01} \mathrm{l}$

$22.14785 E-02$ 1.49590E-02 $\times$

$22.40130 E-031.47030 E-02 x$

$22.44729 E-021.95520 E-02 \times$

$\begin{aligned} & 2 \\ & 2\end{aligned} .78417 \mathrm{E}-03$ 1.80601E-02 $x$

$1.19882 E-041.55252 E-02$ a 7 9.11604E-05 1.95302E-02 ae $71.62866 \mathrm{E}-05$ 2.26386E-02 ae $78.79871 E-03$ 1.48442E-02 ae $76.20168 E-03 \quad 1.88492 E-02$ ae $71.03720 \mathrm{E}-03$ 2.19576E-02 ae 7 1.59331E-02 9.99524E-03 ae 7 1.14014E-02 1.40002E-02 10 $71.90396 \mathrm{E}-03$. $71086 \mathrm{E}-02$ ae 7 4.80867E-02 1.00747E-03 ae 


\section{CONCLUSIONS}

The data files and extraction utility discussed in this document have brought a large radionuclide data base from the ORNL IBM mainframe environment to the PC environment, while at the same time creating a convenient system for management of nuclear decay data. Access time to the data for a particular radionuclide has been noticeably reduced, and additional conveniences have been included, such as extraction of data for an entire decay chain. Furthermore, the index files provide a convenient source of information on the half-lives, decay modes, and radioactive decay products for the radionuclides.

\section{REFERENCES}

1. Dillman, L. T., and Von der Lage, F. C. Radionuclide Decay Schemes and Nuclear Parameters for Use in Radiation-Dose Estimation, MIRD Pamphlet No. 10, 1975.

2. Kocher, D. C. Radioactive Decay Data Tables, DOE/TIC-11026, 1981.

3. International Commission on Radiological Protection. Radionuclide Transformations: Energy and Intensity of Emissions, ICRP Publication 38, 1983.

4. Weber, D. A., Eckerman, K. F., Dillman, L. T., and Ryman, J. C. MIRD: Radionuclide Data and Decay Schemes (Society of Nuclear Medicine, New York), 1989.

5. Lederer, C. M., Hollander, J. M., and Perlman, I. Table of Isotopes, 6th ed. (John Wiley \& Sons, New York), 1967.

6. National Council on Radiation Protection and Measurements. A Handbook of Radioactivity Measurements Procedures, 2nd ed., NCRP Report No. 58, 1985.

7. Dillman, L. T. EDISTR - A Computer Program to Obtain a Nuclear Decay Data Base for Radiation Dosimetry, ORNL/TM-6689, 1980.

8. National Nuclear Data Center, Brookhaven National Laboratory. ENSDF: The Evaluated Nuclear Structure Data File, (ENSDF Formats: Tuli, J. K, Evaluated Nuclear Structure Data File, BNL-NCS-51655), 1987.

9. International Commission on Radiological Protection. Limits for Intakes of Radionuclides by Workers, ICRP Publication 30, Parts 1-4, 1979-1988.

10. Cristy, M., and Eckerman, K. F. SEECAL: Program to Calculate Age-dependent Specific Effective Energies, ORNL/TM-12351, 1993. 
11. Eckerman, K. F., Leggett, R. W., Cristy, M., Ward, R. C., Sjoreen, A. L., Ryman, J. C., and Nelson, C. B. DCAL: Radiation Dose and Risk Calculational System, ORNL/TM-12431, in preparation.

12. Ward, R. C. FASTPLOT-An Interface to Microsoft FORTRAN Graphics, ORNL/TM-12373, in preparation.

13. J. C. Ryman, private communication.

14. Dillman, L. T., and Jones, T. D. Internal Dosimetry of Spontaneously Fissioning Nuclides, Health Phys. 29: 111-123, 1975. 


\section{APPERIDIX A \\ SUMMARY OF NUCLEAR DECAY DATA}

Tables A.1 and A.2 list the nuclides present in the ICRP38 and MIRD collections, respectively. It should be noted that, unlike the ICRP38 collection, the MIRD collection is not complete with respect to inclusion of all decay chain members.

The tables contain the following information. The physical half-life of the radionuclides is given in the second column of the table. The time units are abbreviated as: $y$ for year, $d$ for day, $h$ for hour, $\mathrm{m}$ for minutes, $\mathrm{s}$ for second, $\mathrm{ms}$ for millisecond, and $\mu \mathrm{s}$ for microsecond. The modes of nuclear transformation applicable to the radionuclide are given in the column headed "Decay Mode." The modes are abbreviated as: $\mathrm{B}-$ for beta minus decay, $\mathrm{B}+$ for beta plus decay, EC for electron capture, A for alpha decay, IT for isometric transition, and SF for spontaneous fission. The nuclear transformations of a radionuclide (the parent) may form a nucleus which is also radioactive (radioactive decay product). The entries in the columns headed by "Radioactive Decay Products and Fractional Yield" identifies radioactive nuclei formed by nuclear transformations of the parent radionuclide and gives the fraction (referred to as the branching fraction) of the parent's transformations forming the decay product. No attempt is made to identify the radioactive nuclei formed by spontaneous fission. The notation "SF" simply indicates that the accompanying branching fraction refers to spontaneous fission. The three columns on the extreme right give the total kinetic energy per nuclear transformation of emitted alpha particles, electrons, and photons ${ }^{1}$ (excluding electrons and photons from spontaneous fission). The entry for alpha particles represents only the kinetic energy of the alpha particles and does not include the recoil energy of the newly formed nucleus. The entry for electrons includes the kinetic energy of all beta particles, internal conversion

\footnotetext{
${ }^{1}$ The total kinetic energy of radiation type $R, E_{T, R}$, is computed as

$$
E_{T, R}=\sum_{i=1}^{n} y_{i, R} E_{i, R},
$$

where $y_{i, R}$ is the mean number of radiations of type $R$ emitted per nuclear transformation with unique or mean energy $E_{i, R}$. This quantity should not be confused with the mean energy of radiation type $R$, which is

$$
\bar{E}_{R}=\frac{E_{T, R}}{\sum_{i=1}^{n} y_{i, R}}
$$
}


electrons, and Auger electrons emitted in the nuclear transformations. Similarly, the photon entry presents gamma rays, and characteristic $x$ rays, and annihilation photons. If nuclear transformations of the radionuclide do not result in emission of a particular radiation then a dash, " - ", is shown in the appropriate column. If, however, radiations of a particular type are emitted, but the total energy per nuclear transformation is less that $1 \mathrm{keV}$, then the symbol "<" appears in the column.

For each radionuclide, the radioactive decay products, if formed, are identified in the tables. Consider the radionuclide ${ }^{144} \mathrm{Ce}$. The ${ }^{144} \mathrm{Ce}$ entry in Table A.1 indicates that ${ }^{144} \mathrm{Ce}$ has a $\mathrm{T}_{1 / 2}$ of 284.3 days and forms ${ }^{144} \operatorname{Pr}$ in $98.22 \%$ of its transformations and ${ }^{144 m} \operatorname{Pr}$ in $1.78 \%$ of its transformations. The entry for ${ }^{114 \mathrm{~m}} \mathrm{Pr}, \mathrm{T}_{1 / 2}=7.2 \mathrm{~m}$, indicates that it decays (in $99.90 \%$ of the transformations) by internal transition to ${ }^{14} \mathrm{Pr}$; the remaining transformations form the stable nucleus ${ }^{144} \mathrm{Nd}$. Nuclear transformations of ${ }^{144} \mathrm{Pr}$, half-life of 17.28 minutes, do not form a radioactive decay product. Thus, by repeated entry into Table A.1, one can follow the serial transformations (decay chain) associated with a radionuclide. For nuclides with multiple modes of transformation, the serial chain formed by each mode must be followed. In some instances the chains may converge. It should be noted that the branching fractions may not always add to exactly one, since only branches leading to radioactive decay products are tabulated, and because of uncertainties in the fractions. The stated values are considered to be appropriate for use in dosimetric calculations.

In some instances a radionuclide is not uniquely identified by its atomic number (or chemical symbol) and mass number. Nuclei of the same atomic and mass numbers, but with distinguishable nuclear properties, are referred to as isomers. Identification of an isomer requires reference to its physical half-life. The nuclide designations in our decay data collections (ICRP38 and MIRD) involve some nonstandard notation to reference isomers.

To differentiate isomers, when neither isomer has been designated as a metastable state, an " $\mathrm{a}$ " or " $\mathrm{b}$ " has been added to the chemical symbol-mass number notation; e.g., the ${ }^{89} \mathrm{Nb}$ entry in Table A.1 is the isomer of ${ }^{89} \mathrm{Nb}$ with a half-life of $66 \mathrm{~m}$. Which isomer was assigned " $a$ " and which "b" was done arbitrarily. To identify multiple metastable states, " $\mathrm{m}$ " and " $\mathrm{n}$ " are used; e.g., ${ }^{124 \mathrm{~m}}$ Sb in Table A.1 refers to the metastable state with a half-life of $93 \mathrm{~s}$ while ${ }^{124 \mathrm{n}} \mathrm{Sb}$ refers to the state with a half-life of 20.2 min. Additional examples of $\mathrm{a}, \mathrm{b}, \mathrm{m}$, and $\mathrm{n}$ isomers can be seen in Table 12 and Table A.1 for indium (In), europium (Eu), terbium ( $\mathrm{Tb}$ ), rhenium ( $\mathrm{Re})$, iridium (Ir), tantalum (Ta), and neptunium (Np). Note that in Table A. ${ }^{178 \times} \mathrm{Ta}$ and ${ }^{1786} \mathrm{Ta}$ appear, while in Table A.2 ${ }^{178 a} \mathrm{Ta}$ appears as ${ }^{178} \mathrm{Ta}$, because only one isomer is in the collection. With respect to this non-standard notation, the MIRD collection contains only the isomers ${ }^{190 \mathrm{~m}} \mathrm{Ir}$ and ${ }^{190 \mathrm{n}} \mathrm{Ir}$. 
Toble A-1. Sumary Information on the Fuclear Tremstormation of the Radionuclides in ICRP38 Collection.

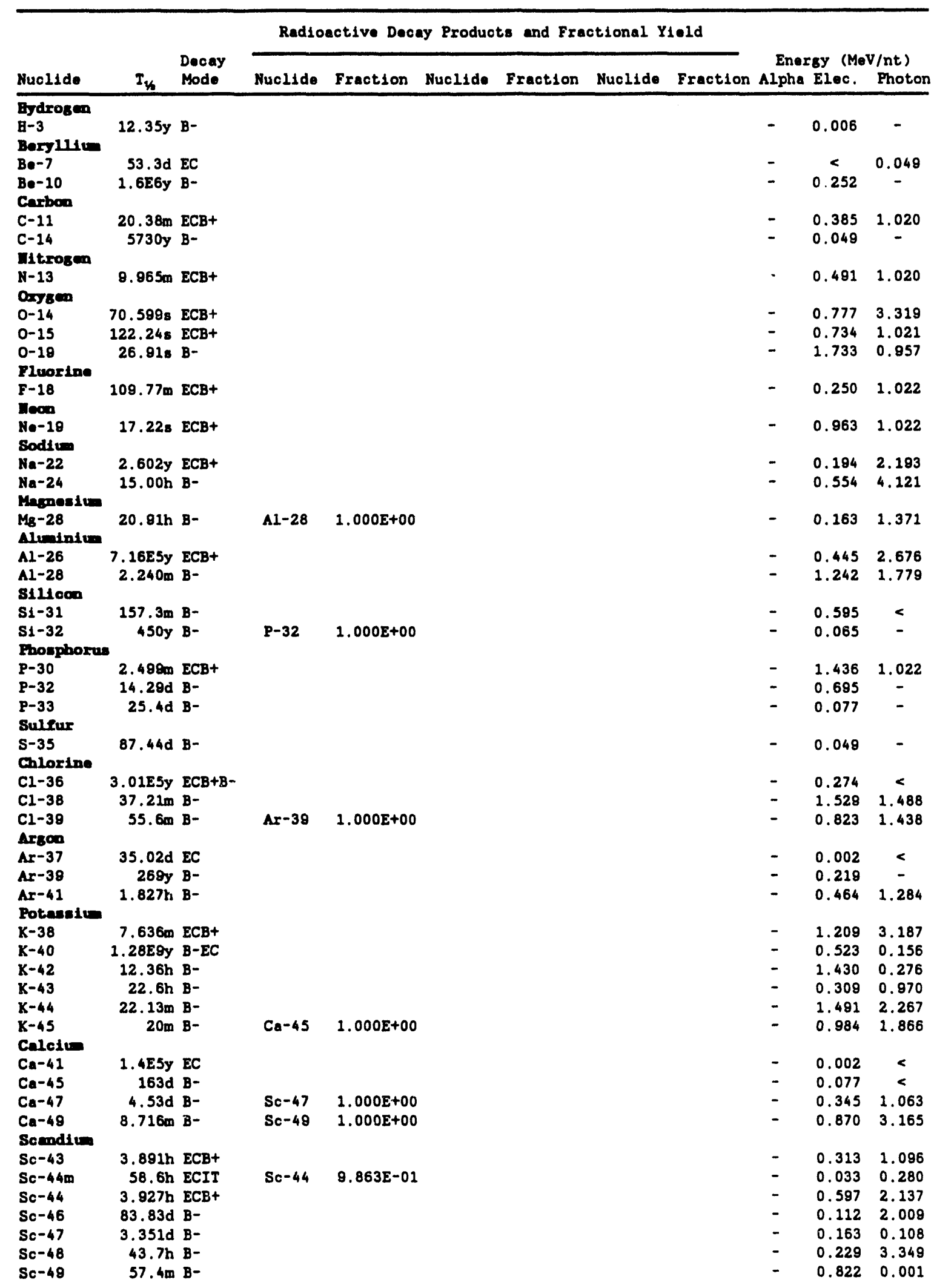


Iable A-1 (cout'd).

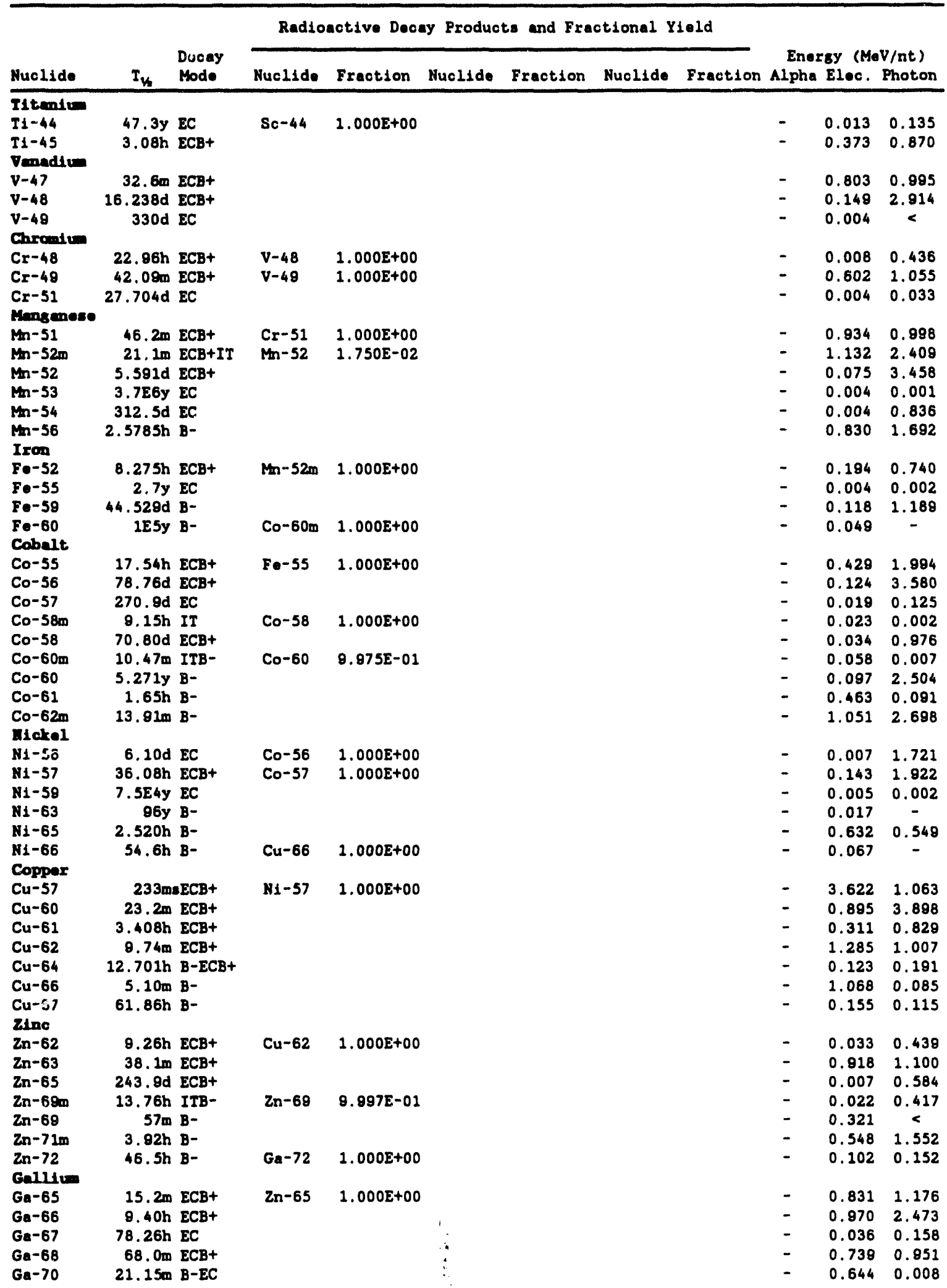


Table A-1 (cont'd).

\begin{tabular}{|c|c|c|c|c|c|c|c|c|c|c|c|}
\hline \multirow[b]{2}{*}{ Nuclide } & \multirow[b]{2}{*}{$T_{w}$} & \multirow[b]{2}{*}{$\begin{array}{l}\text { Decay } \\
\text { Mode }\end{array}$} & \multicolumn{6}{|c|}{ Radioactive Decay Products and Fractional Yield } & \multirow{2}{*}{\multicolumn{3}{|c|}{$\begin{array}{l}\text { Energy (MeV/nt) } \\
\text { Alpha Elec. Photor }\end{array}$}} \\
\hline & & & Nuc11de & Fraction & Nuclide & Fraction & Nuclide & Fraction & & & \\
\hline \multicolumn{12}{|c|}{ Galliva, cont'd } \\
\hline Ga-72 & $14.1 \mathrm{~h}$ & B- & & & & & & & - & 0.497 & 2.711 \\
\hline Ga-73 & $4.91 \mathrm{~h}$ & B- & & & & & & & - & 0.494 & 0.316 \\
\hline \multicolumn{12}{|c|}{ Gerninitum } \\
\hline$G e-66$ & $2.27 \mathrm{~h}$ & $\mathrm{ECB}+$ & $G a-66$ & $1.000 E+00$ & & & & & - & 0.102 & 0.687 \\
\hline Ge-67 & $18.7 \mathrm{~m}$ & $\mathrm{ECB}+$ & Ga-67 & $1.000 \mathrm{E}+00$ & & & & & - & 1.287 & 1.406 \\
\hline Ge-68 & $288 d$ & EC & $G a-68$ & $1.000 E+00$ & & & & & - & 0.005 & 0.004 \\
\hline$G e-69$ & $39.05 \mathrm{~h}$ & $\mathrm{ECB}+$ & & & & & & & - & 0.179 & 0.873 \\
\hline Ge-71 & $11.8 \mathrm{~d}$ & EC & & & & & & & - & 0.005 & 0.004 \\
\hline$G e-75$ & $82.78 \mathrm{~m}$ & B- & & & & & & & - & 0.420 & 0.034 \\
\hline Ge-77 & $11.30 \mathrm{~h}$ & B- & As-77 & $1.000 \mathrm{E}+00$ & & & & & - & 0648 & 1.086 \\
\hline Ge-78 & $87 m$ & B- & $A s-78$ & $1.000 E+00$ & & & & & - & 0.238 & 0.278 \\
\hline \multicolumn{12}{|l|}{ Arsenic } \\
\hline$A s-69$ & $15.2 \mathrm{~m}$ & $\mathrm{ECB}+$ & Ge-69 & $1.000 \mathrm{E}+00$ & & & & & - & 1.274 & 1.013 \\
\hline As -70 & $52.6 m$ & $\mathrm{ECB}+$ & & & & & & & - & 0.865 & 4.095 \\
\hline As-71 & $64.8 \mathrm{~h}$ & $\mathrm{ECB}+$ & $G_{e}-71$ & $1.000 E+00$ & & & & & - & 0.119 & 0.574 \\
\hline$A=-72$ & 26. Oh & $\mathrm{ECB}+$ & & & & & & & - & 1.026 & 1.794 \\
\hline$A s-73$ & $80.30 \mathrm{~d}$ & EC & & & & & & & - & 0.060 & 0.016 \\
\hline As -74 & $17.76 d$ & $B-E C B+$ & & & & & & & - & 0.268 & 0.759 \\
\hline$A 8-76$ & $26.32 \mathrm{~h}$ & B- & & & & & & & - & 1.064 & 0.430 \\
\hline$A s-77$ & $38.8 \mathrm{~h}$ & B- & & & & & & & - & 0.229 & 0.009 \\
\hline$A E-78$ & $90.7 \mathrm{~m}$ & B- & & & & & & & - & 1.356 & 1.252 \\
\hline \multicolumn{12}{|c|}{ Selenium } \\
\hline $5 e-70$ & $41.0 \mathrm{~m}$ & ECB+ & $A s-70$ & $1.000 \mathrm{E}+00$ & & & & & - & 0.488 & 0.998 \\
\hline Se-72 & $8.40 \mathrm{~d}$ & EC & $A s-72$ & $1.000 \mathrm{E}+00$ & & & & & - & 0.023 & 0.034 \\
\hline $5 e-73 m$ & $38 m$ & $E C B+I T$ & $5 e-73$ & $7.300 E-02$ & $A a-73$ & $2.700 \mathrm{E}-01$ & & & - & 0.178 & 0.244 \\
\hline$S e-73$ & $7.15 \mathrm{~h}$ & ECB+ & $A s-73$ & $1.000 E+00$ & & & & & - & 0.386 & 1.087 \\
\hline $5 e-75$ & $118.8 \mathrm{~d}$ & EC & & & & & & & - & 0.015 & 0.384 \\
\hline Se-77m & 17.458 & IT & & & & & & & - & 0.072 & 0.088 \\
\hline Se-7g & $65000 y$ & B- & & & & & & & - & 0.056 & - \\
\hline Se-81m & $57.25 \mathrm{~m}$ & ITB- & $S e-81$ & $1.000 \mathrm{E}+00$ & & & & & - & 0.085 & 0.018 \\
\hline Se-81 & 18.50 & B- & & & & & & & - & 0.611 & 0.008 \\
\hline \multicolumn{12}{|l|}{ Brontine } \\
\hline $\mathrm{Br}-74 \mathrm{~m}$ & $41.5 \mathrm{~m}$ & $\mathrm{ECB}+$ & & & & & & & - & 1.412 & 4.082 \\
\hline$B r-74$ & $25.3 \mathrm{~m}$ & ECB+ & & & & & & & - & 1.115 & 4.549 \\
\hline Br-75 & $98 m$ & ECB+ & $S e-75$ & $1.000 \mathrm{E}+00$ & & & & & - & 0.524 & 1.216 \\
\hline Br-76 & $16.2 \mathrm{~h}$ & $\mathrm{ECB}+$ & & & & & & & - & 0.691 & 2.633 \\
\hline $\mathrm{Br}-77$ & $56 \mathrm{~h}$ & ECB+ & & & & & & & - & 0.009 & 0.321 \\
\hline$B r-80 m$ & $4.42 \mathrm{~h}$ & IT & $\mathrm{Br}-80$ & $1.000 E+00$ & & & & & - & 0.060 & 0.024 \\
\hline $\mathrm{Br}-80$ & $17.4 \mathrm{~m}$ & $B-E C B+$ & & & & & & & - & 0.724 & 0.080 \\
\hline$B r-82$ & $35.30 \mathrm{~h}$ & B- & & & & & & & - & 0.139 & 2.642 \\
\hline$B r-83$ & $2.38 \mathrm{~h}$ & B- & $K r-83 m$ & $9.998 E-01$ & & & & & - & 0.321 & 0.008 \\
\hline$B r-84$ & $31.80 \mathrm{~m}$ & B- & & & & & & & - & 1.229 & 1.788 \\
\hline \multicolumn{12}{|l|}{ Cypton } \\
\hline$k r-74$ & $11.50 \mathrm{~m}$ & ECB+ & $B r-74$ & $1.000 \mathrm{E}+00$ & & & & & - & 0.792 & 1.169 \\
\hline$K r-76$ & $14.8 \mathrm{~h}$ & EC & $B r-76$ & $1.000 \mathrm{E}+00$ & & & & & - & 0.015 & 0.435 \\
\hline$K r-77$ & $74.7 \mathrm{~m}$ & ECB+ & $\mathrm{Br}-77$ & $1.000 \mathrm{E}+00$ & & & & & - & 0.642 & 1.016 \\
\hline $\mathrm{Kr}-78$ & $35.04 \mathrm{~h}$ & $\mathrm{ECB}+$ & & & & & & & - & 0.024 & 0.257 \\
\hline$K r-81 m$ & $13 \mathrm{~s}$ & II & $K r-81$ & $1.000 \mathrm{E}+00$ & & & & & - & 0.059 & 0.131 \\
\hline$K r-81$ & 2.1E5y & EC & & & & & & & - & 0.005 & 0.012 \\
\hline$K r-83 m$ & $1.83 \mathrm{~h}$ & IT & & & & & & & - & 0.039 & 0.003 \\
\hline$K r-85 m$ & $4.48 \mathrm{~h}$ & ITB- & $K r-85$ & $2.110 E-01$ & & & & & - & 0.255 & 0.158 \\
\hline$K r-85$ & $10.72 y$ & B- & & & & & & & - & 0.251 & 0.002 \\
\hline$K r-87$ & $76.3 \mathrm{~m}$ & B- & $R b-87$ & $1.000 \mathrm{E}+00$ & & & & & - & 1.324 & 0.793 \\
\hline$K r-88$ & $2.84 \mathrm{~h}$ & B- & $\mathbf{R b}-\mathbf{8 8}$ & $1.000 E+00$ & & & & & - & 0.364 & 1.955 \\
\hline \multicolumn{12}{|c|}{ Rubidium } \\
\hline $\mathbf{R b}-77$ & $3.70 \mathrm{~m}$ & $\mathrm{ECB}+$ & $\mathrm{Kr}-77$ & $1.000 E+00$ & & & & & - & 1.646 & 1.831 \\
\hline $\mathbf{R b}-79$ & 22.80 & ECB+ & $\mathrm{Kr}-79$ & $1.000 \mathrm{E}+00$ & & & & & - & 0.820 & 1.358 \\
\hline $\mathbf{R b}-80$ & 348 & ECB+ & & & & & & & - & 2.011 & 1.246 \\
\hline$R b-81 m$ & $32 \mathrm{~m}$ & IT & $R \mathbf{b}-81$ & $1.000 \mathrm{E}+00$ & & & & & - & 0.074 & 0.010 \\
\hline$R b-81$ & $4.58 \mathrm{~h}$ & ECB+ & $K x-81$ & $1.000 \mathrm{E}+00$ & & & & & - & 0.187 & 0.623 \\
\hline
\end{tabular}


Iable $\Delta-1$ (oont'd).

\begin{tabular}{|c|c|c|c|c|c|c|c|c|c|c|c|}
\hline \multirow[b]{2}{*}{ Nuol1de } & \multirow[b]{2}{*}{$T_{k}$} & \multirow[b]{2}{*}{$\begin{array}{l}\text { Decay } \\
\text { Mode }\end{array}$} & \multicolumn{6}{|c|}{ Radioactive Docay Products and Fractional Yield } & \multirow{2}{*}{\multicolumn{3}{|c|}{$\begin{array}{l}\text { Energy (MeV/nt) } \\
\text { Alpha Elec. Ehoton }\end{array}$}} \\
\hline & & & Nuclide & Fraotion & Nucl1de & Fraotion & Nuclide & Fraotion & & & \\
\hline \multicolumn{12}{|c|}{ Rubldiue, cont'd } \\
\hline $\mathrm{Rb}-82 \mathrm{~m}$ & $6.2 \mathrm{~h}$ & $\mathrm{BCB}+$ & & & & & & & - & 0.095 & 2.910 \\
\hline $\mathbf{R b}-\mathbf{8 2}$ & $1.3 \mathrm{~m}$ & $\mathrm{ECB}+$ & & & & & & & - & 1.407 & 1.093 \\
\hline $\mathbf{R b}-\mathbf{8 3}$ & $86.2 d$ & EC & $K r=83 m$ & $7.620 \mathrm{E}-01$ & & & & & - & 0.015 & 0.504 \\
\hline $\begin{array}{l}R b-84 \\
R b-86\end{array}$ & $\begin{array}{l}32.77 d \\
18.66 d\end{array}$ & $\begin{array}{l}\mathrm{ECB}+\mathrm{B}- \\
\mathrm{B}-\end{array}$ & & & & & & & - & $\begin{array}{l}0.155 \\
0.668\end{array}$ & 0.918 \\
\hline $\mathrm{Rb}-87$ & 4. 7E1OY & B- & & & & & & & - & 0.111 & - \\
\hline $\mathbf{R b}-\mathbf{8 8}$ & 17.80 & B- & & & & & & & - & 2.066 & 0.629 \\
\hline \multicolumn{12}{|c|}{ strontio } \\
\hline $5 r-80$ & $100 \mathrm{~m}$ & EC & $\mathbf{R b}-\mathbf{8 0}$ & $1.000 \mathrm{E}+00$ & & & & & - & 0.005 & 0.008 \\
\hline $5 r-81$ & $25.5 \mathrm{~m}$ & ECB+ & $\mathbf{R b}-81$ & $1.000 \mathrm{E}+00$ & & & & & - & 1.000 & 1.386 \\
\hline $5 z-82$ & $25.0 d$ & EC & $\mathbf{R b}-\mathbf{8 2}$ & $1.000 E+00$ & & & & & - & 0.005 & 0.008 \\
\hline $8 x-83$ & $32.4 \mathrm{~h}$ & $\mathrm{ECB}+$ & $R b-83$ & $1.000 \mathrm{E}+00$ & & & & & - & 0.148 & 0.801 \\
\hline $\begin{array}{l}S r-85 m \\
S r-85\end{array}$ & $\begin{array}{r}89.5 \mathrm{~m} \\
64.84 \mathrm{~d}\end{array}$ & $\begin{array}{l}\text { ITEC } \\
\text { EC }\end{array}$ & $5 r-85$ & $8.780 E-01$ & & & & & - & $\begin{array}{l}0.012 \\
0.008\end{array}$ & $\begin{array}{l}0.220 \\
0.512\end{array}$ \\
\hline $\begin{array}{l}S r-87 m \\
S r-89\end{array}$ & $\begin{array}{r}2.805 h \\
50.5 d\end{array}$ & $\begin{array}{l}\text { ECIT } \\
\text { B- }\end{array}$ & $\mathbf{R} \mathbf{b}-87$ & $3.000 E-03$ & & & & & - & $\begin{array}{l}0.067 \\
0.583\end{array}$ & $\begin{array}{c}0.320 \\
<\end{array}$ \\
\hline $5 r-80$ & $28.12 y$ & B- & $Y-90$ & $1.000 E+00$ & & & & & - & 0.196 & - \\
\hline $8 r-91$ & $9.5 \mathrm{~h}$ & B- & $y-81 m$ & 5. 780E-01 & $y-91$ & $4.220 E-01$ & & & - & 0.856 & 0.687 \\
\hline \multicolumn{12}{|l|}{ Ittriu } \\
\hline $\begin{array}{l}Y-86 m \\
Y-86\end{array}$ & $14.74 \mathrm{~h}$ & $\begin{array}{l}\mathrm{ECB}+\mathrm{IT} \\
\mathrm{ECB}+\end{array}$ & $Y-86$ & 9. $931 E-01$ & & & & & - & $\begin{array}{l}0.025 \\
0.226\end{array}$ & $\begin{array}{l}0.221 \\
3.589\end{array}$ \\
\hline$Y-87$ & $80.3 \mathrm{~h}$ & $\mathrm{ECB}+$ & $S r-87 m$ & 9.8905-01 & & & & & - & 0.007 & 0.457 \\
\hline$Y-88$ & $106.64 d$ & $\mathrm{ECB}+$ & & & & & & & - & 0.007 & 2.692 \\
\hline$Y-80 m$ & $3.18 \mathrm{~h}$ & IT & $y-80$ & $9.920 E-01$ & & & & & - & 0.047 & 0.629 \\
\hline $\mathbf{Y}-90$ & $64.0 \mathrm{~h}$ & B- & & & & & & & - & 0.835 & $<$ \\
\hline$y-81 m$ & $49.71 \mathrm{~m}$ & IT & $Y-81$ & $1.000 \mathrm{E}+00$ & & & & & - & 0.027 & 0.530 \\
\hline$Y-91$ & $58.51 d$ & B- & & & & & & & - & 0.602 & 0.004 \\
\hline$y-82$ & $3.54 \mathrm{~h}$ & B- & & & & & & & - & 1.446 & 0.252 \\
\hline$Y-93$ & $10.1 \mathrm{~h}$ & B- & $2 r-93$ & $1.000 E+00$ & & & & & - & 1.174 & 0.088 \\
\hline$y-94$ & 18. Im & B- & & & & & & & - & 1.675 & 1.110 \\
\hline & $10.7 \mathrm{~m}$ & \multicolumn{9}{|c|}{ zircontu } & 0.894 \\
\hline $2 r-86$ & $16.5 h$ & EC & $Y-86$ & $1.000 E+00$ & & & & & - & 0.030 & 0.288 \\
\hline $2 r-88$ & $83.4 d$ & EC & $Y-88$ & $1.000 E+00$ & & & & & - & 0.016 & 0.403 \\
\hline $2 r-89$ & $78.43 \mathrm{~h}$ & ECB+ & & & & & & & - & 0.101 & 1.165 \\
\hline $2 r-93$ & 1. $53 \mathrm{E} 6 \mathrm{y}$ & B- & $\mathrm{Nb}-93 \mathrm{~m}$ & $1.000 \mathrm{E}+00$ & & & & & - & 0.020 & - \\
\hline $2 x-95$ & $63.88 d$ & B- & $\mathrm{Mb}-95$ & $9.930 \mathrm{E}-01$ & $x b-85$ & $6.980 \mathrm{E}-03$ & & & - & 0.116 & 0.738 \\
\hline \multicolumn{12}{|l|}{ Hablum } \\
\hline $\mathrm{Mb}-88$ & $14.3 \mathrm{~m}$ & ECB+ & $2 r-88$ & $1.000 \mathrm{E}+00$ & & & & & - & 1.237 & 4. 126 \\
\hline $\mathrm{Nb}-89 \mathrm{~b}$ & $122 m$ & $\mathrm{ECB}+$ & $2 r-88$ & $1.000 \mathrm{E}+00$ & & & & & - & 1.115 & 1.381 \\
\hline$M b-89 a$ & $66 m$ & $\mathrm{ECB}+$ & $2 r-89$ & $1.000 \mathrm{E}+00$ & & & & & - & 0.834 & 1.825 \\
\hline $\mathrm{Nb}-90$ & $14.60 \mathrm{~h}$ & $\mathrm{ECB}+$ & & & & & & & - & 0.403 & 4.224 \\
\hline$N b-93 m$ & $13.6 y$ & IT & & & & & & & - & 0.028 & 0.002 \\
\hline $\mathrm{Nb}-94$ & $2.03 E 4 y$ & B- & & & & & & & - & 0.168 & 1.574 \\
\hline $\mathrm{Nb}-85 \mathrm{~m}$ & $86.6 \mathrm{~h}$ & IT & $\mathrm{Nb}-95$ & $1.000 E+00$ & & & & & - & 0.166 & 0.068 \\
\hline $\mathrm{Nb}-85$ & $35.15 d$ & B- & & & & & & & - & 0.044 & 0.766 \\
\hline $\mathrm{Mb}-96$ & $23.35 \mathrm{~h}$ & B- & & & & & & & - & 0.253 & 2.472 \\
\hline $\mathrm{Mb}-97 \mathrm{~m}$ & $60 \mathrm{~s}$ & IT & $\mathrm{Mb}-87$ & $1.000 E+00$ & & & & & - & 0.015 & 0.728 \\
\hline $\mathrm{Bb}-97$ & $72.1 \mathrm{~m}$ & B- & & & & & & & - & 0.468 & 0.655 \\
\hline \multicolumn{12}{|c|}{ Molybdenum } \\
\hline Mo-90 & $5.6 \mathrm{hh}$ & $\mathrm{ECB}+$ & $\mathrm{Nb}-90$ & $1.000 E+00$ & & & & & - & 0.204 & 0.827 \\
\hline$M O-93 m$ & $6.85 \mathrm{~h}$ & IT & Mo-93 & $1.000 \mathrm{E}+00$ & & & & & - & 0.097 & 2.250 \\
\hline Mo-83 & $3.5 E 3 y$ & EC & $\mathrm{Nb}-93 \mathrm{~m}$ & $1.000 \mathrm{E}+00$ & & & & & - & 0.006 & 0.011 \\
\hline $\begin{array}{l}M o-89 \\
M O-101\end{array}$ & $\begin{array}{r}66.0 \mathrm{~h} \\
14.62 \mathrm{~m}\end{array}$ & B- & $\begin{array}{l}\text { Tc-98m } \\
\text { Tc-101 }\end{array}$ & $\begin{array}{l}8.760 E-01 \\
1.000 E+00\end{array}$ & Tc-98 & $1.240 E-01$ & & & $\overline{-}$ & $\begin{array}{l}0.382 \\
0.589\end{array}$ & $\begin{array}{l}0.150 \\
1.368\end{array}$ \\
\hline \multicolumn{12}{|c|}{ Technetive } \\
\hline Ic-93m & 43.50 & ITEC & $\mathrm{Tc}-83$ & $0.180 E-01$ & $M-93$ & $1.820 \mathrm{E}-01$ & & & - & 0.079 & 0.724 \\
\hline
\end{tabular}


Iable $A-1$ (cont'd).

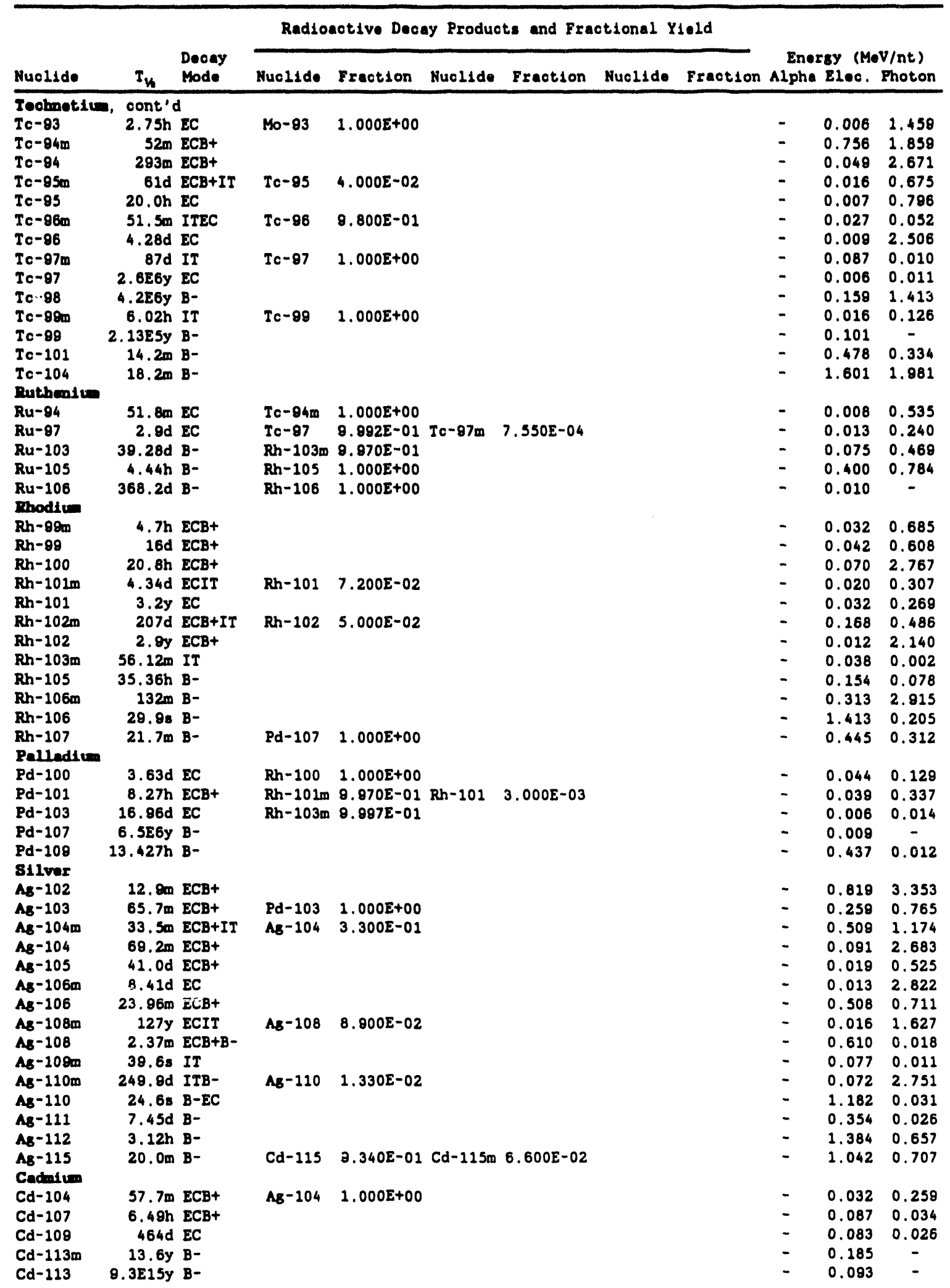


Iable $\Delta-1$ (oont'd).

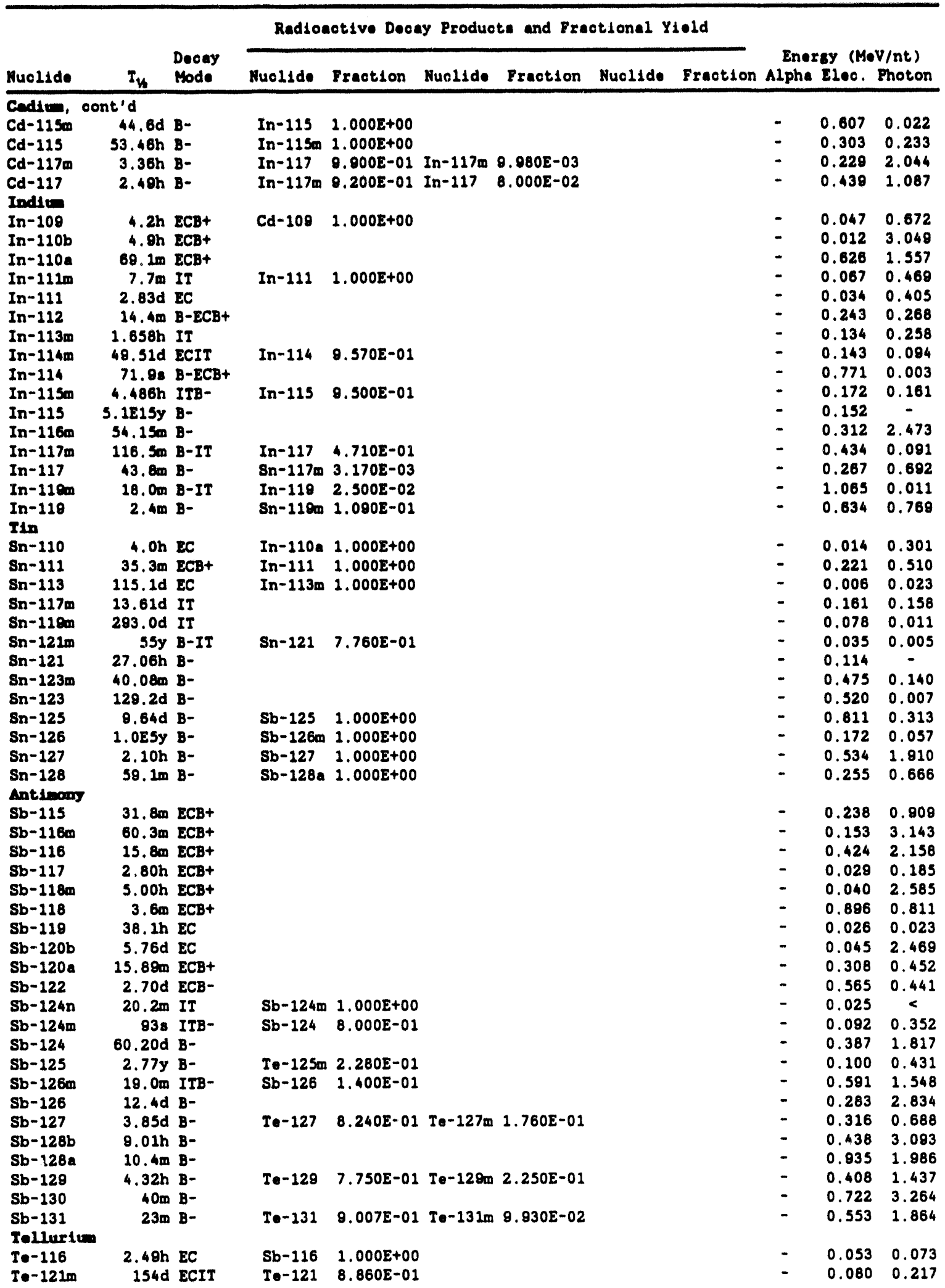


Table $A^{-1}$ (cost'd).

\begin{tabular}{|c|c|c|c|c|c|c|c|c|c|c|c|}
\hline \multirow[b]{2}{*}{ Nuol1de } & \multirow[b]{2}{*}{$I_{n}$} & \multirow[b]{2}{*}{$\begin{array}{l}\text { Decay } \\
\text { Mode }\end{array}$} & \multicolumn{6}{|c|}{ Radioactive Dooay Products and Fractional Yield } & \multirow{2}{*}{\multicolumn{3}{|c|}{$\begin{array}{l}\text { Enorey (Mov/nt) } \\
\text { Alpha Eloo. Photon }\end{array}$}} \\
\hline & & & Nuelsde & Fraction & Nuolide & Fraction & Nuclide & Fraction & & & \\
\hline \multicolumn{12}{|c|}{ Tollurtu, cont'd } \\
\hline To-121 & & EC & & & & & & & - & 0.010 & 0.377 \\
\hline$T 0-123 m$ & $119.7 d$ & IT & Te-123 & $1.0008+00$ & & & & & - & 0.098 & 0.148 \\
\hline $\begin{array}{l}T e-123 \\
T e-125 m\end{array}$ & $\begin{array}{r}1213 y \\
\text { 58d }\end{array}$ & IT & & & & & & & $\overline{-}$ & $\begin{array}{l}0.008 \\
0.100\end{array}$ & $\begin{array}{l}0.020 \\
0.036\end{array}$ \\
\hline To-127m & $109 \mathrm{~d}$ & ITB- & $9 \bullet-127$ & $0.760 \mathrm{E}-01$ & & & & & - & 0.082 & 0.011 \\
\hline $\mathrm{T}=-127$ & $0.35 \mathrm{~h}$ & B- & & & & & & & & 0.223 & 0.005 \\
\hline$T \bullet-128 m$ & $33.6 d$ & IIB- & $T_{0-128}$ & $6.500 E-01$ & $I-128$ & $3.300 E-01$ & & & - & 0.280 & 0.038 \\
\hline$T--12 \theta$ & $69.6 \mathrm{~m}$ & B- & $I-129$ & $1.000 \mathrm{z}+00$ & & & & & - & 0.544 & 0.059 \\
\hline To-131m & $30 \mathrm{~h}$ & ITD- & $I-131$ & $7.780 E-01$ & $T \cdot-131$ & $2.220 E-01$ & & & - & 0.202 & 1.425 \\
\hline$T 0-131$ & $23.0 \mathrm{~m}$ & B- & $I-131$ & $1.000 \mathrm{E}+00$ & & & & & - & 0.719 & 0.420 \\
\hline$T=-132$ & $78.2 \mathrm{~h}$ & B- & $I-132$ & $1.000 \mathrm{E}+00$ & & & & & - & 0.102 & 0.234 \\
\hline $\begin{array}{l}T n-133 m \\
T n-133\end{array}$ & $\begin{array}{r}35.4 m \\
12.45 m\end{array}$ & ITB- & $\begin{array}{l}I-133 \\
I-133\end{array}$ & $\begin{array}{l}8.700 \Sigma-01 \\
1.000 \Sigma+00\end{array}$ & $T \cdot-233$ & $1.300 E-01$ & & & - & $\begin{array}{l}0.709 \\
0.818\end{array}$ & $\begin{array}{l}2.313 \\
0.029\end{array}$ \\
\hline $\begin{array}{l}\text { Te-134 } \\
\text { Iodine }\end{array}$ & $41.8 \mathrm{~m}$ & $B-$ & $1-134$ & $1.000 \mathrm{E}+00$ & & & & & - & 0.300 & 0.886 \\
\hline$I-120 \mathrm{~m}$ & 53m & $\mathrm{ECB}+$ & & & & & & & - & 1.244 & 5.297 \\
\hline$I-120$ & $81.0 \mathrm{~m}$ & $\mathrm{ECB}+$ & & & & & & & - & 1.423 & 2.729 \\
\hline$I-121$ & $2.12 \mathrm{~h}$ & ECB+ & $T e-121$ & $1.000 \mathrm{E}+00$ & & & & & - & 0.083 & 0.418 \\
\hline I-122 & $3,62 \mathrm{~m}$ & $\mathrm{ECB}+$ & & & & & & & - & 1.055 & 0.846 \\
\hline$I-123$ & $13.2 \mathrm{~h}$ & EC & $T=-123$ & $9.9992-01$ & $T--123 m$ & $5.000 E-05$ & & & - & 0.028 & 0.172 \\
\hline$I-124$ & $4.18 \mathrm{~d}$ & ECB+ & & & & & & & - & 0.184 & 1.098 \\
\hline$I-123$ & $60.14 d$ & Ec & & & & & & & - & 0.018 & 0.042 \\
\hline$I-126$ & $13.02 d$ & $8 C B+B-$ & & & & & & & - & 0.157 & 0.455 \\
\hline$I-128$ & $24.09 m$ & $\mathrm{ECB}+\mathrm{B}-$ & & & & & & & - & 0.748 & 0.085 \\
\hline$I-128$ & 1.57E7y & B- & & & & & & & - & 0.064 & 0.025 \\
\hline$I-130$ & $12.36 \mathrm{~h}$ & B- & & & & & & & - & 0.297 & 2.139 \\
\hline$I-131$ & $8.04 d$ & B- & $x_{0}-131 m$ & $1.110 \mathrm{E}-02$ & & & & & - & 0.192 & 0.382 \\
\hline$I-132 m$ & $83.6 \mathrm{~m}$ & ITB- & $I-132$ & $8.600 \mathrm{E}-01$ & & & & & - & 0.159 & 0.322 \\
\hline$I-132$ & $2.30 \mathrm{~h}$ & 8- & & & & & & & - & 0.485 & 2.280 \\
\hline$I-133$ & $20.8 \mathrm{~h}$ & $B-$ & $x \cdot-133$ & $0.710 E-01$ & $x_{0}-133 m$ & $2.900 E-02$ & & & - & 0.411 & 0.607 \\
\hline$I-134$ & $52.6 \mathrm{~m}$ & $8-$ & & & & & & & - & 0.622 & 2.625 \\
\hline $\begin{array}{l}I-135 \\
X \cos \end{array}$ & $6.61 \mathrm{~h}$ & B- & $x \cdot-135$ & $0.460 E-01$ & $x e-135 m$ & $1.540 \mathrm{E}-01$ & & & - & 0.367 & 1.576 \\
\hline $\begin{array}{l}x \cos \\
x=-120\end{array}$ & \multicolumn{3}{|c|}{ 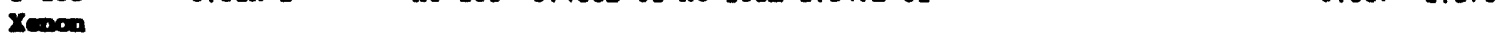 } & & & & & & - & 0.055 & 0.432 \\
\hline$x_{0}-121$ & $40.1 \mathrm{~m}$ & $\mathrm{ECB}+$ & $I-121$ & $2.000 \mathrm{E}+00$ & & & & & - & 0.569 & 1.815 \\
\hline$x_{0}-122$ & $20.1 \mathrm{~h}$ & EC & $I-122$ & $1.000 \mathrm{E}+00$ & & & & & - & 0.010 & 0.068 \\
\hline$x_{0}-123$ & $2.08 \mathrm{~h}$ & $\mathrm{ECB}+$ & $I-123$ & $1.000 \mathrm{E}+00$ & & & & & - & 0.184 & 0.634 \\
\hline$x_{0}-125$ & $17.0 \mathrm{~h}$ & ECB+ & $I-125$ & $1.000 \mathrm{E}+00$ & & & & & - & 0.034 & 0.271 \\
\hline$x_{0}-127$ & $36.41 d$ & EC & & & & & & & - & 0.033 & 0.280 \\
\hline Xe-128m & 8.0d & IT & & & & & & & - & 0.185 & 0.051 \\
\hline$x=-131 m$ & $11.8 d$ & I IT & & & & & & & - & 0.144 & 0.020 \\
\hline$x=-133 m$ & $2.188 \mathrm{~d}$ & IT & $X_{0}-133$ & $1.000 E+00$ & & & & & - & 0.192 & 0.041 \\
\hline$x=-133$ & $5.245 d$ & $18-$ & & & & & & & - & 0.136 & 0.048 \\
\hline$x \cdot-135 m$ & $15.20 \mathrm{~m}$ & ITB- & $x 0-135$ & $1.000 \mathrm{E}+00$ & $C_{8-135}$ & $4.000 E-05$ & & & - & 0.098 & 0.429 \\
\hline$x e-135$ & $8.09 \mathrm{~h}$ & B- & $C_{8}-135$ & $1.000 E+00$ & & & & & - & 0.317 & 0.249 \\
\hline $\begin{array}{l}X_{0-138} \\
\cos 10\end{array}$ & $14.17 \mathrm{~m}$ & B- & $C 8-138$ & $1.000 \mathrm{E}+00$ & & & & & - & 0.673 & 1.125 \\
\hline C8 -125 & $45 \mathrm{~m}$ & ECB+ & $x_{0}-125$ & $1.000 \mathrm{E}+00$ & & & & & - & 0.347 & 0.678 \\
\hline$C=-126$ & $1.64 \mathrm{~m}$ & ECB+ & & & & & & & - & 1.464 & 1.086 \\
\hline$C=-127$ & $6.25 \mathrm{~h}$ & ECB+ & $x 0-127$ & $1.000 \mathrm{E}+00$ & & & & & - & 0.028 & 0.420 \\
\hline$C=-128$ & $3.8 \mathrm{~m}$ & ECB+ & & & & & & & - & 0.846 & 0.900 \\
\hline$C=-129$ & $32.06 \mathrm{~h}$ & $\mathrm{ECB}+$ & & & & & & & - & 0.018 & 0.282 \\
\hline$C=-130$ & 28.800 & ECB+ & & & & & & & - & 0.401 & 0.517 \\
\hline Cs-131 & $9.68 d$ & EC & & & & & & & - & 0.007 & 0.023 \\
\hline$C s-132$ & $6.475 d$ & ECB+B- & & & & & & & - & 0.014 & 0.705 \\
\hline $\mathrm{Cs}-134 \mathrm{~m}$ & $2.80 \mathrm{~h}$ & IT & $\mathrm{Cs}-134$ & $1.000 E+00$ & & & & & - & 0.112 & 0.027 \\
\hline Cs -134 & $2,062 y$ & ECB- & & & & & & & - & 0.164 & 1.555 \\
\hline Cs-135m & $53 m$ & IT & $C 8 \cdots 135$ & $1.000 \mathrm{E}+00$ & & & & & - & 0.036 & 1.586 \\
\hline Cs-135 & 2.3E6y & B- & & & & & & & - & 0.067 & - \\
\hline$C:-136$ & $13.1 d$ & $B-$ & & & & & & & - & 0.139 & 2.166 \\
\hline $\mathrm{Cs}-137$ & $30.0 y$ & B- & $\mathrm{Ba}-137 \mathrm{~m}$ & $9.460 E-01$ & & & & & - & 0.187 & - \\
\hline$C s-138$ & $32.2 \mathrm{~m}$ & $\mathrm{~B}-$ & & & & & & & - & 1.207 & 2.361 \\
\hline
\end{tabular}


Iable $A-1$ (oont'd).

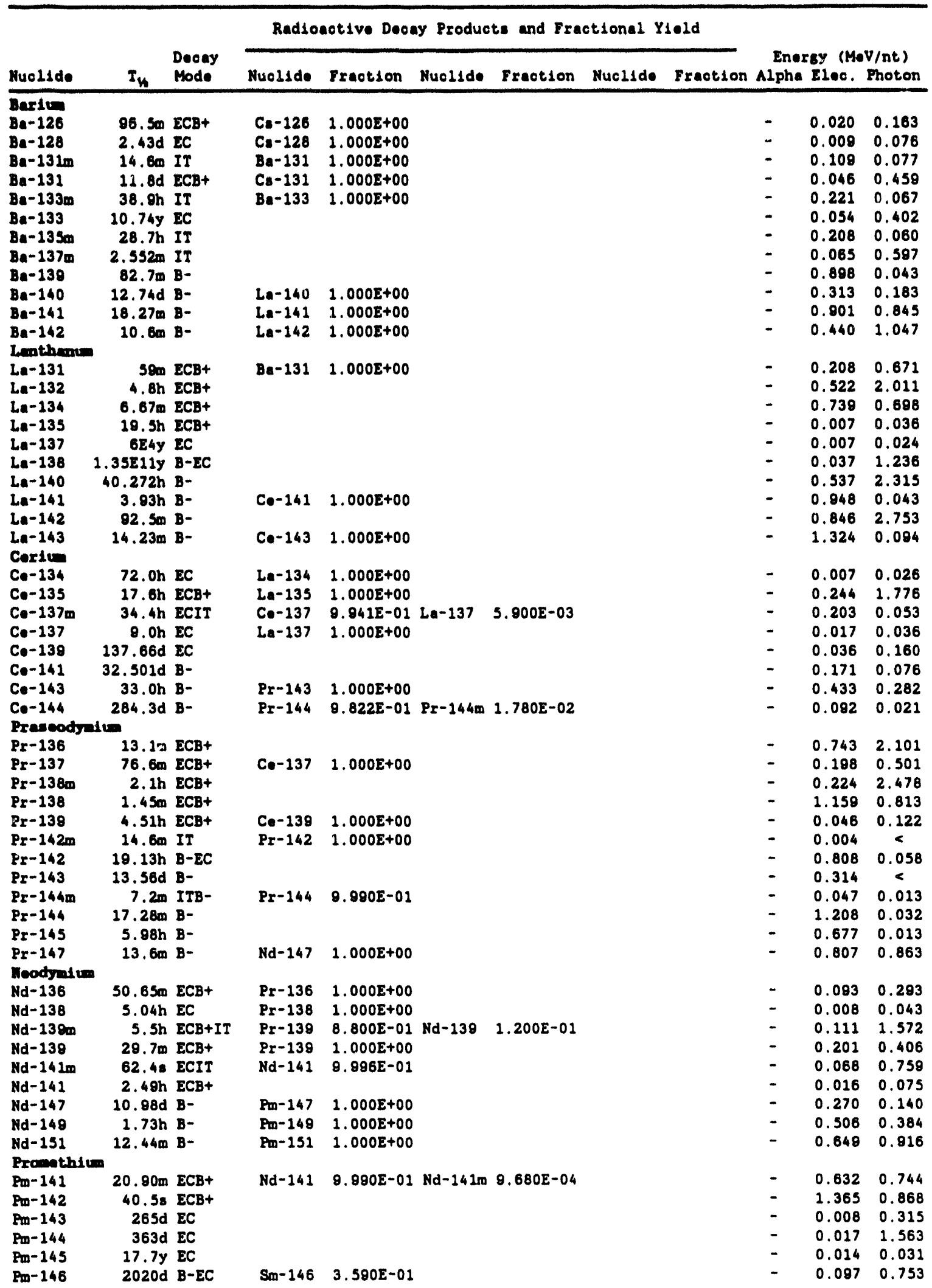


Table A-1 (ooat'd).

\begin{tabular}{|c|c|c|c|c|c|c|c|c|c|c|c|}
\hline \multirow[b]{2}{*}{ Nucl1de } & \multirow[b]{2}{*}{$\mathbf{T}_{\mathbf{n}}$} & \multirow[b]{2}{*}{$\begin{array}{l}\text { Decay } \\
\text { Mode }\end{array}$} & \multicolumn{6}{|c|}{ Radioactive Decay Products and Fractional Yield } & \multirow{2}{*}{\multicolumn{3}{|c|}{$\begin{array}{l}\text { Energy (MeV/nt) } \\
\text { Alpha Elec. Photon }\end{array}$}} \\
\hline & & & Nuclide & Fraction & Nuclide & Fraction & Nuclide & Fraction & & & \\
\hline \multicolumn{12}{|c|}{ Promothium, cont'd } \\
\hline$P m-147$ & $2.6234 y$ & B- & $8 m-147$ & $1.000 \mathrm{E}+00$ & & & & & - & 0.062 & $<$ \\
\hline$P m-148 m$ & $41.3 \mathrm{~d}$ & $B-I T$ & $P w-148$ & $4.600 \mathrm{E}-02$ & & & & & - & 0.170 & 2.000 \\
\hline$P m-148$ & $5.37 d$ & B- & & & & & & & - & 0.724 & 0.575 \\
\hline Pm-149 & $53.08 \mathrm{~h}$ & B- & & & & & & & - & 0.366 & 0.011 \\
\hline mon-130 & $2.88 \mathrm{~h}$ & B- & & & & & & & - & 0.807 & 1.431 \\
\hline Pm-151 & 28.40h & B- & $5 m-151$ & $1.000 \mathrm{E}+00$ & & & & & - & 0.306 & 0.321 \\
\hline \multicolumn{12}{|l|}{8 maxtum } \\
\hline $8 m-141 m$ & $22.6 \mathrm{~m}$ & ITECB+ & $P m-141$ & $9.969 E-01$ & $\mathrm{Sm}-141$ & $3.100 \mathrm{E}-03$ & & & - & 0.435 & 1.984 \\
\hline $8 m-141$ & $10.2 \mathrm{~m}$ & ECB+ & $P m-141$ & $1.0008+00$ & & & & & - & 0.706 & 1.405 \\
\hline $\operatorname{Sm}-142$ & $72.48 \mathrm{~m}$ & ECB + & $\operatorname{Pra}-142$ & $1.000 E+00$ & & & & & - & 0.034 & 0.094 \\
\hline$S m-245$ & $340 d$ & $\mathrm{EC}$ & $P m-145$ & $1.000 \mathrm{E}+00$ & & & & & - & 0.032 & 0.065 \\
\hline $5 m-146$ & $1.03 \mathrm{E} 8 \mathrm{y}$ & $A$ & & & & & & & 2.474 & - & - \\
\hline $8 m-147$ & $1.06 E 11 y$ & $\boldsymbol{A}$ & & & & & & & 2.248 & - & - \\
\hline Sm-151 & $90 y$ & B- & & & & & & & - & 0.020 & $<$ \\
\hline Sm-153 & $46.7 \mathrm{~h}$ & B- & & & & & & & - & 0.273 & 0.062 \\
\hline Sm-155 & $22.1 \mathrm{~m}$ & $B-$ & Eu-155 & $1.000 \mathrm{E}+00$ & & & & & - & 0.566 & 0.103 \\
\hline \multirow{2}{*}{\multicolumn{12}{|c|}{ Europion }} \\
\hline & & & & & & & & & & & \\
\hline Eu-145 & $5.94 d$ & ECBt & $8 m-145$ & $1.000 \mathrm{E}+00$ & & & & & - & 0.029 & 1.458 \\
\hline$E u-146$ & $4.61 d$ & $\mathrm{ECB}+$ & $\sin -146$ & $1.000 \mathrm{E}+00$ & & & & & - & 0.048 & 2.504 \\
\hline$E u-147$ & 24d & $A E C B+$ & $\operatorname{Sen}-147$ & $1.000 \mathrm{E}+00$ & $P m-143$ & $2.200 E-05$ & & & $<$ & 0.042 & 0.497 \\
\hline$E u-148$ & $54.5 d$ & $A E C B+$ & $P m-144$ & $8.400 E-00$ & & & & & $<$ & 0.023 & 2.177 \\
\hline Eu-148 & $93.1 \mathrm{~d}$ & $\mathrm{EC}$ & & & & & & & - & 0.011 & 0.063 \\
\hline$E u-150 b$ & $34.2 y$ & EC & & & & & & & - & 0.044 & 1.496 \\
\hline$E u-150 a$ & $12.62 \mathrm{~h}$ & B-ECB+ & & & & & & & - & 0.312 & 0.047 \\
\hline$E u-152 m$ & $0.32 \mathrm{~h}$ & $\mathrm{ECB}+\mathrm{B}-$ & Gd-152 & $7.200 \mathrm{E}-01$ & & & & & - & 0.507 & 0.293 \\
\hline$E u-152$ & $13.33 \mathrm{y}$ & B-ECB+ & Gd-152 & $2.782 \mathrm{E}-01$ & & & & & - & 0.138 & 1.155 \\
\hline Eu-154 & $8.8 y$ & $\mathrm{ECB}-$ & & & & & & & - & 0.292 & 1.242 \\
\hline Eu-155 & $4.96 y$ & B- & & & & & & & - & 0.063 & 0.061 \\
\hline Eu-156 & $15.19 \mathrm{~d}$ & B- & & & & & & & - & 0.423 & 1.329 \\
\hline Eu-157 & $15.15 \mathrm{~h}$ & B- & & & & & & & - & 0.395 & 0.262 \\
\hline$E u-158$ & 45.80 & B- & & & & & & & - & 0.963 & 1.057 \\
\hline \multicolumn{12}{|c|}{ Gadolinim } \\
\hline Gd-145 & $22.8 \mathrm{~m}$ & $E C B+$ & Eu-145 & $1.000 \mathrm{E}+00$ & & & & & - & 0.549 & 2.257 \\
\hline Gd-146 & $48.3 d$ & EC & $E u-146$ & $1.0008+00$ & & & & & - & 0.130 & 0.250 \\
\hline$G d-167$ & $38.1 \mathrm{~h}$ & $\mathrm{ECB}+$ & Eu-147 & $1.000 \mathrm{E}+00$ & & & & & - & 0.060 & 1.337 \\
\hline$G d-148$ & 93y & $A$ & & & & & & & 3.183 & - & - \\
\hline $\begin{array}{l}G d-149 \\
G d-151\end{array}$ & $\begin{array}{l}9.4 d \\
120 d\end{array}$ & $\begin{array}{l}\text { EC } \\
A E C\end{array}$ & $\begin{array}{l}\text { Eu-148 } \\
\text { Su-147 }\end{array}$ & $\begin{array}{l}1.000 E+00 \\
8.000 E-08\end{array}$ & & & & & $<$ & $\begin{array}{l}0.059 \\
0.034\end{array}$ & $\begin{array}{l}0.420 \\
0.064\end{array}$ \\
\hline Gd-152 & $1.08 \mathrm{E} 14 \mathrm{y}$ & $A$ & & & & & & & 2.148 & - & - \\
\hline Gd-153 & $242 d$ & $\mathrm{EC}$ & & & & & & & - & 0.044 & 0.106 \\
\hline Gd-158 & $18.56 \mathrm{~h}$ & B- & & & & & & & - & 0.304 & 0.050 \\
\hline \multicolumn{12}{|l|}{ Terbilu } \\
\hline$T b-147$ & $1.65 \mathrm{~h}$ & ECB+ & Gd-147 & $1.0008+00$ & & & & & - & 0.564 & 1.590 \\
\hline$T b-148$ & $4.15 \mathrm{~h}$ & $E C B+A$ & $G d-149$ & $8.000 E-01$ & Eu-145 & $2.000 \mathrm{E}-01$ & & & 0.793 & 0.186 & 1.614 \\
\hline$T b-150$ & $3.27 \mathrm{~h}$ & ECB+ & & & & & & & - & 0.546 & 1.678 \\
\hline$T b-151$ & $17.6 \mathrm{~h}$ & $E C B+A$ & $G d-151$ & $1.000 \mathrm{E}+00$ & $E u-147$ & 9.500z-05 & & & $<$ & 0.080 & 0.892 \\
\hline $\mathrm{Tb}-153$ & $2.34 d$ & ECB+ & Gd-153 & $1.000 \mathrm{E}+00$ & & & & & - & 0.049 & 0.229 \\
\hline$T b-154$ & $21.4 \mathrm{~h}$ & $\mathrm{ECB}+$ & & & & & & & - & 0.081 & 2.352 \\
\hline$T b-155$ & $5.32 d$ & EC & & & & & & & - & 0.034 & 0.140 \\
\hline Tb-156m & $24.4 \mathrm{~h}$ & IT & $\mathrm{Tb}-156$ & $1.000 E+00$ & & & & & - & 0.024 & 0.025 \\
\hline$T b-156 n$ & $5.0 \mathrm{~h}$ & IT & $\mathrm{Tb}-156$ & $1.000 E+00$ & & & & & - & 0.084 & 0.004 \\
\hline $\mathrm{Tb}-156$ & $5.34 d$ & EC & & & & & & & - & 0.103 & 1.826 \\
\hline $\mathrm{Tb}-157$ & $150 y$ & EC & & & & & & & - & 0.005 & 0.003 \\
\hline$T b-158$ & $150 y$ & $B-E C$ & & & & & & & - & 0.116 & 0.798 \\
\hline $\mathrm{Tb}-160$ & $72.3 d$ & $B-$ & & & & & & & - & 0.257 & 1.124 \\
\hline$T b-161$ & $6.81 d$ & $8-$ & & & & & & & - & 0.197 & 0.035 \\
\hline \multicolumn{12}{|c|}{ Desprositum } \\
\hline Dy-155 & $10.0 \mathrm{~h}$ & $\mathrm{ECB}+$ & $T b-155$ & $1.000 E+00$ & & & & & - & 0.028 & 0.582 \\
\hline Dy -157 & 8. 1h & EC & $T b-157$ & $1.000 E+00$ & & & & & - & 0.013 & 0.357 \\
\hline Dy -158 & $144.4 d$ & EC & & & & & & & - & 0.013 & 0.045 \\
\hline
\end{tabular}


Iable A-1 (cont'd).

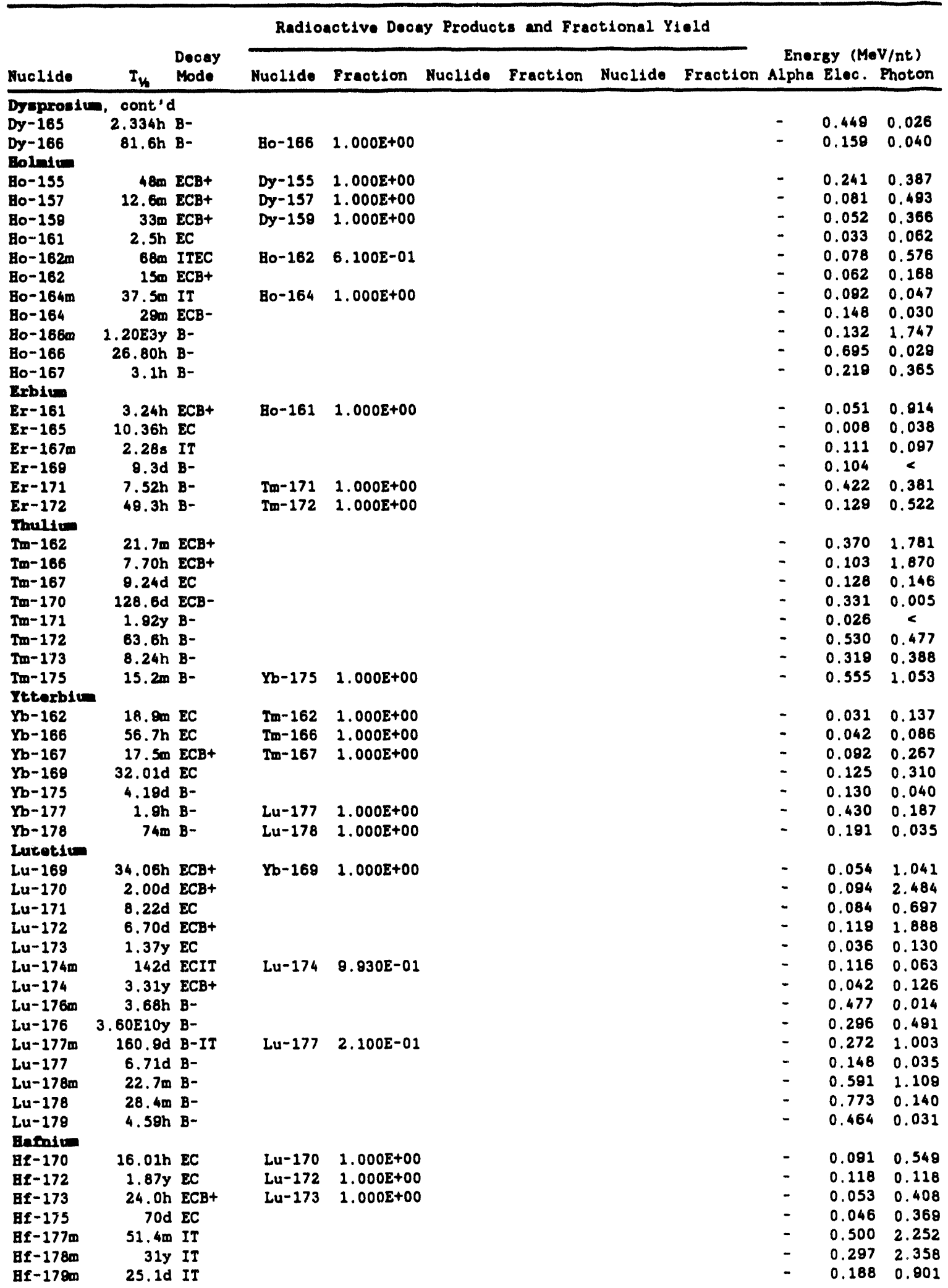


Table A-1 (cont'd).

\begin{tabular}{|c|c|c|c|c|c|c|c|c|c|c|c|}
\hline \multirow[b]{2}{*}{ Nuclide } & \multirow[b]{2}{*}{$T_{\mathbf{W}}$} & \multirow[b]{2}{*}{$\begin{array}{l}\text { Decay } \\
\text { Mode }\end{array}$} & \multicolumn{6}{|c|}{ Radioactive Decay Products and Fractional Yield } & \\
\hline & & & Nuclide & Fraction & Nuclide & Fraction & Nuclide & Fraction & $\begin{array}{l}\text { Ener } \\
\text { Alpha }\end{array}$ & $\begin{array}{l}\text { rgy (Me } \\
\text { Elec. }\end{array}$ & $\begin{array}{l}\text { V(nt) } \\
\text { Photon }\end{array}$ \\
\hline $\begin{array}{l}\text { Bateniva, } \\
\text { Bf-180m }\end{array}$ & $\begin{array}{l}\text { cont'd } \\
5.5 \mathrm{~h}\end{array}$ & IT & & & & & & & - & 0.139 & 1.008 \\
\hline Bf-181 & $42.4 d$ & B- & & & & & & & - & 0.203 & 0.555 \\
\hline Ef $-182 m$ & $61.5 \mathrm{~m}$ & ITB- & $T a-182$ & $5.400 E-01$ & Bf -182 & $4.600 \mathrm{E}-01$ & & & - & 0.235 & 0.933 \\
\hline Bf-182 & 9E6y & B- & $T a-182$ & $1.000 \mathrm{E}+00$ & & & & & - & 0.083 & 0.239 \\
\hline$B f-183$ & $64 \mathrm{~m}$ & B- & $T a-183$ & $1.000 \mathrm{E}+00$ & & & & & - & 0.451 & 0.752 \\
\hline $\begin{array}{l}\text { Bf-184 } \\
\text { Ientelva }\end{array}$ & $4.12 \mathrm{~h}$ & B- & $\mathrm{Ta}-184$ & $1.000 \mathrm{E}+00$ & & & & & - & 0.477 & 0.251 \\
\hline $\mathrm{Ta}-172$ & $36.8 \mathrm{~m}$ & $\mathrm{ECB}+$ & Bf-172 & $1.000 \mathrm{E}+00$ & & & & & - & 0.505 & 1.550 \\
\hline $\mathrm{Ta}-173$ & $3.65 \mathrm{~h}$ & $E C B+$ & Bf -173 & $1.000 E+00$ & & & & & - & 0.358 & 0.585 \\
\hline $\mathrm{T}=-174$ & $1.2 \mathrm{~h}$ & $\mathrm{ECB}+$ & SF & $1.000 \mathrm{E}+00$ & & & & & - & 0.367 & 0.627 \\
\hline $\mathrm{Ta}-175$ & $10.5 \mathrm{~h}$ & ECB+ & Bf- 175 & $1.000 E+00$ & & & & & - & 0.064 & 0.933 \\
\hline $\mathrm{Ta}-176$ & $8.08 \mathrm{~h}$ & $\mathrm{ECB}+$ & & & & & & & - & 0.104 & 2.145 \\
\hline $\mathrm{Ta}-177$ & $56.6 \mathrm{~h}$ & EC & & & & & & & - & 0.024 & 0.067 \\
\hline$T a-178 b$ & $2.2 \mathrm{~h}$ & EC & & & & & & & - & 0.155 & 1.023 \\
\hline $\mathrm{Ta}-178 \mathrm{a}$ & $9.31 \mathrm{~m}$ & EC & & & & & & & - & 0.034 & 0.109 \\
\hline $\mathrm{Ta}-179$ & $664.8 d$ & EC & & & & & & & - & 0.008 & 0.032 \\
\hline $\mathrm{Ta}-180 \mathrm{~m}$ & 8.1h & ECB- & & & & & & & - & 0.055 & 0.049 \\
\hline$T a-180$ & $1.0 \mathrm{E} 13 \mathrm{y}$ & $\overline{E C}$ & & & & & & & - & 0.123 & 0.560 \\
\hline $\mathrm{Ta}-182 \mathrm{~m}$ & $15.84 \mathrm{~m}$ & IT & $T a-182$ & $1.000 E+00$ & & & & & - & 0.251 & 0.252 \\
\hline $\mathrm{Ta}-182$ & $115.0 \mathrm{~d}$ & B- & & & & & & & - & 0.217 & 1.294 \\
\hline$T a-183$ & $5.1 d$ & B- & & & & & & & - & 0.345 & 0.293 \\
\hline $\mathrm{Ta}-184$ & $8.7 \mathrm{~h}$ & B- & & & & & & & - & 0.547 & 1.612 \\
\hline $\mathrm{Ta}-185$ & $48 \mathrm{~m}$ & B- & $\omega-185$ & $1.000 \mathrm{E}+00$ & & & & & - & 0.725 & 0.193 \\
\hline $\begin{array}{l}\text { Ta-186 } \\
\text { Woleram }\end{array}$ & $10.5 \mathrm{~m}$ & B- & & & & & & & - & 0.892 & 1.560 \\
\hline$w-176$ & $2.3 h$ & EC & $\mathrm{Ta}-176$ & $1.000 \mathrm{E}+00$ & & & & & - & 0.073 & 0.177 \\
\hline$W-177$ & 1350 & ECB+ & $\mathrm{Ta}-177$ & $1.000 E+00$ & & & & & - & 0.104 & 0.803 \\
\hline$W-178$ & $21.7 d$ & EC & $T a-178 a$ & $1.000 E+00$ & & & & & - & 0.007 & 0.014 \\
\hline$W-179$ & $37.5 \mathrm{~m}$ & EC & $\mathrm{Ta}-179$ & $1.000 \mathrm{E}+00$ & & & & & - & 0.027 & 0.060 \\
\hline$W-181$ & $121.2 d$ & EC & & & & & & & - & 0.021 & 0.040 \\
\hline$W-185$ & $75.1 d$ & B- & & & & & & & - & 0.127 & $<$ \\
\hline$W-187$ & $23.9 \mathrm{~h}$ & B- & $R e-187$ & $1.000 \mathrm{E}+00$ & & & & & - & 0.312 & 0.481 \\
\hline $\begin{array}{l}W-188 \\
\text { Phentu }\end{array}$ & $69.4 d$ & B- & $R=-188$ & $1.000 E+00$ & & & & & - & 0.100 & 0.002 \\
\hline$R e-177$ & $14.0 \mathrm{~m}$ & ECB+ & $\omega-177$ & $1.000 \mathrm{E}+00$ & & & & & - & 0.361 & 0.620 \\
\hline Re-178 & $13.2 \mathrm{~m}$ & ECB+ & $W-178$ & $1.000 \mathrm{E}+00$ & & & & & - & 0.578 & 1.218 \\
\hline$R e-180$ & $2.43 m$ & ECB+ & & & & & & & - & 0.156 & 1.183 \\
\hline$R e-181$ & $20 \mathrm{~h}$ & $\mathrm{ECB}+$ & $W-181$ & $1.000 E+00$ & & & & & - & 0.137 & 0.771 \\
\hline$R e-182 b$ & $64.0 \mathrm{~h}$ & EC & & & & & & & - & 0.213 & 1.886 \\
\hline$R e-182 a$ & $12.7 \mathrm{~h}$ & $\mathrm{ECB}+$ & & & & & & & - & 0.088 & 1.179 \\
\hline$R e-184 m$ & $165 d$ & ITEC & $R e-184$ & $7.470 \mathrm{E}-01$ & & & & & - & 0.141 & 0.390 \\
\hline Re-184 & $38.0 \mathrm{~d}$ & EC & & & & & & & - & 0.056 & 0.891 \\
\hline Re-186m & $2.055 y$ & IT & $R_{\theta-186}$ & $1.000 \mathrm{E}+00$ & & & & & - & 0.124 & 0.019 \\
\hline$R \cdot-186$ & $90.64 \mathrm{~h}$ & $B-E C$ & & & & & & & - & 0.345 & 0.021 \\
\hline$R=-187$ & SE10Y & B- & & & & & & & - & $<$ & - \\
\hline$R e-188 m$ & $18.6 \mathrm{~m}$ & IT & $R e-188$ & $1.000 E+00$ & & & & & - & 0.098 & 0.080 \\
\hline$R e-188$ & $16.98 \mathrm{~h}$ & B- & & & & & & & - & 0.780 & 0.058 \\
\hline $\begin{array}{l}\text { Re-189 } \\
\text { Omilu }\end{array}$ & $24.3 h$ & B- & $08-189 m$ & $2.410 E-01$ & & & & & - & 0.340 & 0.069 \\
\hline $0 s-180$ & $22 m$ & ECB+ & $R=-180$ & $1.000 E+00$ & & & & & - & 0.028 & 0.065 \\
\hline $08-181$ & $105 \mathrm{~m}$ & ECB+ & $R e-181$ & $1.000 \mathrm{E}+00$ & & & & & - & 0.208 & 1.222 \\
\hline $08-182$ & $22 \mathrm{~h}$ & $\mathbf{E C}$ & $R e-182 a$ & $1.000 \mathrm{E}+00$ & & & & & - & 0.056 & 0.435 \\
\hline $08-185$ & 94d & EC & & & & & & & - & 0.019 & 0.719 \\
\hline $0=-189 \mathrm{~m}$ & $6.0 \mathrm{~h}$ & IT & & & & & & & - & 0.029 & 0.002 \\
\hline $08-190 m$ & $9.8 \mathrm{~m}$ & IT & & & & & & & - & 0.116 & 1.588 \\
\hline $08-191 m$ & $13.03 \mathrm{~h}$ & IT & $0 s-191$ & $1.000 E+00$ & & & & & - & 0.065 & 0.009 \\
\hline $08-191$ & $15.4 \mathrm{~d}$ & B- & & & & & & & - & 0.135 & 0.080 \\
\hline $08-193$ & $30.0 \mathrm{~h}$ & B- & & & & & & & - & 0.373 & 0.073 \\
\hline $\begin{array}{l}08-194 \\
\text { Irddiug }\end{array}$ & $6.0 y$ & B- & Ir -194 & $1.000 E+00$ & & & & & - & 0.034 & 0.002 \\
\hline Ir -182 & 150 & $\mathrm{ECB}+$ & $08-182$ & $1.000 \mathrm{E}+00$ & & & & & - & 0.935 & 1.340 \\
\hline$I r-184$ & $3.02 \mathrm{~h}$ & ECB + & & & & & & & - & 0.279 & 1.908 \\
\hline
\end{tabular}


Table A-1 (cont'd) .

\begin{tabular}{|c|c|c|c|c|c|c|c|c|c|c|c|}
\hline \multirow[b]{2}{*}{ Nuc11de } & \multirow[b]{2}{*}{$T_{\mathbf{w}}$} & \multirow[b]{2}{*}{$\begin{array}{l}\text { Docay } \\
\text { Mode }\end{array}$} & \multicolumn{6}{|c|}{ Radioactive Decay Products and Fractional Yield } & \multirow{2}{*}{\multicolumn{3}{|c|}{$\begin{array}{l}\text { Energy (MeV/nt) } \\
\text { Alpha Elec. Photor }\end{array}$}} \\
\hline & & & Nuclide & Fraction & Kuclide & Fraction & Nuclide & Fraction & & & \\
\hline \multicolumn{12}{|c|}{ Iridiu, cont'd } \\
\hline Ir-185 & $14.0 \mathrm{~h}$ & ECB+ & $08-185$ & $1.000 \mathrm{E}+00$ & & & & & - & 0.115 & 0.601 \\
\hline$I r-186 a$ & $15.8 \mathrm{~h}$ & ECB+ & & & & & & & - & 0.113 & 1.641 \\
\hline Ir $-186 b$ & $1.75 \mathrm{~h}$ & ECB+ & & & & & & & - & 0.203 & 0.864 \\
\hline$I r-187$ & $10.5 \mathrm{~h}$ & EC & & & & & & & - & 0.060 & 0.363 \\
\hline Ir -188 & $41.5 \mathrm{~h}$ & ECB+ & & & & & & & - & 0.058 & 1.584 \\
\hline Ir -188 & $13.3 d$ & EC & $08-188 x$ & $8.300 \mathrm{E}-02$ & & & & & - & 0.049 & 0.081 \\
\hline Ir-180n & 3. 1h & ITEC & Ir $-190 \mathrm{~m}$ & $5.000 \mathrm{E}-02$ & & & & & - & 0.126 & 1.555 \\
\hline$I r-180 m$ & $1.2 \mathrm{~h}$ & IT & $I x-180$ & $1.000 \Sigma+00$ & & & & & - & 0.024 & 0.002 \\
\hline$I r-180$ & $1.2 .1 \mathrm{~d}$ & EC & & & & & & & - & 0.129 & 1.443 \\
\hline$I r-191 m$ & 4.948 & IT & & & & & & & - & 0.096 & 0.075 \\
\hline$I x-192 m$ & $241 . y$ & IT & $I r-192$ & $1.000 E+00$ & & & & & - & - & 0.161 \\
\hline$I r-192$ & $74.02 d$ & $B-E C$ & & & & & & & - & 0.217 & 0.818 \\
\hline$I r-194 m$ & $171 d$ & B- & & & & & & & - & 0.156 & 2.335 \\
\hline$I r-194$ & $19.15 \mathrm{~h}$ & B- & & & & & & & - & 0.812 & 0.090 \\
\hline$I r-185 m$ & 3. $8 \mathrm{~h}$ & ITB- & $I I-185$ & $4.000 \Sigma-02$ & & & & & - & 0.480 & 0.432 \\
\hline $\begin{array}{l}\text { Ir-185 } \\
\text { Platimu }\end{array}$ & $2.5 \mathrm{~h}$ & B- & & & & & & & - & 0.380 & 0.059 \\
\hline$P t-186$ & $2.0 \mathrm{~h}$ & A EC & $I r-186 b$ & $1.000 E+00$ & $08-182$ & $1.400 \mathrm{E}-06$ & & & $<$ & 0.012 & 0.740 \\
\hline$P t-188$ & $10.2 d$ & EC & Ir -188 & $1.000 E+00$ & & & & & - & 0.080 & 0.202 \\
\hline Pt- 189 & $10.87 \mathrm{~h}$ & ECB+ & $I r-189$ & $2.000 \mathrm{E}+00$ & & & & & - & 0.055 & 0.325 \\
\hline Pt -181 & $2.8 d$ & EC & & & & & & & - & 0.064 & 0.304 \\
\hline Pt-193m & $4.33 d$ & IT & Pt- 183 & $1.000 \mathrm{E}+00$ & & & & & - & 0.137 & 0.013 \\
\hline Pt -183 & $50 y$ & $\mathrm{EC}$ & & & & & & & - & 0.007 & 0.002 \\
\hline Pt-195m & $4.02 d$ & II & & & & & & & - & 0.183 & 0.076 \\
\hline Pt-197m & $94.4 m$ & B-IT & $P t-187$ & 9.670E-01 & & & & & - & 0.324 & 0.083 \\
\hline Pt -197 & $18.3 \mathrm{~h}$ & B- & & & & & & & - & 0.254 & 0.025 \\
\hline Pt -188 & $30.8 \mathrm{~m}$ & B- & Au-189 & $1.000 \mathrm{E}+00$ & & & & & - & 0.535 & 0.202 \\
\hline $\begin{array}{l}\text { Pt-200 } \\
\text { Cold }\end{array}$ & $12.5 \mathrm{~h}$ & B- & $A u-200$ & $1.000 \mathrm{E}+00$ & & & & & - & 0.243 & 0.061 \\
\hline Au-183 & $17.65 \mathrm{~h}$ & $\mathbf{E C}$ & $P t-183$ & $1.000 E+00$ & & & & & - & 0.064 & 0.160 \\
\hline$A u-184$ & $39.5 \mathrm{~h}$ & $\mathrm{ECB}+$ & & & & & & & - & 0.043 & 1.067 \\
\hline Au-185m & 30.58 & IT & $A u-185$ & $1.000 E+00$ & & & & & - & 0.117 & 0.201 \\
\hline Au-195 & $183 d$ & EC & & & & & & & - & 0.051 & 0.085 \\
\hline Au- $198 m$ & $2.30 d$ & IT & $A u-188$ & $1.000 E+00$ & & & & & - & 0.288 & 0.577 \\
\hline Au-188 & $2.696 d$ & B- & & & & & & & - & 0.327 & 0.405 \\
\hline Au-189 & $3.139 d$ & B- & & & & & & & - & 0.143 & 0.089 \\
\hline Au-200m & 18. $7 \mathrm{~h}$ & B-IT & $A u-200$ & $1.800 \mathrm{E}-01$ & & & & & - & 0.276 & 2.087 \\
\hline$A u-200$ & $48.4 m$ & B- & & & & & & & - & 0.740 & 0.272 \\
\hline$A u-201$ & $26.4 m$ & B- & & & & & & & - & 0.422 & 0.053 \\
\hline Marcusy & & & & & & & & & & & \\
\hline $\mathrm{B}_{8}-183 m$ & 11. Ih & $\mathrm{ECB}+\mathrm{IT}$ & $A u-183$ & $9.2005-01$ & $8 s-183$ & $8.000 E-02$ & & & - & 0.138 & 1.046 \\
\hline$B_{g}-193$ & $3.5 \mathrm{~h}$ & $\mathrm{ECB}+$ & $A u-193$ & $1.000 \mathrm{E}+00$ & & & & & - & 0.125 & 0.203 \\
\hline B8-184 & $260 y$ & $\mathbf{E C}$ & Au-184 & $1.000 \mathrm{E}+00$ & & & & & - & 0.007 & 0.003 \\
\hline Bg-185m & $41.6 \mathrm{~h}$ & ITEC & $\mathrm{B} 8-185$ & $5.420 E-01$ & $A u-195$ & $4.580 E-01$ & & & - & 0.150 & 0.214 \\
\hline $\mathrm{Bg}-195$ & $9.9 \mathrm{~h}$ & EC & Au-185 & $1.000 \mathrm{E}+00$ & & & & & - & 0.065 & 0.204 \\
\hline$B g-187 m$ & $23.8 \mathrm{~h}$ & ECIT & Bg-197 & 9.300E-01 & & & & & - & 0.215 & 0.094 \\
\hline B8-187 & $64.1 \mathrm{~h}$ & $\mathbf{E C}$ & & & & & & & - & 0.066 & 0.070 \\
\hline $\mathrm{B}_{8}-189 \mathrm{~m}$ & $42.6 \mathrm{~m}$ & IT & & & & & & & - & 0.352 & 0.186 \\
\hline$B_{8}-203$ & $46.60 d$ & B- & & & & & & & - & 0.098 & 0.238 \\
\hline $\begin{array}{l}\text { Bg-206 } \\
\text { Thallite }\end{array}$ & $8.15 \mathrm{~m}$ & B- & $T 1-206$ & $1.000 \mathrm{E}+00$ & & & & & - & 0.428 & 0.106 \\
\hline$T 1-194 \mathrm{~m}$ & 32.80 & $\mathrm{ECB}+$ & $\mathrm{Bg}-194$ & $1.0005+00$ & & & & & - & 0.342 & 2.318 \\
\hline$T 1-194$ & $33 m$ & $\mathbf{E C}$ & $\mathrm{Bg}-194$ & $1.000 E+00$ & & & & & - & 0.030 & 0.779 \\
\hline T1-195 & $1.16 \mathrm{~b}$ & $\mathrm{ECB}+$ & $\mathrm{B}_{8}-185$ & $1.000 \mathrm{E}+00$ & & & & & - & 0.096 & 1.271 \\
\hline T1-187 & $2.84 \mathrm{~h}$ & $\mathrm{ECB}+$ & $8 g-187$ & $1.000 \mathrm{E}+00$ & & & & & - & 0.061 & 0.408 \\
\hline T1-188m & $1.87 \mathrm{~h}$ & $\mathrm{ECB}+\mathrm{IT}$ & TI-198 & $4.700 E-01$ & & & & & - & 0.201 & 1.195 \\
\hline T1-198 & $5.3 \mathrm{~h}$ & $\mathrm{ECB}+$ & & & & & & & - & 0.041 & 2.006 \\
\hline T1-199 & $7.42 \mathrm{~h}$ & $\mathrm{ECB}+$ & & & & & & & - & 0.056 & 0.249 \\
\hline$T 1-200$ & 26. Ih & $\mathrm{ECB}+$ & & & & & & & - & 0.040 & 1.311 \\
\hline T1-201 & $3.044 d$ & $\mathbf{E C}$ & & & & & & & - & 0.043 & 0.093 \\
\hline T1-202 & $12.23 d$ & $\mathrm{ECB}+$ & & & & & & & - & 0.023 & 0.468 \\
\hline
\end{tabular}


Table A-1 (cont'd).

\begin{tabular}{|c|c|c|c|c|c|c|c|c|c|c|c|}
\hline \multirow[b]{2}{*}{ Nuc11de } & \multirow[b]{2}{*}{$\mathbf{I}_{\boldsymbol{n}}$} & \multirow[b]{2}{*}{$\begin{array}{l}\text { Decey } \\
\text { Mode }\end{array}$} & \multicolumn{6}{|c|}{ Radioactive Decay Products and Fractional Yield } & \multirow{2}{*}{\multicolumn{3}{|c|}{ Energy (MeV/nt) }} \\
\hline & & & Nuclide & Fraction & Nuclide & Fraction & Nuclide & Fraction & & & \\
\hline Thallite & , cont'd & & & & & & & & & & \\
\hline $\begin{array}{l}T 1-204 \\
T 1-206\end{array}$ & $\begin{array}{r}3.778 \mathrm{y} \\
4.20 \mathrm{~m}\end{array}$ & $\begin{array}{l}\text { ECB- } \\
\text { B- }\end{array}$ & & & & & & & - & $\begin{array}{l}0.238 \\
0.537\end{array}$ & $\begin{array}{c}0.001 \\
<\end{array}$ \\
\hline$T 1-207$ & $4.77 m$ & B- & & & & & & & - & 0.493 & 0.002 \\
\hline$T 1-208$ & $3.07 \mathrm{~m}$ & B- & & & & & & & - & 0.598 & 3.375 \\
\hline T1-209 & $2.20 \mathrm{~m}$ & B- & $\mathbf{F b}-208$ & $1.000 \mathrm{E}+00$ & & & & & - & 0.688 & 2.032 \\
\hline $\begin{array}{l}\text { T1-210 } \\
\text { Lead }\end{array}$ & $1.30 \mathrm{~m}$ & B- & $P b-210$ & $1.000 \mathrm{E}+00$ & & & & & - & 1.273 & 2.736 \\
\hline $\mathrm{Pb}-185 \mathrm{~m}$ & $15.8 \mathrm{~mm}$ & $\mathrm{ECB}+$ & $T 1-185$ & $1.000 \mathrm{E}+00$ & & & & & - & 0.302 & 1.598 \\
\hline $\mathbf{F b}-188$ & 2.4h & EC & $\mathrm{T} 1-188$ & $1.000 E+00$ & & & & & - & 0.078 & 0.439 \\
\hline$P b-199$ & 80m & $\mathrm{ECB}+$ & T1-189 & $1.000 \mathrm{E}+00$ & & & & & - & 0.054 & 1.476 \\
\hline$P b-200$ & $21.5 \mathrm{~h}$ & EC & $T 1-200$ & $1.000 E+00$ & & & & & - & 0.098 & 0.209 \\
\hline $\mathrm{Pb}-201$ & 9.4h & $\mathrm{ECB}+$ & $I 1-201$ & $1.000 \mathrm{E}+00$ & & & & & - & 0.058 & 0.758 \\
\hline $\mathrm{Pb}-202 \mathrm{~m}$ & $3.62 \mathrm{~h}$ & ITEC & $\mathrm{Pb}-202$ & $9.050 \mathrm{E}-01$ & $T 1-202$ & $9.500 E-02$ & & & - & 0.076 & 2.043 \\
\hline $\mathrm{Pb}-202$ & 3E5 & EC & $T 1-202$ & $1.000 E+00$ & & & & & - & 0.006 & 0.002 \\
\hline $\mathrm{Fb}-203$ & $52.05 \mathrm{~h}$ & EC & & & & & & & - & 0.052 & 0.312 \\
\hline $\mathrm{Pb}-204 \mathrm{~m}$ & $67.2 \mathrm{~m}$ & IT & & & & & & & - & 0.025 & 2.105 \\
\hline $\mathrm{Pb}-205$ & $1.43 E 7 y$ & EC & & & & & & & - & 0.007 & 0.002 \\
\hline $\mathrm{Pb}-209$ & $3.253 \mathrm{~h}$ & B- & & & & & & & - & 0.198 & - \\
\hline $\mathrm{Pb}-210$ & $22.3 y$ & B- & $B 1-210$ & $1.000 \mathrm{E}+00$ & & & & & - & 0.038 & 0.005 \\
\hline $\mathrm{Pb}-211$ & $36.1 \mathrm{~m}$ & B- & $B 1-211$ & $1.000 E+00$ & & & & & - & 0.456 & 0.051 \\
\hline $\mathrm{Pb}-212$ & $10.64 \mathrm{~h}$ & B- & $B 1-212$ & $1.000 \mathrm{E}+00$ & & & & & - & 0.176 & 0.148 \\
\hline $\begin{array}{l}\mathrm{Pb}-214 \\
\text { Bicreath }\end{array}$ & 26.800 & B- & $B 1-214$ & $1.0005+00$ & & & & & - & 0.283 & 0.250 \\
\hline$B 1-200$ & $36.4 m$ & $\mathrm{ECB}+$ & $F b-200$ & $1.000 E+00$ & & & & & - & 0.190 & 2.393 \\
\hline$B 1-201$ & 108 & $\mathbf{E C}$ & $\mathrm{Fb}-201$ & $1.000 E+00$ & & & & & - & 0.258 & 1.339 \\
\hline$B 1-202$ & $1.67 \mathrm{~h}$ & $\mathrm{ECB}+$ & $\mathrm{Pb}-202$ & $9.975 E-01$ & $\mathrm{~Pb}-202 \mathrm{~m}$ & 2. $500 E-03$ & & & - & 0.108 & 2.713 \\
\hline$B 1-203$ & $11.76 \mathrm{~h}$ & ECB+ & Pb-203 & 1. $000 E+00$ & & & & & - & 0.080 & 2.384 \\
\hline$B 1-204$ & $11.22 \mathrm{~h}$ & $\mathrm{ECB}+$ & $\mathrm{Pb}-204 \mathrm{~m}$ & 9.928E-02 & & & & & - & 0.085 & 3.064 \\
\hline$B 1-205$ & $15.31 d$ & ECB+ & Fb-205 & $1.000 E+00$ & & & & & - & 0.034 & 1.690 \\
\hline$B 1-206$ & $6.243 d$ & EC & & & & & & & - & 0.136 & 3.278 \\
\hline$B 1-207$ & $38 y$ & ECB+ & & & & & & & - & 0.117 & 1.540 \\
\hline$B 1-210 m$ & 3.0E6y & $\mathbf{A}$ & $T 1-206$ & $1.000 \mathrm{E}+00$ & & & & & 4.913 & 0.047 & 0.257 \\
\hline$B 1-210$ & $5.012 d$ & B- & Po-210 & $1.000 E+00$ & & & & & - & 0.389 & - \\
\hline $\begin{array}{l}B 1-211 \\
B_{1}-212\end{array}$ & $\begin{array}{r}2.14 \mathrm{~m} \\
60.55 \mathrm{~m}\end{array}$ & $\begin{array}{l}A B- \\
B-A\end{array}$ & $\begin{array}{l}T 1-207 \\
P 0-212\end{array}$ & $\begin{array}{l}9.972 E-01 \\
6.407 E-01\end{array}$ & $\begin{array}{l}P o-211 \\
T 1-208\end{array}$ & $\begin{array}{l}2.800 E-03 \\
3.593 E-01\end{array}$ & & & $\begin{array}{l}6.550 \\
2.174\end{array}$ & $\begin{array}{l}0.010 \\
0.472\end{array}$ & $\begin{array}{l}0.047 \\
0.186\end{array}$ \\
\hline$B i-213$ & $45.65 \mathrm{~m}$ & $B-A$ & Po-213 & $9.784 \mathrm{E}-01$ & $T 1-209$ & $2.160 E-02$ & & & 0.126 & 0.442 & 0.133 \\
\hline$B 1-214$ & 19.8m & B- & Po-214 & $9.898 E-01$ & & & & & - & 0.659 & 1.508 \\
\hline Poloniva & & & & & & & & & & & \\
\hline Po-203 & $36.7 \mathrm{~m}$ & ECB+ & $B 1-203$ & $9.989 E-01$ & & & & & - & 0.164 & 1.644 \\
\hline Po-205 & $1.80 \mathrm{~h}$ & A ECBt & $B 1-205$ & $9.990 \mathrm{E}-01$ & $\mathbf{P b}-201$ & $1.400 E-03$ & & & 0.007 & 0.060 & 1.581 \\
\hline Po-207 & $350 m$ & $\mathrm{ECB}+$ & $B 1-207$ & $1.000 \mathrm{E}+00$ & & & & & - & 0.052 & 1.331 \\
\hline Po-208 & $102 y$ & $A \quad E C$ & Fb-205 & $9.974 E-01$ & & & & & 4.867 & $<$ & 0.003 \\
\hline Po-210 & $138.38 d$ & $\mathbf{A}$ & & & & & & & 5.297 & $<$ & $<$ \\
\hline Po-211 & 0.5168 & $\mathbf{A}$ & & & & & & & 7.442 & $<$ & 0.008 \\
\hline Po-212 & $0.305 u$ & & & & & & & & 8.785 & - & - \\
\hline Po-213 & 4.2us & & $\mathrm{Pb}-209$ & $1.000 E+00$ & & & & & 8.376 & - & - \\
\hline Po- 214 & 164.348 & $\mathbf{8 A}$ & $P b-210$ & $1.000 E+00$ & & & & & 7.687 & $<$ & $<$ \\
\hline Po-215 & $0.001780 \mathrm{~s}$ & $\mathbf{A}$ & $P b-211$ & $1.0005+00$ & & & & & 7.386 & $<$ & $<$ \\
\hline Po-216 & 0.158 & $A$ & $\mathrm{~Pb}-2.2$ & $1.000 \mathrm{E}+00$ & & & & & 6.779 & $<$ & $<$ \\
\hline Po-218 & $3.05 \mathrm{~m}$ & $A B-$ & $P b-214$ & $9.998 E-01$ & At -218 & $2.000 E-04$ & & & 6.001 & $<$ & $<$ \\
\hline Astatine & & & & & & & & & & & \\
\hline At -207 & $1.80 \mathrm{~h}$ & ECA & Po-207 & 9. $000 \mathrm{E}-01$ & $B 1-203$ & $1.000 E-01$ & & & 0.576 & 0.080 & 1.325 \\
\hline At -211 & $7.214 \mathrm{~h}$ & ECA & Po-211 & $5.830 \mathrm{E}-01$ & $B 1-207$ & $4.170 E-01$ & & & 2.446 & 0.006 & 0.039 \\
\hline At-215 & $0.10 \mathrm{~ms}$ & $\mathrm{AA}$ & $B 1-211$ & $1.000 E+00$ & & & & & 8.026 & $<$ & $<$ \\
\hline At -216 & $0.30 \mathrm{~m}$ & $8 \mathrm{~A}$ & $B 1-212$ & $1.000 \mathrm{E}+00$ & & & & & 7.798 & $<$ & 0.002 \\
\hline At -217 & $0.0323 \mathrm{~s}$ & $A$ & $B 1-213$ & $1.000 E+00$ & & & & & 7.067 & $<$ & $<$ \\
\hline At-218 & 28 & $A$ & $B 1-214$ & $1.000 E+00$ & & & & & 6.697 & 0.040 & 0.007 \\
\hline Radon & & & & & & & & & & & \\
\hline$R n-218$ & $35 \mathrm{~ms}$ & & Po- 214 & $1.000 E+00$ & & & & & 7.132 & $<$ & $<$ \\
\hline$R n-219$ & 3.968 & $A$ & Po-215 & $1.000 \mathrm{E}+00$ & & & & & 6.757 & 0.006 & 0.056 \\
\hline$R_{n}-220$ & 55.68 & $\mathbf{A}$ & $P 0-216$ & $1.000 \mathrm{E}+00$ & & & & & 6.288 & $<$ & $<$ \\
\hline$R n-222$ & $3.8235 d$ & $A$ & Po-218 & $1.000 E+00$ & & & & & 5.489 & $<$ & $<$ \\
\hline
\end{tabular}


Iable $\Delta-1$ (cont'd).

\begin{tabular}{|c|c|c|c|c|c|c|c|c|c|c|c|}
\hline \multirow[b]{2}{*}{ Nucl1de } & \multirow[b]{2}{*}{$T_{\mathbf{k}}$} & \multirow[b]{2}{*}{$\begin{array}{l}\text { Decay } \\
\text { Mode }\end{array}$} & \multicolumn{6}{|c|}{ Radioactive Decay Products and Fractional Yield } & \multirow{2}{*}{\multicolumn{3}{|c|}{ Energy (MeV/nt) }} \\
\hline & & & Nuclide & Fraction & Nuclide & Fraction & Nuclide & Fraction & & & \\
\hline \multicolumn{12}{|l|}{ Premelu } \\
\hline Fr-218 & \multicolumn{2}{|c|}{$21 \mathrm{msA}$} & At -215 & $1.000 E+00$ & & & & & 7.313 & $<$ & 0.003 \\
\hline Fr -220 & 27.48 & $\mathbf{A}$ & At -216 & $1.000 \mathrm{E}+00$ & & & & & 6.637 & 0.028 & 0.012 \\
\hline Fr-221 & $4.8 \mathrm{~m}$ & $\mathbf{A}$ & At-217 & $1.000 \mathrm{E}+00$ & & & & & 6.304 & 0.010 & 0.031 \\
\hline Fr-222 & $14.4 \mathrm{~m}$ & B- & Ra-222 & $1.000 \mathrm{E}+00$ & & & & & - & 0.731 & - \\
\hline$F r-223$ & $21.8 \mathrm{~m}$ & B- & $R a-223$ & $1.000 \mathrm{E}+00$ & & & & & - & 0.400 & 0.059 \\
\hline \multicolumn{12}{|l|}{ Radium } \\
\hline Ra-222 & 38.08 & $\mathbf{A}$ & $\operatorname{Rn}-218$ & $1.000 E+00$ & & & & & 6.546 & $<$ & 0.009 \\
\hline$R a-223$ & $11.434 d$ & $A$ & $\mathrm{Rn}-218$ & $1.000 E+00$ & & & & & 5.667 & 0.076 & 0.134 \\
\hline$R a-224$ & $3.66 \mathrm{~d}$ & $\mathbf{A}$ & $R n-220$ & $1.000 E+00$ & & & & & 5.674 & 0.002 & 0.010 \\
\hline$R a-225$ & $14.8 d$ & B- & $A c-225$ & $1.000 \mathrm{E}+00$ & & & & & - & 0.107 & 0.014 \\
\hline$R a-226$ & $1600 y$ & $\mathbf{A}$ & $R n-222$ & $1.000 \mathrm{E}+00$ & & & & & 4.774 & 0.004 & 0.007 \\
\hline$R a-227$ & $42.2 \mathrm{~m}$ & B- & $A c-227$ & $1.000 E+00$ & & & & & - & 0.439 & 0.167 \\
\hline$R a-228$ & $5.75 y$ & B- & $A C-228$ & $1.000 \mathrm{E}+00$ & & & & & - & 0.017 & $<$ \\
\hline \multicolumn{12}{|l|}{ Actintu } \\
\hline$A c-223$ & $2.2 \mathrm{~m}$ & $A$ & Fr -219 & $1.000 E+00$ & & & & & 6.553 & 0.015 & 0.006 \\
\hline$A C-224$ & $2.9 \mathrm{~h}$ & $A$ EC & Ra-224 & $9.000 \mathrm{E}-01$ & $5 x-220$ & $1.000 E-01$ & & & 0.611 & 0.040 & 0.200 \\
\hline$A c-225$ & $10.0 d$ & $\mathbf{A}$ & Fr-221 & $1.000 \mathrm{E}+00$ & & & & & 5.787 & 0.022 & 0.018 \\
\hline$A c-226$ & $28 \mathrm{~h}$ & $A B-E C$ & Th-226 & 8. 280E-01 & $\operatorname{Ra}-226$ & ?. 720E-01 & Fr -222 & $6.000 \mathrm{E}-05$ & $<$ & 0.289 & 0.130 \\
\hline$A c-227$ & $21.773 y$ & B-A & Th-227 & $9.862 E-01$ & $F r-223$ & $1.380 \mathrm{E}-02$ & & & 0.068 & 0.016 & $<$ \\
\hline $\begin{array}{l}\text { Ac-228 } \\
\text { Thortum }\end{array}$ & $6.13 \mathrm{~h}$ & B- & Th-228 & $1.000 E+00$ & & & & & - & 0.475 & 0.971 \\
\hline Th-226 & $30.9 m$ & $A$ & $R a-222$ & $1.000 \mathrm{E}+00$ & & & & & 6.308 & 0.021 & 0.009 \\
\hline Th-227 & $18.718 d$ & $A$ & $R a-223$ & $1.000 E+00$ & & & & & 5.884 & 0.053 & 0.110 \\
\hline Th-228 & $1.9131 y$ & $A$ & Ra-224 & $1.000 \mathrm{E}+00$ & & & & & 5.400 & 0.021 & 0.003 \\
\hline Th-229 & $7340 y$ & $A$ & $\mathrm{Ra}-225$ & $1.000 E+00$ & & & & & 4.873 & 0.116 & 0.096 \\
\hline Th-230 & $7.7 E 4 y$ & $A$ & $R a-226$ & $1.000 E+00$ & & & & & 4.671 & 0.015 & 0.002 \\
\hline Th-231 & $25.52 \mathrm{~h}$ & B- & $\mathrm{Pa}-231$ & $1.000 E+00$ & & & & & - & 0.165 & 0.026 \\
\hline Th-232 & $1.405 \mathrm{E} 10 \mathrm{y}$ & $\mathbf{A}$ & $R a-228$ & $1.000 E+00$ & & & & & 3.996 & 0.012 & 0.001 \\
\hline Th-234 & $24.10 \mathrm{~d}$ & B- & $\mathrm{Pa}-234 \mathrm{~m}$ & $9.980 \mathrm{E}-01$ & $P a-234$ & $2.000 \mathrm{E}-03$ & & & - & 0.060 & 0.008 \\
\hline \multicolumn{12}{|c|}{ Protectinium } \\
\hline $\mathrm{Pa}-227$ & $38.3 \mathrm{~m}$ & ECA & $A c-223$ & 8.500E-01 & Th-227 & $1.500 \mathrm{E}-01$ & & & 5.468 & 0.016 & 0.022 \\
\hline$P a-228$ & $22 \mathrm{~h}$ & A ECB+ & Th-228 & $9.800 E-01$ & $\mathrm{Ac}-224$ & $2.000 \mathrm{E}-02$ & & & 0.120 & 0.165 & 1.141 \\
\hline$P a-230$ & $17.4 d$ & A ECB- & Th-230 & $9.050 \mathrm{E}-01$ & $U-230$ & $9.500 \mathrm{E}-02$ & Ac-226 & $3.200 E-05$ & $<$ & 0.068 & 0.652 \\
\hline$P a-231$ & $3.276 E 4 y$ & $A$ & $A c-227$ & $1.000 \mathrm{E}+00$ & & & & & 4.969 & 0.065 & 0.048 \\
\hline$P a-232$ & $1.31 d$ & B- & $\mathrm{U}-232$ & $1.000 E+00$ & & & & & - & 0.175 & 0.939 \\
\hline $\mathrm{Pa}-233$ & $27.0 d$ & B- & $\mathrm{U}-233$ & $1.000 E+00$ & & & & & - & 0.196 & 0.204 \\
\hline $\mathrm{Pa}-234 \mathrm{~m}$ & $1.17 \mathrm{~m}$ & B-IT & $v-234$ & $9.987 \mathrm{E}-01$ & $P a-234$ & $1.300 \mathrm{E}-03$ & & & - & 0.822 & 0.012 \\
\hline \multicolumn{11}{|l|}{ Urentu } & 1.919 \\
\hline$U-230$ & $20.8 d$ & $A$ & Th-226 & $1.000 E+00$ & & & & & 5.864 & 0.022 & 0.003 \\
\hline$U-231$ & $4.2 d$ & ECA & $P a-231$ & $1.000 E+00$ & $T h-227$ & 5. 500E-0.5 & & & $<$ & 0.071 & 0.082 \\
\hline $\mathrm{U}-232$ & $72 y$ & $A$ & $T h-228$ & $1.000 E+00$ & & & & & 5.302 & 0.017 & 0.002 \\
\hline$U-233$ & $1.585 E 5 y$ & $A$ & Th-228 & $1.000 \mathrm{E}+00$ & & & & & 4.817 & 0.006 & 0.001 \\
\hline$U-234$ & 2. $445 E 5 y$ & $\mathbf{A}$ & Th-230 & $1.000 E+00$ & & & & & 4.758 & 0.013 & 0.002 \\
\hline$U-235$ & $703.8 \mathrm{E} 6 \mathrm{y}$ & $A$ & $T h-231$ & $1.000 \mathrm{E}+00$ & & & & & 4.396 & 0.049 & 0.156 \\
\hline $\mathrm{U}-236$ & $2.3415 E 7 y$ & $A$ & Th-232 & $1.000 E+00$ & & & & & 4.505 & 0.011 & 0.002 \\
\hline$U-237$ & $6.75 d$ & B- & $\mathrm{Np}-237$ & $1.000 \mathrm{E}+00$ & & & & & - & 0.186 & 0.143 \\
\hline$U-238$ & 4. $468 E 9 y$ & SFA & Th-234 & $1.000 \mathrm{E}+00$ & $\mathbf{S F}$ & $5.400 E-05$ & & & 4.187 & 0.010 & 0.001 \\
\hline$v-239$ & $23.54 \mathrm{~m}$ & $B-$ & $\mathrm{Np}-239$ & $1.000 E+00$ & & & & & - & 0.412 & 0.053 \\
\hline$U-240$ & $14.1 \mathrm{~h}$ & B- & $\mathrm{Np}-240 \mathrm{~m}$ & $1.000 E+00$ & & & & & - & 0.138 & 0.008 \\
\hline \multicolumn{12}{|c|}{ Neptumiue } \\
\hline $\mathrm{Np}-232$ & $14.7 m$ & $\mathrm{ECB}+$ & $\mathrm{U}-232$ & $1.000 E+00$ & & & & & - & 0.106 & 1.203 \\
\hline $\mathrm{Np}-233$ & $36.2 \mathrm{~m}$ & EC & $\mathrm{U}-233$ & $1.000 E+00$ & & & & & - & 0.014 & 0.091 \\
\hline$N p-234$ & $4.4 d$ & ECB+ & $U-234$ & $1.000 \mathrm{E}+00$ & & & & & - & 0.069 & 1.442 \\
\hline Np-235 & $386.1 d$ & ECA & $U-235$ & $9.999 E-01$ & $\mathrm{~Pa}-231$ & $1.400 \mathrm{E}-09$ & & & $<$ & 0.010 & 0.007 \\
\hline $\mathrm{Np}-236 a$ & $115 \mathrm{E} 3 \mathrm{y}$ & ECB- & $U-236$ & $9.100 \mathrm{E}-01$ & Pu-236 & 8. $900 \mathrm{E}-02$ & & & - & 0.208 & 0.136 \\
\hline $\mathrm{Np}-236 \mathrm{~b}$ & $22.5 \mathrm{~h}$ & $B-E C$ & $U-236$ & $5.200 E-01$ & Pu-236 & 4. $800 \mathrm{E}-01$ & & & - & 0.087 & 0.051 \\
\hline $\mathrm{Np}-237$ & 2.14E6y & $\mathbf{A}$ & $\mathrm{Pa}-233$ & $1.000 \mathrm{E}+00$ & & & & & 4.769 & 0.070 & 0.035 \\
\hline $\mathrm{Np}-238$ & $2.117 d$ & B- & Pu-238 & $1.000 E+00$ & & & & & - & 0.264 & 0.553 \\
\hline $\mathrm{Np}-239$ & $2.355 d$ & B- & Pu-239 & $1.000 \mathrm{E}+00$ & & & & & - & 0.260 & 0.173 \\
\hline $\mathrm{Np}-240 \mathrm{~m}$ & $7.4 \mathrm{~m}$ & B- & $\mathrm{Pu}-240$ & $1.000 \mathrm{E}+00$ & & & & & - & 0.683 & 0.337 \\
\hline $\mathrm{Np}-240$ & $65 m$ & B- & $P u-240$ & $1.000 \mathrm{E}+00$ & & & & & - & 0.528 & 1.313 \\
\hline
\end{tabular}


Iable A-1 (cont'd).

\begin{tabular}{|c|c|c|c|c|c|c|c|c|c|c|c|}
\hline \multirow[b]{2}{*}{ Nuclide } & \multirow[b]{2}{*}{$\mathbf{T}_{\mathbf{h}}$} & \multirow[b]{2}{*}{$\begin{array}{l}\text { Decay } \\
\text { Mode }\end{array}$} & \multicolumn{6}{|c|}{ Radioactive Decay Products and Fractional Yiold } & \multirow{2}{*}{\multicolumn{3}{|c|}{$\begin{array}{c}\text { Energy (MeV/nt) } \\
\text { Alpha Elec. Photon }\end{array}$}} \\
\hline & & & Nuclide & Fraction & Nuclide & Fraction & Nuclide & Fraction & & & \\
\hline \multicolumn{12}{|c|}{ Plutonion } \\
\hline$P u-234$ & $8.8 h$ & $A E C$ & $\mathrm{~Np}-234$ & 9. $400 E-01$ & $U-230$ & $6.000 E-02$ & & & 0.371 & 0.011 & 0.068 \\
\hline Pu-235 & $25.3 \mathrm{~m}$ & ECA & $N p-235$ & $1.000 E+00$ & $U-231$ & $2.700 \mathrm{E}-05$ & & & $<$ & 0.021 & 0.085 \\
\hline$P u-236$ & $2.851 y$ & SFA & $U-232$ & $1.000 \mathrm{E}+00$ & $\mathbf{S F}$ & 8. 100E-10 & & & 5.753 & 0.013 & 0.002 \\
\hline Pu-237 & $45.3 d$ & A EC & $\mathrm{Np}-237$ & $1.000 E+00$ & $U-233$ & $5.000 E-05$ & & & $<$ & 0.016 & 0.052 \\
\hline Pu-238 & $87.74 y$ & SFA & $v-234$ & $1.000 \mathrm{E}+00$ & SF & $1.840 \mathrm{E}-09$ & & & 5.487 & 0.011 & 0.002 \\
\hline Pu-239 & $24065 y$ & $A$ & $\mathrm{U}-235$ & $1.000 \mathrm{E}+00$ & & & & & 5.148 & 0.007 & $<$ \\
\hline Pu-240 & $6537 y$ & SFA & $\mathrm{U}-236$ & $1.000 E+00$ & $\mathbf{S F}$ & $4.950 E-08$ & & & 5.156 & 0.011 & 0.002 \\
\hline Pu-241 & $14.4 y$ & $A$ B- & Am-241 & $1.000 \mathrm{E}+00$ & $U-237$ & $2.450 \mathrm{E}-05$ & & & $<$ & 0.005 & $<$ \\
\hline Pu-242 & 3.763E5y & SFA & $U-238$ & $1.000 E+00$ & $\mathbf{S F}$ & $5.500 \mathrm{E}-06$ & & & 4.891 & 0.009 & 0.001 \\
\hline Pu-243 & $4.956 \mathrm{~h}$ & B- & Am-243 & $1.000 \mathrm{E}+00$ & & & & & - & 0.173 & 0.026 \\
\hline Pu-244 & B.26E7y & SFA & $U-240$ & $9.888 E-01$ & $\mathbf{S F}$ & $1.250 \mathrm{E}-03$ & & & 4.575 & 0.007 & 0.001 \\
\hline Pu-245 & $10.5 h$ & B- & Am-245 & $1.000 \mathrm{E}+00$ & & & & & - & 0.350 & 0.417 \\
\hline Pu-246 & $10.85 \mathrm{~d}$ & B- & $A m-246 m$ & $1.000 \mathrm{E}+00$ & & & & & - & 0.125 & 0.140 \\
\hline \multicolumn{12}{|c|}{ Americtum } \\
\hline$A m-237$ & $73.0 \mathrm{~m}$ & $A$ EC & Pu-237 & $9.897 E-01$ & $\mathrm{~Np}-233$ & $2.500 E-04$ & & & 0.002 & 0.077 & 0.370 \\
\hline Am-238 & $98 m$ & ECA & $P u-238$ & $1.000 \mathrm{E}+00$ & $\mathrm{~Np}-234$ & $1.000 \mathrm{E}-06$ & & & $<$ & 0.052 & 0.891 \\
\hline$A m-239$ & $11.9 \mathrm{~h}$ & $A E C$ & Pu-239 & $9.989 E-01$ & Np-235 & $1.000 E-04$ & & & $<$ & 0.168 & 0.239 \\
\hline$A m-240$ & $50.8 \mathrm{~h}$ & $A E C$ & Pu-240 & $1.000 \mathrm{E}+00$ & $\mathrm{~Np}-236 b$ & $1.800 \mathrm{E}-06$ & & & $<$ & 0.075 & 1.029 \\
\hline Am-241 & $432.2 y$ & $A$ & $N p-237$ & $1.000 \mathrm{E}+00$ & & & & & 5.478 & 0.052 & 0.033 \\
\hline$A m-242 m$ & $152 y$ & A IT & $A m-242$ & $9.850 \mathrm{E}-01$ & $N p-238$ & $4.760 E-03$ & & & 0.025 & 0.044 & 0.005 \\
\hline Am-242 & $16.02 \mathrm{~h}$ & ECB- & $\mathrm{Cm}-242$ & 8.270E-01 & $\mathrm{Pu}-242$ & $1.730 \mathrm{E}-01$ & & & - & 0.179 & 0.018 \\
\hline Am-243 & $7380 y$ & $A$ & $N p-239$ & $1.000 \mathrm{E}+00$ & & & & & 5.270 & 0.022 & 0.056 \\
\hline Am-244m & $26 m$ & B- & $C m-244$ & $1.000 E+00$ & & & & & - & 0.509 & 0.002 \\
\hline Am-244 & $10.1 \mathrm{~h}$ & B- & $C m-244$ & $1.000 E+00$ & & & & & - & 0.342 & 0.807 \\
\hline Am-245 & $2.05 \mathrm{~h}$ & B- & $C m-245$ & $1.000 \mathrm{E}+00$ & & & & & - & 0.288 & 0.032 \\
\hline$A m-246 m$ & $25.0 \mathrm{~m}$ & B- & $\mathrm{Cm}-246$ & $1.000 \mathrm{E}+00$ & & & & & - & 0.498 & 1.018 \\
\hline Am-246 & $38 m$ & B- & $c m-246$ & $1.000 E+00$ & & & & & - & 0.655 & 0.698 \\
\hline \multicolumn{12}{|l|}{ Curive } \\
\hline $\mathrm{Cm}-238$ & $2.4 \mathrm{~h}$ & ECA & $A m-238$ & $9.000 \mathrm{E}-01$ & $P u-234$ & $1.000 E-01$ & & & 0.652 & 0.010 & 0.077 \\
\hline $\mathrm{Cm}-240$ & $27 d$ & $\mathbf{A}$ & Pu-236 & $1.000 \mathrm{E}+00$ & & & & & 6.247 & 0.011 & 0.002 \\
\hline$C m-241$ & $32.8 d$ & A EC & $A m-241$ & 9.800E-01 & Pu- 237 & $1.000 E-02$ & & & 0.059 & 0.133 & 0.502 \\
\hline $\mathrm{Cm}-242$ & $162.8 d$ & SFA & Pu-238 & $1.000 \mathrm{E}+00$ & $\mathbf{S F}$ & $6.800 E-08$ & & & 6.102 & 0.010 & 0.002 \\
\hline $\mathrm{Cm}-243$ & $28.5 y$ & $A E C$ & Pu-239 & $9.980 E-01$ & Am-243 & $2.400 \mathrm{E}-03$ & & & 5.797 & 0.138 & 0.134 \\
\hline $\mathrm{Cm}-244$ & $18.11 y$ & SFA & Pu-240 & $1.000 \mathrm{E}+00$ & SF & $1.350 E-06$ & & & 5.795 & 0.009 & 0.002 \\
\hline$C m-245$ & $8500 y$ & $\mathbf{A}$ & Pu-241 & $1.000 \mathrm{E}+00$ & & & & & 5.363 & 0.065 & 0.096 \\
\hline$C m-246$ & $4730 y$ & SFA & Pu-242 & $9.897 \mathrm{E}-01$ & $\mathbf{S F}$ & $2.614 E-04$ & & & 5.376 & 0.008 & 0.002 \\
\hline $\mathrm{Cm}-247$ & $1.56 \mathrm{E} 7 \mathrm{y}$ & $A$ & $P u-243$ & $1.000 \mathrm{E}+00$ & & & & & 4.949 & 0.021 & 0.316 \\
\hline $\mathrm{Cm}-248$ & $3.3955 y$ & SFA & Pu-244 & $9.174 E-01$ & $\mathbf{S F}$ & $8.260 \mathrm{E}-02$ & & & 4.651 & 0.006 & 0.001 \\
\hline $\mathrm{Cm}-24 \mathrm{~g}$ & $64.15 \mathrm{~m}$ & B- & $B k-248$ & $1.000 E+00$ & & & & & - & 0.284 & 0.019 \\
\hline $\begin{array}{l}\text { Cm-250 } \\
\text { Bertellu }\end{array}$ & $6900 y$ & SFA B- & $\mathbf{S F}$ & $6.100 \mathrm{E}-01$ & Pu-246 & $2.500 E-01$ & $B k-250$ & $1.400 E-01$ & 1.296 & 0.002 & - \\
\hline$B k-245$ & $4.94 d$ & $A E C$ & $C m-245$ & $9.990 \mathrm{E}-01$ & $A m-241$ & $1.200 \mathrm{E}-03$ & & & 0.007 & 0.133 & 0.234 \\
\hline Bk-246 & $1.83 \mathrm{~d}$ & EC & $\mathrm{Cm}-246$ & $1.000 E+00$ & & & & & - & 0.054 & 0.851 \\
\hline$B k-247$ & $1380 y$ & A & $A m-243$ & $1.000 \mathrm{E}+00$ & & & & & 5.610 & 0.061 & 0.105 \\
\hline$B k-249$ & $320 \mathrm{~d}$ & SFB-A & $C f-249$ & $1.000 E+00$ & $A m-245$ & $1.450 \mathrm{E}-05$ & SF & $4.700 E-10$ & $<$ & 0.033 & $<$ \\
\hline$B k-250$ & $3.222 \mathrm{~h}$ & B- & $C f-250$ & $1.000 E+00$ & & & & & - & 0.293 & 0.887 \\
\hline \multicolumn{12}{|c|}{ Californiom } \\
\hline$C f-244$ & $19.4 \mathrm{~m}$ & $A$ & $\mathrm{Cm}-240$ & $1.000 E+00$ & & & & & 7.200 & 0.009 & 0.002 \\
\hline$C f-246$ & $35.7 \mathrm{~h}$ & SFA & $\mathrm{Cm}-242$ & $9.997 E-01$ & $\mathbf{S F}$ & $2.000 E-06$ & & & 6.747 & 0.006 & 0.001 \\
\hline$C f-248$ & $333.5 d$ & SFA & $\mathrm{Cm}-244$ & $1.000 E+00$ & $\mathbf{S F}$ & $2.900 \mathrm{E}-05$ & & & 6.253 & 0.006 & 0.001 \\
\hline$C f-249$ & $350.6 y$ & A SF & $\mathrm{Cm}-245$ & $1.000 E+00$ & $\mathbf{S F}$ & $5.200 E-09$ & & & 5.831 & 0.044 & 0.335 \\
\hline$C f-250$ & $13.08 y$ & SEA & $\mathrm{Cm}-246$ & $9.992 E-01$ & $\mathbf{S F}$ & $7.700 \mathrm{E}-04$ & & & 6.019 & 0.006 & 0.001 \\
\hline Cf-251 & $898 y$ & $A$ & $C m-247$ & $1.000 E+00$ & & & & & 5.784 & 0.198 & 0.132 \\
\hline$C f-252$ & $2.638 y$ & SFA & $\mathrm{Cm}-248$ & $9.691 E-01$ & SF & $3.092 E-02$ & & & 5.922 & 0.006 & 0.001 \\
\hline$C f-253$ & $17.81 d$ & $B-A$ & Es-253 & $9.869 E-01$ & $C m-249$ & $3.100 E-03$ & & & 0.018 & 0.079 & $<$ \\
\hline$C f-254$ & $60.5 d$ & SFA & SF & $9.969 E-01$ & $\mathrm{Cm}-250$ & $3.100 E-03$ & & & 0.018 & $<$ & $<$ \\
\hline \multicolumn{12}{|c|}{ Einsteinium } \\
\hline$E_{s}-250$ & $2.1 \mathrm{~h}$ & EC & $C f-250$ & $1.000 E+00$ & & & & & - & 0.022 & 0.397 \\
\hline Es-251 & $33 \mathrm{~h}$ & ECA & Cf-251 & $9.950 E-01$ & $B k-247$ & $5.000 E-03$ & & & 0.032 & 0.052 & 0.088 \\
\hline Es-253 & $20.47 d$ & SFA & $B k-249$ & $1.000 E+00$ & $\mathbf{S F}$ & 8. 700E-08 & & & 6.628 & 0.004 & 0.001 \\
\hline$E_{8}-254 m$ & $39.3 \mathrm{~h}$ & A B- & Fm-254 & $9.800 E-01$ & $B k-250$ & $3.200 \mathrm{E}-03$ & & & 0.020 & 0.256 & 0.470 \\
\hline$E_{8}-254$ & $275.7 d$ & A & $B k-250$ & $1.000 \mathrm{E}+00$ & & & & & 6.423 & 0.071 & 0.019 \\
\hline
\end{tabular}


Iable A-1 (cont'd).

\begin{tabular}{|c|c|c|c|c|c|c|c|c|c|c|c|}
\hline \multirow[b]{2}{*}{ Nuclide } & \multirow[b]{2}{*}{$T_{\mathbf{w}}$} & \multirow[b]{2}{*}{$\begin{array}{l}\text { Decay } \\
\text { Mode }\end{array}$} & \multicolumn{6}{|c|}{ Radioactive Decay Products and Fractional Yield } & \\
\hline & & & Nuclide & Fraction & Nuclide & Fraction & Nuclide & Fraction & $\begin{array}{l}\text { Ener } \\
\text { Alphe }\end{array}$ & $\begin{array}{l}\text { rgy (Me } \\
\text { Elec. }\end{array}$ & $\begin{array}{l}V / n t) \\
\text { Photon }\end{array}$ \\
\hline \multicolumn{12}{|l|}{ Permium } \\
\hline $\mathrm{Fm-252}$ & $22.7 \mathrm{~h}$ & $A$ & $C f-248$ & $1.000 E+00$ & & & & & 7.034 & 0.005 & 0.001 \\
\hline Fm-253 & $3.00 \mathrm{~d}$ & ECA & $E s-253$ & $8.800 \mathrm{E}-01$ & $C f-249$ & $1.200 E-01$ & & & 0.822 & 0.022 & 0.083 \\
\hline $5 m-254$ & $3.240 \mathrm{~h}$ & $A$ & CI-250 & $1.000 E+00$ & & & & & 7.182 & 0.006 & 0.001 \\
\hline Fm-25s & $20.07 \mathrm{~h}$ & $\mathbf{A}$ & $c f-251$ & $1.000 \mathrm{E}+00$ & & & & & 7.019 & 0.098 & 0.014 \\
\hline $5 m-257$ & $100.5 d$ & $\mathbf{A}$ & Cf -253 & $1.000 E+00$ & & & & & 6.511 & 0.121 & 0.111 \\
\hline \multicolumn{12}{|c|}{ Mendelevium } \\
\hline$M d-257$ & $5.2 \mathrm{~h}$ & A EC & Pm-257 & $9.000 \mathrm{E}-01$ & Es-253 & $1.000 \mathrm{E}-01$ & & & 0.707 & 0.015 & 0.114 \\
\hline$M d-258$ & $55 d$ & $\mathbf{A}$ & Es-254 & $1.000 \mathrm{E}+00$ & & & & & 7.232 & 0.047 & 0.006 \\
\hline
\end{tabular}


Iable A-2. Sumary Information on the Huclear Iremeformation of the Radionuclides in Mrrob Collection.

\begin{tabular}{|c|c|c|c|c|c|c|c|c|c|c|c|}
\hline \multirow[b]{2}{*}{ Nuclide } & \multirow[b]{2}{*}{$T_{h}$} & \multirow[b]{2}{*}{$\begin{array}{l}\text { Decay } \\
\text { Mode }\end{array}$} & \multicolumn{6}{|c|}{ Radioactive Decay Products and Fractional Yield } & \multirow{2}{*}{\multicolumn{3}{|c|}{ Energy (MoV/nt) }} \\
\hline & & & Nuclide & Fraction & Nuolide & Fraction & Nuclide & Fraction & & & \\
\hline \multicolumn{12}{|l|}{ Bydrogen } \\
\hline $\begin{array}{l}\text { B-3 } \\
\text { Bers L11u. }\end{array}$ & $12.33 y$ & B- & & & & & & & - & 0.006 & - \\
\hline $\begin{array}{l}\text { Be-7 } \\
\text { Carbon }\end{array}$ & $53.29 d$ & EC & & & & & & & - & $<$ & 0.050 \\
\hline$c-11$ & $20.385 \mathrm{~m}$ & $\mathrm{ECB}+$ & & & & & & & - & 0.385 & 1.020 \\
\hline$C-14$ & $5730 y$ & B- & & & & & & & - & 0.048 & - \\
\hline \multicolumn{12}{|l|}{ Mitrogen } \\
\hline \multicolumn{2}{|l|}{ Oxysen } & & & & & & & & - & 0.491 & 1.020 \\
\hline $0-14$ & 70.5998 & $\mathbf{E C B}+$ & & & & & & & - & 0.777 & 3.319 \\
\hline $0-15$ & 122.248 & ECB+ & & & & & & & - & 0.734 & 1.021 \\
\hline \multicolumn{11}{|l|}{ Fluorine } & 0.957 \\
\hline$F-18$ & $108.77 \mathrm{~m}$ & $\mathrm{ECB}+$ & & & & & & & - & 0.250 & 1.022 \\
\hline \multicolumn{12}{|l|}{ Inos } \\
\hline $\begin{array}{l}\text { Ne-19 } \\
\text { Sodtu }\end{array}$ & $17.22 \mathrm{~s}$ & $\mathbf{E C B}+$ & & & & & & & - & 0.863 & 1.022 \\
\hline $\mathrm{Ha}-22$ & $2.602 y$ & $\mathrm{ECB}+$ & & & & & & & - & 0.194 & 2.193 \\
\hline Ma-24 & $15.020 \mathrm{~h}$ & B- & & & & & & & - & 0.554 & 4.123 \\
\hline $\begin{array}{l}\text { M8-28 } \\
\text { Aluiniu }\end{array}$ & $20.91 \mathrm{~h}$ & B- & $A l-2 B$ & $1.000 \mathrm{E}+00$ & & & & & - & 0.163 & 1.371 \\
\hline $\begin{array}{l}\text { Al-28 } \\
\text { Fhosphorus }\end{array}$ & $2.240 \mathrm{~m}$ & B- & & & & & & & - & 1.242 & 1.778 \\
\hline$P-30$ & $2.498 \mathrm{~m}$ & $\mathrm{ECB}+$ & & & & & & & - & 1.436 & 1.022 \\
\hline P-32 & $14.26 \mathrm{~d}$ & B- & & & & & & & - & 0.695 & - \\
\hline \multirow{2}{*}{\multicolumn{12}{|c|}{ Sulfur }} \\
\hline & & & & & & & & & & & \\
\hline $\begin{array}{l}\text { S-35 } \\
\text { Chlorine }\end{array}$ & 87.44d & B- & & & & & & & - & 0.048 & - \\
\hline \multicolumn{12}{|l|}{ Argon } \\
\hline$A r-37$ & $35.02 d$ & EC & & & & & & & - & 0.002 & $<$ \\
\hline \multicolumn{12}{|l|}{ Potanailu } \\
\hline$k-38$ & $7.636 \mathrm{~m}$ & ECB+ & & & & & & & - & 1.209 & 3.187 \\
\hline$k-40$ & $1.28 \mathrm{Egy}$ & $B-E C$ & & & & & & & - & 0.523 & 0.156 \\
\hline$x-42$ & $12.36 \mathrm{~h}$ & B- & & & & & & & - & 1.430 & 0.276 \\
\hline $\begin{array}{l}K-43 \\
\text { Calciue }\end{array}$ & $22.6 \mathrm{~h}$ & B- & & & & & & & - & 0.309 & 0.870 \\
\hline $\mathrm{Ca}-45$ & $163.8 d$ & B- & & & & & & & - & 0.077 & $<$ \\
\hline$C a-47$ & $4.536 d$ & B- & Sc -47 & $1.000 \mathrm{E}+00$ & & & & & - & 0.351 & 1.047 \\
\hline $\begin{array}{l}C a-4 \theta \\
\text { Scenditu }\end{array}$ & $8.715 \mathrm{~m}$ & B- & $\mathrm{Sc}-49$ & $1.000 \mathrm{E}+00$ & & & & & - & 0.870 & 3.168 \\
\hline Sc-46 & $83.83 d$ & B- & & & & & & & - & 0.112 & 2.008 \\
\hline Sc -47 & $3.345 \mathrm{~d}$ & B- & & & & & & & - & 0.163 & 0.108 \\
\hline $\begin{array}{l}\text { Sc-49 } \\
\text { Venadilum }\end{array}$ & $57.2 \mathrm{~m}$ & B- & & & & & & & - & 0.818 & 0.002 \\
\hline $\begin{array}{l}\text { V-48 } \\
\text { Chromilum }\end{array}$ & $15.974 d$ & $\mathrm{ECB}+$ & & & & & & & - & 0.148 & 2.913 \\
\hline $\begin{array}{l}C r-48 \\
C r-51\end{array}$ & $\begin{array}{r}21.56 \mathrm{~h} \\
27.704 \mathrm{~d}\end{array}$ & $\begin{array}{l}\text { ECB }+ \\
\text { EC }\end{array}$ & $v-48$ & $1.000 E+00$ & & & & & - & $\begin{array}{l}0.009 \\
0.004\end{array}$ & $\begin{array}{l}0.432 \\
0.033\end{array}$ \\
\hline \multicolumn{12}{|c|}{ Mengemone } \\
\hline$m-51$ & $46.2 \mathrm{~m}$ & ECB+ & $C x-51$ & $1.000 E+00$ & & & & & - & 0.835 & 0.898 \\
\hline $\operatorname{mn}-52$ & $5.591 d$ & ECB+ & & & & & & & - & 0.075 & 3.458 \\
\hline$m-52 m$ & $21.1 \mathrm{~m}$ & $E C B+I T$ & $M n-52$ & $1.750 \mathrm{E}-02$ & & & & & - & 1.133 & 2.410 \\
\hline $\begin{array}{l}\text { Mn-54 } \\
\text { Iron }\end{array}$ & $312.5 d$ & EC & & & & & & & - & 0.004 & 0.836 \\
\hline Fo-52 & $8.275 \mathrm{~h}$ & ECB+ & $M n-52 m$ & $1.000 \mathrm{E}+00$ & & & & & - & 0.194 & 0.740 \\
\hline Fe-55 & $2.73 y$ & EC & & & & & & & - & 0.004 & 0.002 \\
\hline$F=-59$ & $44.496 d$ & B- & & & & & & & - & 0.118 & 1.188 \\
\hline
\end{tabular}


Iable $A-2$ (cont'd).

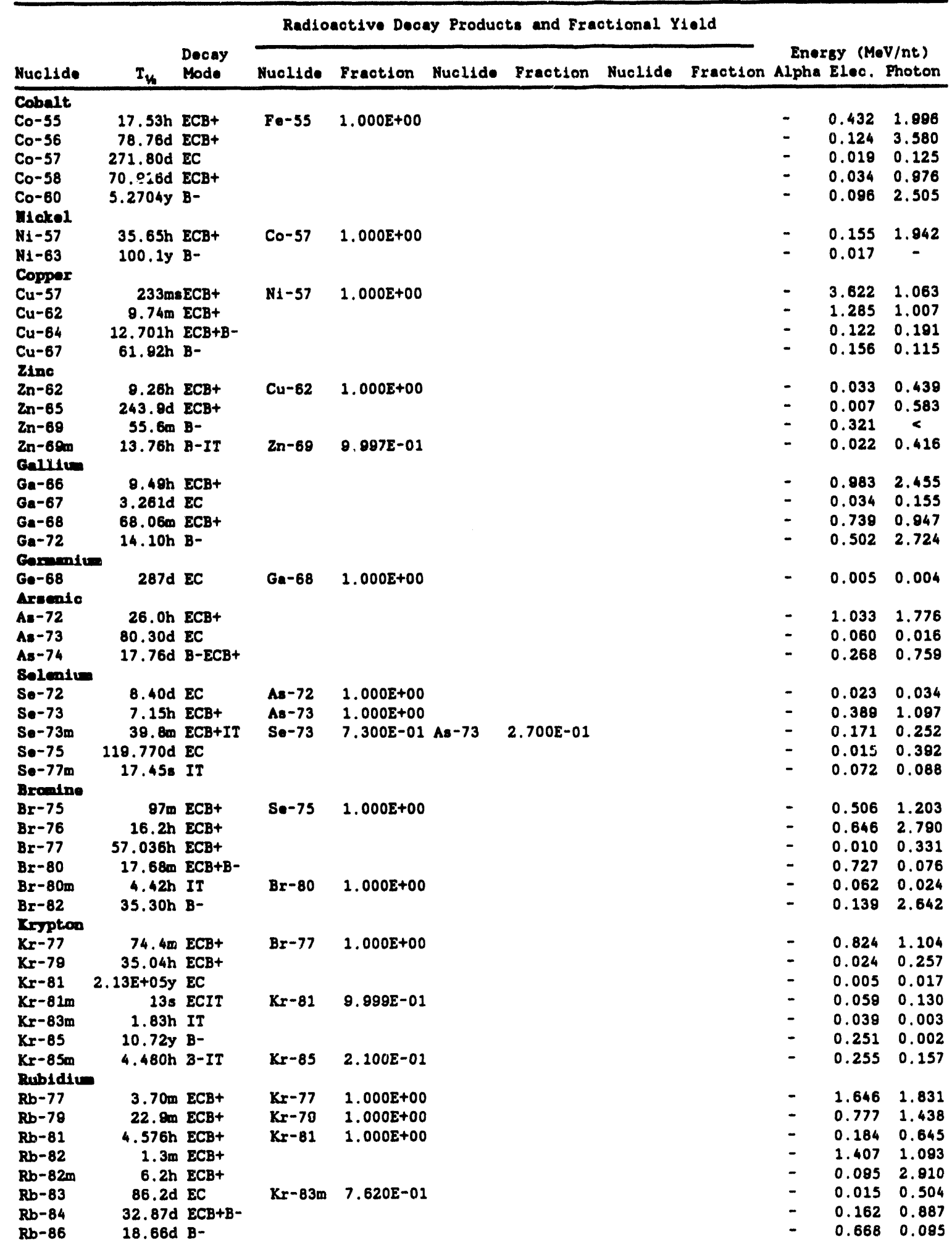


Table A-2 (oont'd).

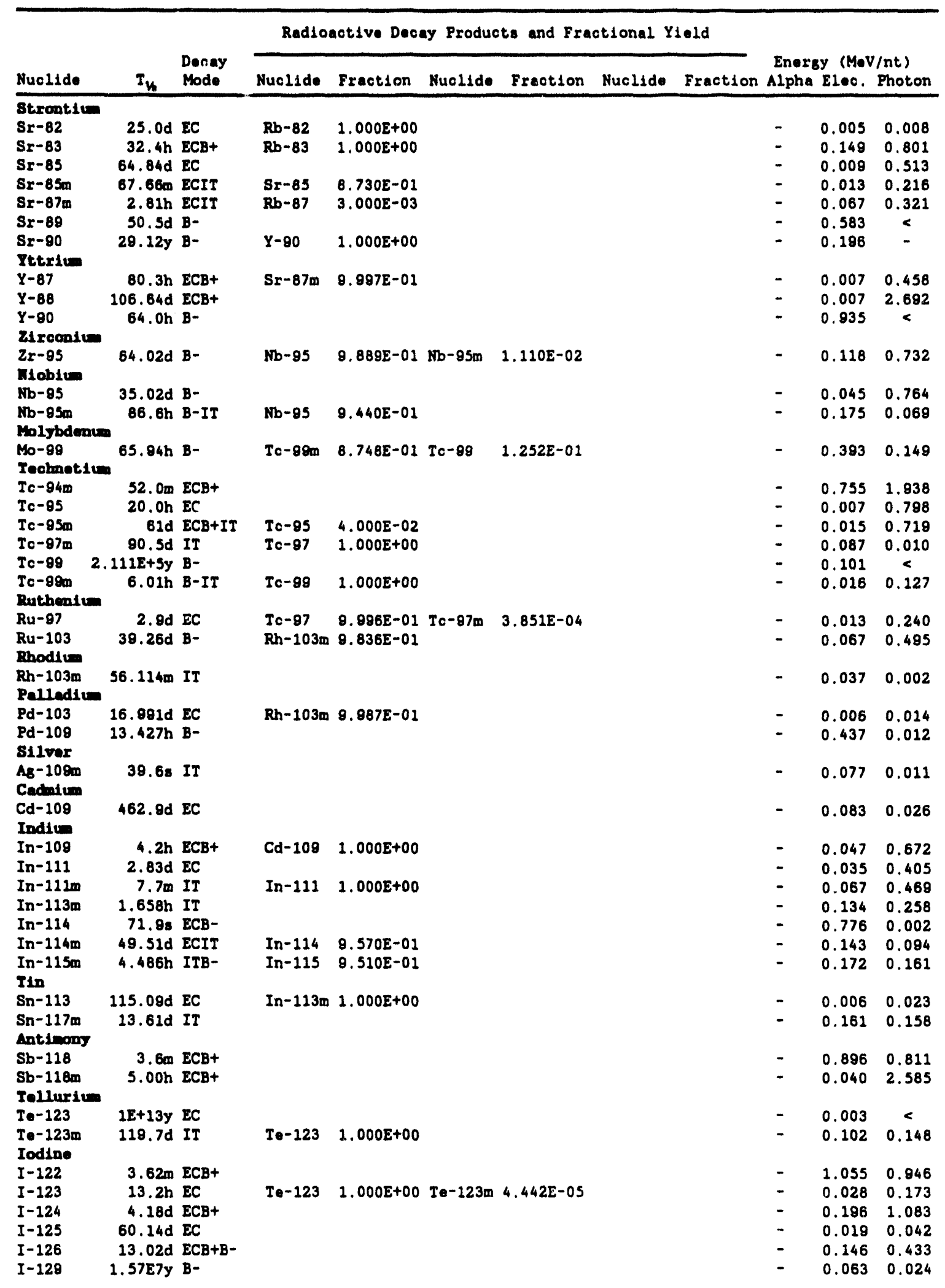


Table $\Delta-2$ (cont'd).

\begin{tabular}{|c|c|c|c|c|c|c|c|c|c|c|}
\hline \multirow[b]{2}{*}{ Nuclide } & \multirow[b]{2}{*}{$\mathbf{T}_{\mathbf{n}}$} & \multirow[b]{2}{*}{$\begin{array}{l}\text { Deoay } \\
\text { Mode }\end{array}$} & \multicolumn{5}{|c|}{ Radioactive Decay Products and Fractional Yiold } & \multirow{2}{*}{\multicolumn{3}{|c|}{$\begin{array}{l}\text { Energy (MoV/nt) } \\
\text { Alphe Eloc. Photon }\end{array}$}} \\
\hline & & & Nuclide & Fraction & Fraction & Nuolide & Fraction & & & \\
\hline \multicolumn{11}{|c|}{ Iodine, cont'd } \\
\hline$I-130$ & $12.36 \mathrm{~h}$ & B- & & & & & & - & 0.287 & 2.138 \\
\hline$I-131$ & 8.04d & B- & $x_{0}-131 \mathrm{~m}$ & $1.110 \mathrm{E}-02$ & & & & - & 0.192 & 0.382 \\
\hline$I-132$ & $2.30 \mathrm{~h}$ & B- & & & & & & - & 0.485 & 2.280 \\
\hline$I-132 m$ & $83.6 \mathrm{~m}$ & ITB- & $I-132$ & $8.600 \mathrm{E}-01$ & & & & - & 0.156 & 0.321 \\
\hline$I-133$ & $20.8 \mathrm{~h}$ & B- & $x \cdot-133$ & $9.710 E-01$ Xe-133m & $2.900 E-02$ & & & - & 0.411 & 0.607 \\
\hline \multicolumn{11}{|c|}{ 然 } \\
\hline$x_{e-122}$ & $20.1 \mathrm{~h}$ & EC & $I-122$ & $1.000 \mathrm{E}+00$ & & & & - & 0.010 & 0.068 \\
\hline$x=-123$ & $2.08 \mathrm{~h}$ & $\mathrm{ECB}+$ & $I-123$ & $1.000 \mathrm{E}+00$ & & & & - & 0.188 & 0.641 \\
\hline$x=-127$ & $36.4 d$ & EC & & & & & & - & 0.032 & 0.280 \\
\hline$x 0-1280$ & $8.89 \mathrm{~d}$ & IT & & & & & & - & 0.185 & 0.051 \\
\hline$x_{0}-1310$ & $11.9 \mathrm{~d}$ & IT & & & & & & - & 0.144 & 0.020 \\
\hline$x--133$ & $5.245 d$ & B- & & & & & & - & 0.136 & 0.046 \\
\hline \multicolumn{11}{|l|}{ Coniu } \\
\hline$C=-128$ & $3.62 \mathrm{~m}$ & $\mathrm{ECB}+$ & & & & & & - & 0.870 & 0.890 \\
\hline$C=-129$ & $32.06 \mathrm{~h}$ & EC & & & & & & - & 0.018 & 0.281 \\
\hline$C=-130$ & 29.00 & $\mathrm{ECB}+$ & & & & & & - & 0.401 & 0.517 \\
\hline$C=-131$ & $9.69 d$ & $\mathrm{EC}$ & & & & & & - & 0.007 & 0.023 \\
\hline$C s-132$ & $6.475 d$ & $E C B+B-$ & & & & & & - & 0.014 & 0.705 \\
\hline$C s-134$ & $2.062 y$ & ECB- & & & & & & - & 0.164 & 1.555 \\
\hline$C s-134 m$ & $2.91 \mathrm{~h}$ & $I T$ & $C=-134$ & $1.000 \mathrm{E}+00$ & & & & - & 0.112 & 0.027 \\
\hline \multicolumn{11}{|l|}{ Bariv } \\
\hline$B a-128$ & $2.43 d$ & $\mathrm{EC}$ & C8-128 & $1.000 \mathrm{E}+00$ & & & & - & 0.009 & 0.066 \\
\hline $\mathrm{Ba}-131 \mathrm{~m}$ & $14.6 \mathrm{~m}$ & $\mathrm{IT}$ & $B a-132$ & $1.000 \mathrm{E}+100$ & & & & - & 0.108 & 0.077 \\
\hline $\mathrm{Ba}-133$ & $10.74 y$ & $\mathbf{E C}$ & & & & & & - & 0.054 & 0.402 \\
\hline Ba-135m & $28.7 \mathrm{~h}$ & IT & & & & & & - & 0.208 & 0.060 \\
\hline \multicolumn{11}{|l|}{$\begin{array}{l}\text { Ba-137m } \\
\text { Lenthemil }\end{array}$} \\
\hline$L a-134$ & $6.45 \mathrm{~m}$ & ECB+ & & & & & & - & 0.759 & 0.716 \\
\hline $\begin{array}{l}\text { La-140 } \\
\text { Coriug }\end{array}$ & $40.272 \mathrm{~h}$ & $\mathrm{~B}-$ & & & & & & - & 0.535 & 2.316 \\
\hline Co-134 & $75.9 \mathrm{~h}$ & EC & Le -134 & $1.0008+00$ & & & & - & 0.008 & 0.028 \\
\hline$C \theta-138$ & $137.66 \mathrm{~d}$ & $\mathrm{EC}$ & & & & & & - & 0.036 & 0.159 \\
\hline$C e-141$ & $32.50 \mathrm{~d}$ & B- & & & & & & - & 0.171 & 0.077 \\
\hline \multicolumn{11}{|c|}{ Promothiu } \\
\hline$P m-145$ & $17.7 y$ & EC & & & & & & - & 0.013 & 0.031 \\
\hline$P m-147$ & $2.6234 y$ & $\mathrm{~B}-$ & $5 m-147$ & $1.000 E+00$ & & & & - & 0.062 & $<$ \\
\hline \multicolumn{11}{|l|}{ Semariue } \\
\hline $5 m-145$ & $340 d$ & $\mathrm{EC}$ & Pm-145 & $1.000 E+00$ & & & & - & 0.031 & 0.064 \\
\hline Sm-153 & $46.7 \mathrm{~h}$ & $B-$ & & & & & & - & 0.270 & 0.062 \\
\hline \multicolumn{11}{|l|}{ Europiu } \\
\hline Eu-154 & $8.8 y$ & ECB- & & & & & & - & 0.292 & 1.242 \\
\hline \multicolumn{11}{|c|}{ Gadolintu } \\
\hline Gd-153 & $241.6 \mathrm{~d}$ & $\mathrm{EC}$ & & & & & & - & 0.042 & 0.101 \\
\hline Dyaprosiu & - & & & & & & & & & \\
\hline Dy-157 & $8.1 \mathrm{~h}$ & EC & $T b-157$ & $1.000 E+00$ & & & & - & 0.014 & 0.341 \\
\hline Dy -158 & $144.4 d$ & EC & & & & & & - & 0.013 & 0.045 \\
\hline Dy-165 & $2.334 \mathrm{~h}$ & B- & & & & & & - & 0.448 & 0.026 \\
\hline Exblum & & & & & & & & & & \\
\hline Er-165 & $10.36 \mathrm{~h}$ & EC & & & & & & - & 0.008 & 0.038 \\
\hline Er-167m & $2.28 \mathrm{~s}$ & IT & & & & & & - & 0.111 & 0.097 \\
\hline Er-171 & $7.52 \mathrm{~h}$ & $B-$ & $T m-171$ & $1.000 \mathrm{E}+00$ & & & & - & 0.420 & 0.373 \\
\hline Thultio & & & & & & & & & & \\
\hline $\operatorname{Tm}-167$ & $9.24 d$ & $\mathbf{E C}$ & & & & & & - & 0.128 & 0.146 \\
\hline $\operatorname{Tm}-170$ & $128.6 d$ & 1 ECB- & & & & & & - & 0.331 & 0.005 \\
\hline$T m-171$ & $1.92 y$ & $8-$ & & & & & & - & 0.026 & $<$ \\
\hline Itterbiu & & & & & & & & & & \\
\hline$Y \mathrm{~b}-169$ & $32.022 d$ & EC & & & & & & - & 0.123 & 0.311 \\
\hline $\begin{array}{l}\text { Tentalua } \\
\text { Ta-177 }\end{array}$ & $56.6 \mathrm{~h}$ & EC & & & & & & - & 0.024 & 0.067 \\
\hline
\end{tabular}


Iable A-2 (ooat'd).

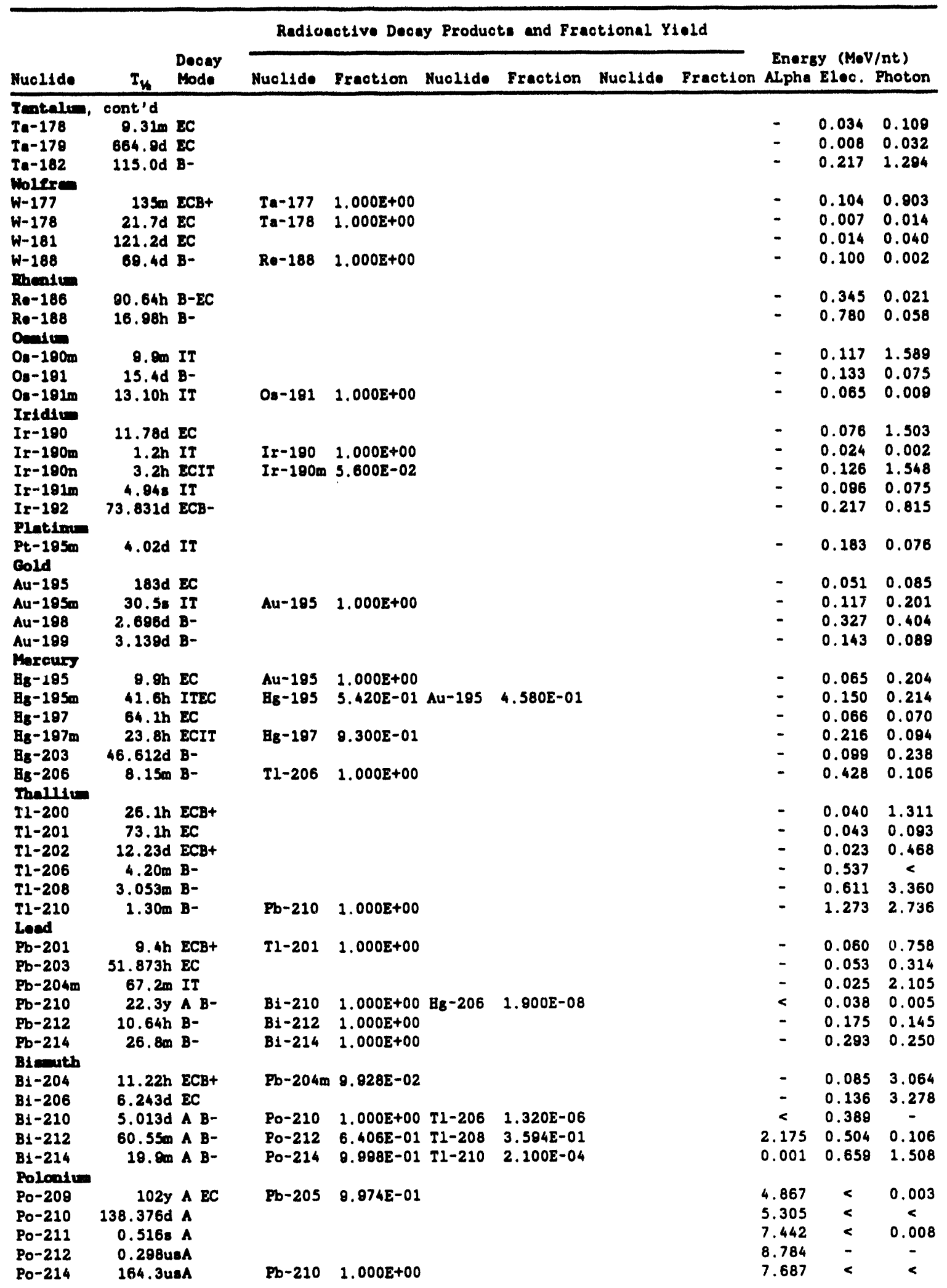


Iable A-2 (oont'd).

\begin{tabular}{|c|c|c|c|c|c|c|c|c|c|c|c|}
\hline \multirow[b]{2}{*}{ Nuclide } & \multirow[b]{2}{*}{$I_{\boldsymbol{n}}$} & \multirow[b]{2}{*}{$\begin{array}{l}\text { Decay } \\
\text { Mode }\end{array}$} & \multicolumn{6}{|c|}{ Radioactive Decay Produots and Fractional Yield } & \\
\hline & & & Nuclide & Fraction & Nuclide & Fraction & Nuclide & Fraction & $\begin{array}{l}\text { Ener } \\
\text { Alpha }\end{array}$ & $\begin{array}{l}8 y \text { (MeV } \\
\text { Elec. }\end{array}$ & $\begin{array}{l}\text { (nt) } \\
\text { Ehoton }\end{array}$ \\
\hline $\begin{array}{l}\text { Polonite } \\
\text { Po-216 } \\
\text { Po-218 } \\
\text { Antatine }\end{array}$ & $\begin{array}{c}\text { cont'd } \\
0.1458 \\
3.05 \mathrm{~s}\end{array}$ & $A B-$ & $\begin{array}{l}F b-212 \\
F b-214\end{array}$ & $\begin{array}{l}1.000 E+00 \\
9.998 E-01\end{array}$ & $A t-218$ & $2.000 E-04$ & & & $\begin{array}{l}6.778 \\
6.001\end{array}$ & - & - \\
\hline $\begin{array}{l}A t-211 \\
A t-218 \\
\text { Indoa }\end{array}$ & $\begin{array}{r}7.214 h \\
2 s\end{array}$ & $\hat{A}^{A C C}$ & $\begin{array}{l}P 0-211 \\
B 1-214\end{array}$ & $\begin{array}{l}5.830 E-01 \\
9.990 E-01\end{array}$ & $B 1-207$ & $4.170 E-01$ & & & $\begin{array}{l}2.446 \\
6.897\end{array}$ & $\begin{array}{l}0.006 \\
0.040\end{array}$ & $\begin{array}{l}0.038 \\
0.007\end{array}$ \\
\hline$R n-220$ & $55.6 \mathrm{~s}$ & $A$ & Po-216 & $1.000 \mathrm{E}+00$ & & & & & 6.288 & $<$ & $<$ \\
\hline $\begin{array}{l}\text { Rn-222 } \\
\text { Indive }\end{array}$ & $3.8235 d$ & $\mathbf{A}$ & Po-218 & $1.000 E+00$ & & & & & 5.488 & $<$ & $<$ \\
\hline $\begin{array}{l}R a-224 \\
R a-226\end{array}$ & $\begin{array}{l}3.66 \mathrm{~d} \\
1600 \mathrm{y}\end{array}$ & $\hat{A}$ & $\begin{array}{l}R n-220 \\
R n-222\end{array}$ & $\begin{array}{l}1.000 \mathrm{E}+00 \\
1.000 \mathrm{E}+00\end{array}$ & & & & & $\begin{array}{l}5.674 \\
4.774\end{array}$ & $\begin{array}{l}0.002 \\
0.004\end{array}$ & $\begin{array}{l}0.010 \\
0.007\end{array}$ \\
\hline Am-241 & $432.2 y$ & $\mathbf{A}$ & Np-237 & $1.000 \mathrm{E}+00$ & & & & & 5.478 & 0.059 & 0.034 \\
\hline $\begin{array}{l}\text { Callfornd } \\
\text { Ce-252 }\end{array}$ & $2.638 \mathrm{y}$ & SFA & $C m-248$ & $9.681 \Sigma-01$ & $\mathbf{S F}$ & $3.092 \mathrm{E}-02$ & & & 5.922 & 0.006 & 0.001 \\
\hline
\end{tabular}




\section{INTERNAL DISTRIBUTION}

1. B. A. Berven

2. J. S. Bogard

3. E. M. Brackett

4-8. M. Cristy

9-12. K. F. Eckerman

13. C. E. Easterly

14. G. D. Kerr

15. D. C. Kocher

16. R. W. Leggett

17. D. A. McLaughlin

18. G. L. Murphy

19. R. R. Rawl

20. D. E. Reichle

21. P. S. Rohwer

22. J. C. Ryman

23. A. L. Sjoreen

24. R. E. Swaja

25. C. C. Travis

26. J. E. Turner

27. R. C. Ward

28. Central Research Library

29. ORNL Y-12 Research Library

Document Reference Section

30. Laboratory Records Department

31. Laboratory Records, ORNL (RC)

32. ORNL Patent Office

\section{EXTERNAL DISTRIBUTION}

33. Assistant Manager of Energy Research and Development, U. S. Department of Energy, Oak Ridge Operations Office, P. O. Box 2001, Oak Ridge, TN 37831-8600

34. S. J. Adelstein, Harvard Medical School, 25 Shattuck Street, Boston MA 02115

35. M. R. Bailey, Head, Dose Assessments Department, NRPB, Chilton, Didcot, Oxfordshire, OX11, ORQ, United Kingdom

36. V. Berkovski, Ukraine Scientific Centre for Radiological Medicine 53, Melnikova Street, 252050, Kiev, Ukraine

37. L. Bertelli, Environmental Radiation \& Toxicology Laboratory, School of Medicine, 1771 So., 900 W., Suite 10, Salt Lake City, Utah 84104

38. A. Birchall, NRPB, Chilton, Didcot, Oxon, OX11, ORQ, United Kingdom 
39. B. B. Boecker, Inhalation Toxicology Research Institute, Lovelace Biomedical and Environmental Research Institute, P. O. Box 5890, Albuquerque, NM 87185

40. L. Bologna, ENEA-DISP, Direzione Centrale Sicurezza, Nucleare E. Protezione Sanitaria, Via V. Brancati 48, 00144 Roma, Italy

41. A. Bouville, National Cancer Institute, Radiaiion Effects Branch, Executive Plaza North, Suite 530, Bethesda, MD 20892

42. R. S. Caswell, U. S. Department of Commerce, NIST, Bldg. 245/C-229, Gaithersburg, MD 20899

43. R. Chatterjee, Atomic Energy Control, P. O. Box 1046, 270 Albert Street, Ottawa, Ontario K1P 5S9, Canada

44. D. Cool, Radiation Protection and Health Effects Branch, U. S. Nuclear Regulatory Commission, MS NLS-130, Washington, DC 20555

45. F. T. Cross, Battelle Pacific Northwest Laboratories, P. O. Box 999, K4-13, Richland, WA 99352

46. L. T. Dillman, 184 W. Lincoln Ave., Delaware, OH 43015

47. K. Ennow, Naticnal Board of Health, National Institute for Radiation Hygiene, Frederikssundsvej 378, DK-2700 Bronshoj, Denmark

48. D. Fisher, Battelle Pacific Northwest Laboratory, P. O. Box 999, K3-53, Richland WA 99352

49. F. A. Fry, National Radiological Protection Board, Chilton, Didcot, Oxon, OX11, ORQ, United Kingdom

50. R. Guilmette, Inhalation \& Toxicology Research Institute, Lovelace Biomedical \& Environmental Research Institute, P. O. Box 5890, Albuquerque, NM-87185

51. J. D. Harrison, National Radiological Protection Board, Chilton, Didcot, Oxon, OX11 ORQ, United Kingdom

52. K. Henrichs, Siemens, 2PL1 VWS3, D-81730 München, Germany

53. J. S. Hughes, National Radiological Protection Board, Chilton, Didcot, Oxon, OX11, ORQ, United Kingdom

54. L. A. Ilyin, Institute of Biophysics, Ministry of Health, Zhivopisnaya ul. 46, 123182 Moscow, Russia

55. J. Inaba, National Institute of Radiological Sciences, 9-1 Anagawa-4-Chome, Chiba-shi, 260, Japan

56. A. C. James, Pacific Northwest Laboratory, P. O. Box 999, Richland WA 99352 
57. H. Kawamura, Laboratory for Radioecology National Institute of Radiological Sciences, 3609 Isozaki, Nakaminato-shi, Ibaraki, 311-12, Japan

58. A. Kaul, Bundesamt für Strahlenschutz, Albert-Schweitzer Strasse 18, D-3320 Salzgitter 1, Germany

59. G. M. Kendall, National Radiological Protection Board, Chilton, Didcot, Oxon OX11 ORQ, United Kingdom

60. L. Koblinger, KFKI Atomic Energy Research Institute, P. O. Box 49, H-152 ? Hungary

61. K. A. Lathrop, Hospital Box 433, University of Chicago Medical Center, 5841 S. Maryland Avenue, Chicago, IL 60637

62. I. A. Likhtarev, Ukraine Scientific Centre for Radiation Medicine, Melnikova Street 53, 252050 Kiev-50, Ukraine

63. J. Liniecki, Department of Nuclear Medicine, Medical Academy of Lodz, Czechoslowacka 8/10, 92-216 Lodz, Poland

64. S. Mattsson, Department of Radiation Physics, Malmo General Hospital, S-21401 Malmo, Sweden

65. C. B. Meinhold, Chief, Safety and Environmental Protection Division, Bldg. 525A Brookhaven National Laboratory, Upton NY 11973

66. H. Menzel, DGXII, Commission of the Europea nmunities, Joint Research Centre, Rue de la Loi 200, B-1049 Brussels, Belgium

67. H. Metivier, CEA/ISPN, Direction des Rachercik... in Securite Nucleaire, BP No. 6-92265 Fontenay-aux-Roses, France

68. F. Mettler, Department of Radiology, The School of Medicine, University of New Mexico, Albuquerque, NM 87131

69. N. Mocanu, Str. Giuseppe Garibaldi, Nr. 4, Sc.D., Ap. 50, Sect. 2, 71441 Bucharest, Romania

70. T. Nakano, National Institute of Radiological Sciences, 4-9-1, Anagawa, Inage-ku, Chiba-shi, 263, Japan

71. C. B. Nelson, U. S. EPA Office of Radiation Programs, 401 M. Street, S. W., Mail Code 6602J, Washington, DC 20460

72. J. C. Nenot, Institut de Protection et de Surete Nucleaire, Commissariat a l'Energie Atomique, B P No 6, 92265 Fontenay-aux-Roses, Cedex, France

73. D. Nosske, Bundesamt für Strah!enschutz, Institut für Strahlenhygiene, Ingolstådter Landstrasse 1, D-8042 Neuherberg, Germany 
74. R. O'Brien, Australian Radiation Laboratory, Lower Plenty Road, Yallambie, Victoria 3085, Australia

75. J. Piechowski, Institut de Protection et de Surete Nucleaire, Departement de Protection Sanitaire, Centre d'Etudes de Fontenay-aux-Roses, France

76. J. W. Poston, Department of Nuclear Engineering, College of Engineering, Texas A\&M University, College Station, TX 77843

77. A. K. Poznanski, Department of Radiology, The Children's Memorial Hospital, 2300 Children's Plaza, Chicago, IL 60614

78. P. V. Ramzaev, Institute of Radiation Hygiene, 8 Mira ul, St. Petersburg 197101, Russia

79. A. C. B. Richardson, Deputy Director for Federal Guidance Criteria and Standards Division, Office of Air and Radiation, United States Environmental Protection Agency, Washington, DC 20460

80. P. J. Roberts, Medical Physics \& Medical Engineering, Southampton General Hospital, Tremona Road, Scuthampton, Hants S09,4XY, United Kingdom

81. Dr. Genevieve S. Roessler, Route 1, Box 139H, Elysian, MN 56028

82. J. C. Rosen, GSPH, Department RADHEALTH, University of Pittsburg, Pittsburg, PA 15261

83. M. Rosenstein, Office of Health Physics (HFZ-60), Center for Devices and Radiological Health, 2094 Gaither Road, Rockville, MD 20850

84. D. van Rotterdam, Medical Biological Laboratory, TNO-Health Research, P. O. Box 5815, 2288 HV Rijswijk, The Netherlands

85. M. Roy, Commissariat Energie Atomique, Institut de Protection et Surete Nucleaire, BP No 6, F-992265 Fontenay-aux-Roses Cedex, France

86. Gene Runkle, U. S. Department of Energy, Albuquerque Operations, Environmental Safety and Health Division, Albuquerque, NM 87115

87. E. L. Saenger, Eugene L. Saenger Radioisotope Laboratory, University of Cincinnati Hospital, Cincinnati General Division, 234 Goodman Street, Cincinnati, OH 45267

88. Y. Sasaki, Department of Radiology, Faculty of Medicine, The University of Tokyo, 7-3-1 Hongo, Bunkyou-ku, Tokyo 113, Japan

89. K. W. Skrable, University of Lowell, Lowell, MA 01854

90. K. Skulina, Lawrence Livermore National Laboratory, P. O. Box 808, Livermore, CA 94550

91. L. A. Slaback, NIST, Bldg. 245/C125, Gaithersburg, MD 20899 
92. M. T. Stabin, Radiopharmaceutical Internal Dose Center, Oak Ridge Associated Universities, MERT, P.O. Box 117, Oak Ridge, TN 37831

93. J. W. Stather, National Radiological Protection Board, Chilton, Didcot, Oxon, OX11 ORQ, United Kingdom

94. J. B. Stubbs, Oak Ridge Associated University, MERT Division, Building 2714-G, Room W17, P. O. Box 117, Oak Ridge, TN 37830

95. C. Sun, Radiological Sciences Division, Department of Nuclear Energy, Brookhaven National Laboratory, Building 703M, Upton, NY 11973

96. Gi-ichiro Tanaka, Asian Center for Reference Man Studies, 4-20-3 Ogikubo, Syuginami-ku, Tokyo 167, Japan

97. D. M. Taylor, University of Wales, Cardiff School of Chemistry and Applied Chemistry, P. O. Box 912, Cardiff CF1 3TB, United Kingdom

98. J. E. Till, Route 2, Box 122, Neeses, SC 29107

99. B. W. Wachholz, Low Level Radiation Effects Branch, National Cancer Institute, Landow Building 8C-09, 9000 Rockville Pike, Bethesda, MD 20205

100. M. E. Wangler, Director, T-ansportation \& Packaging Safety Division, U. S. Department of Energy, Office of Safety \& Quality Assurance, EH-33.2, 270 CC, Washington, DC 20585

101. E. E. Watson, Radiopharmaceutical Internal Dose Center, Oak Ridge Associated Universities, MERT, P. O. Box 117, Oak Ridge, TN 37831

102. D. A. Weber, Brookhaven National Laboratory, Medical Department, Building 490, Upton, NY 11973-5000

103. Dr. Ward Whicker, Professor, Department of Radiology and Health Sciences, Colorado State University, Fort Collins, CO 80523

104. L. R. Williams, Indiana University at South Bend, Mathematics Department, 1700 Mishawaka Avenue, South Bend, IN 46634

105. B. C. Winkler, Private Bag X256, Pretoria, 0001, South Africa

106. R. W. Wood, Physical and Technology Research Division, ER-74, Office of Health and Environmental Research, U. S. Department of Energy (GTN), Washington, DC 20545

107. M. E. Wrenn, Environmental Radiation \& Toxicology Laboratory School of Medicine, 1771 So., 900 W., Suite 10, Salt Lake City, Utah 84104

108. H. Yamaguchi, National Institute of Radiological Sciences, Division of Physics, 9-1, Anagawa4-chome, Chiba-shi 260, Japan 
109. Shlomo Yaniv, Health Effects Branch - MS 1130-SS, Division of Health, Siting and Waste Management, RES, U. S. Nuclear Regulatory Commission, Washington, DC 20555

110. Office of the Assistant Manager for Energy, Research and Development, U. S. Department of Energy Field Office, Oak Ridge (DOE-OR), P. O. Box 2001, Oak Ridge, TN 37831

111-120.Office of Scientific and Technical Information, P. O. Box 62, Oak Ridge, TN 37831 

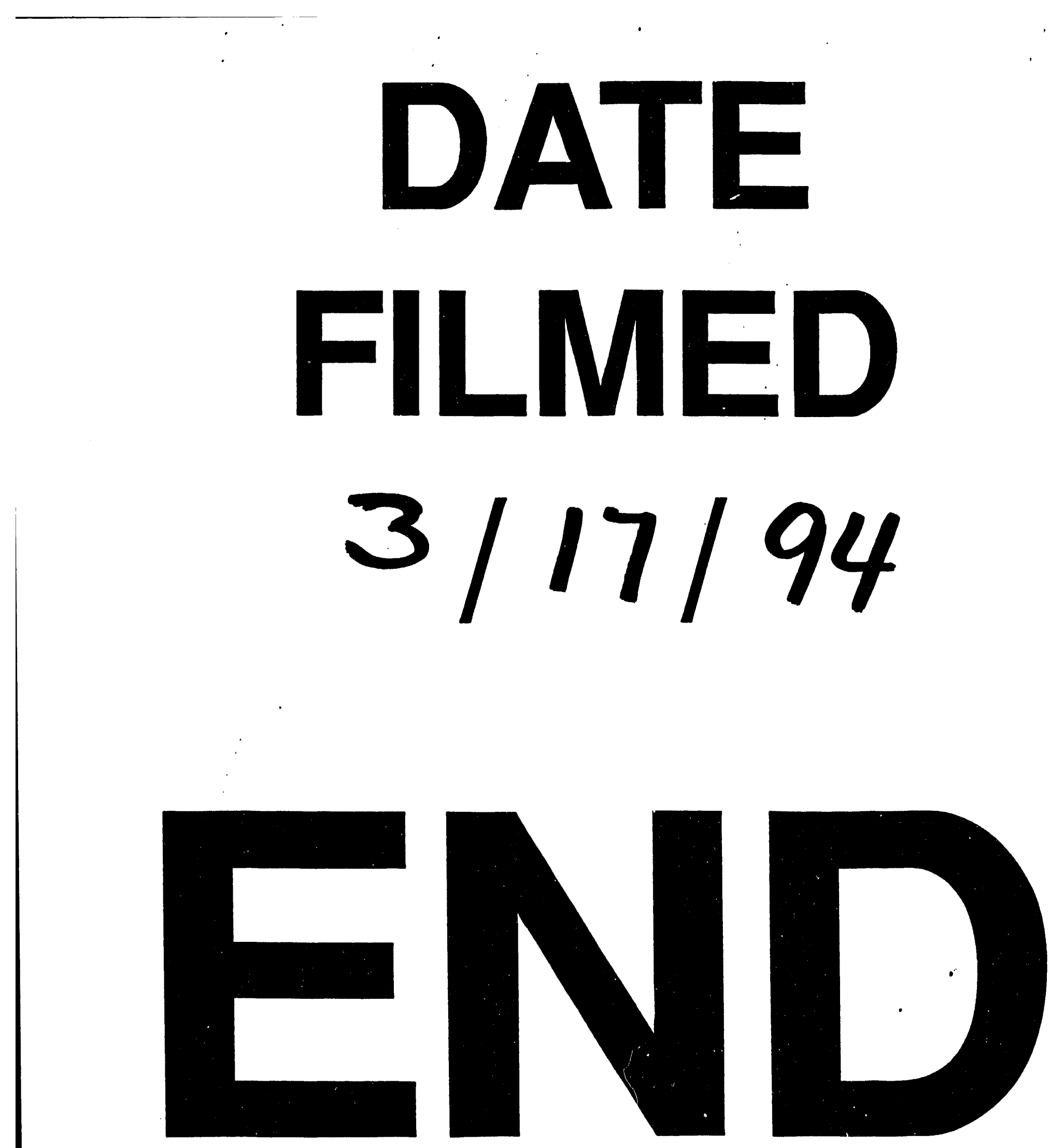


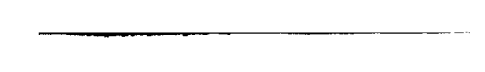

